University of Louisville ThinkIR: The University of Louisville's Institutional Repository

Electronic Theses and Dissertations

$5-2016$

\title{
Analyzing the phenologic dynamics of kudzu (Pueraria montana) infestations using remote sensing and the normalized difference vegetation index.
}

Faye Peters

University of Louisville

Follow this and additional works at: https://ir.library.louisville.edu/etd

Part of the Earth Sciences Commons, Environmental Sciences Commons, and the Weed Science Commons

\section{Recommended Citation}

Peters, Faye, "Analyzing the phenologic dynamics of kudzu (Pueraria montana) infestations using remote sensing and the normalized difference vegetation index." (2016). Electronic Theses and Dissertations. Paper 2437.

https://doi.org/10.18297/etd/2437

This Master's Thesis is brought to you for free and open access by ThinkIR: The University of Louisville's Institutional Repository. It has been accepted for inclusion in Electronic Theses and Dissertations by an authorized administrator of ThinkIR: The University of Louisville's Institutional Repository. This title appears here courtesy of the author, who has retained all other copyrights. For more information, please contact thinkir@louisville.edu. 


\title{
ANALYZING THE PHENOLOGIC DYNAMICS OF KUDZU (PUERARIA MONTANA) INFESTATIONS USING REMOTE SENSING AND THE NORMALIZED DIFFERENCE VEGETATION INDEX
}

\author{
By \\ Faye Peters \\ B.A., University of New Mexico, 2007

\begin{abstract}
A Thesis
Submitted to the Faculty of the

College of Arts and Sciences of the University of Louisville In Partial Fulfillment of the Requirements
\end{abstract}

For the Degree of

\author{
Master of Science \\ in Applied Geography \\ Department of Geography and Geosciences \\ University of Louisville \\ Louisville, KY
}

May 2016 
Copyright 2016 by Faye Elizabeth Peters

All rights reserved 



\section{ANALYZING THE PHENOLOGIC DYNAMICS OF KUDZU (PUERARIA MONTANA) INFESTATIONS USING REMOTE SENSING AND THE NORMALIZED DIFFERENCE VEGETATION INDEX}

\section{By}

Faye Peters

B.A., University of New Mexico, 2007

A Thesis Approved on

April 18, 2016

By the following Thesis Committee:

\begin{tabular}{c} 
Thesis Advisor \\
Dr. Forrest R. Stevens \\
\hline Dr. Andrea E. Gaughan \\
\hline
\end{tabular}

Dr. Margaret M. Carreiro 


\section{ACKNOWLEDGEMENTS}

Thank you to the University of Louisville Geography and Geosciences Department for providing me the opportunity to be part of a welcoming and helpful academic community that cares about all its students. Thank you to Dr. Forrest Stevens for all his help and patience walking me through the thesis process. I now have a much greater appreciation for the power of computer programming and the opportunities provided by advancements in big data processing. Thank you to my co-advisor Dr. Andrea Gaughan for introducing me to the wild world of remote sensing and her comments that strengthened this thesis. Dr. Margaret Carreiro thank you for being my outside mentor and sharing a passion for invasive species with me. Thank you to Dr. Carol Hanchette and Dr. Keith Mountain for the warm welcomes and guidance throughout my two years in the department. Mr. Robert Forbes, thank you for all your assistance with anything GIS. I would like to send a special thank you to my boyfriend Ben Lacy for his unwavering belief in me and for being a patient critic of all the PowerPoint presentations he got to watch. Thank you to my dad, mom, sister, BB, Bobby and the rest of my family and friends for always supporting me and being there when I need them. 


\begin{abstract}
ANALYZING THE PHENOLOGIC DYNAMICS OF

KUDZU (PUERARIA MONTANA) INFESTATIONS USING REMOTE SENSING AND THE NORMALIZED DIFFERENCE VEGETATION INDEX
\end{abstract}

Faye E. Peters

April 18, 2016

Non-native invasive species are one of the major threats to worldwide ecosystems. Kudzu (Pueraria montana) is a fast-growing vine native to Asia that has invaded regions in the United States making management of this species an important issue. Estimated normalized difference vegetation index (NDVI) values for the years 2000 to 2015 were calculated using data collected by Landsat and MODIS platforms for three infestation sites in Kentucky. The STARFM image-fusing algorithm was used to combine Landsatand MODIS-derived NDVI into time series with a $30 \mathrm{~m}$ spatial resolution and 16 day temporal resolution. The fused time series was decomposed using the Breaks for Additive Season and Trend (BFAST) algorithm. Results showed that fused NDVI could be estimated for the three sites but could not detect changes over time. Combining this method with field data collection and other types of analyses may be useful for kudzu monitoring and management. 
TABLE OF CONTENTS

PAGE

ACKNOWLEDGEMENTS .............................................................................. ii

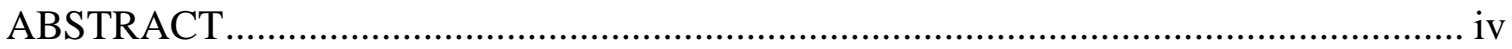

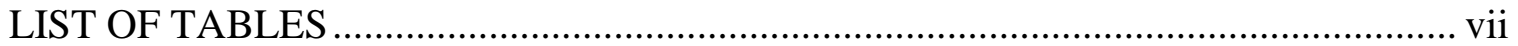

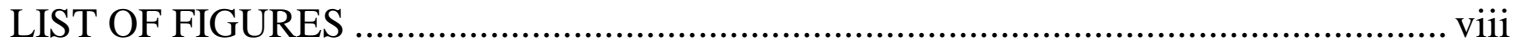

CHAPTER 1: INTRODUCTION ......................................................................

Research Objectives and Hypotheses .............................................................

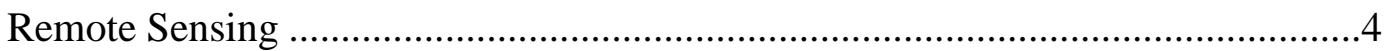

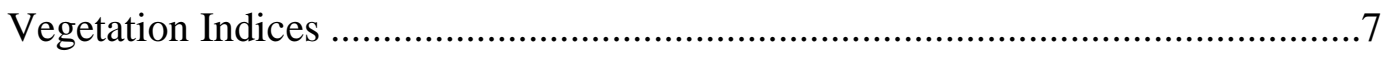

Google Earth Engine ................................................................................ 9

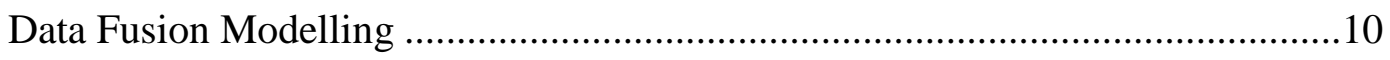

Temporal Decomposition..................................................................... 13

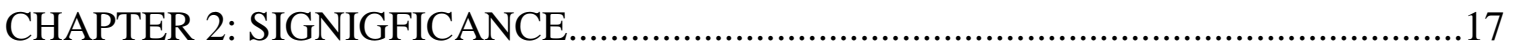

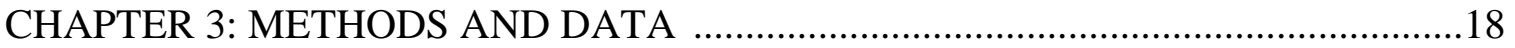

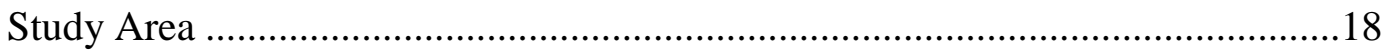

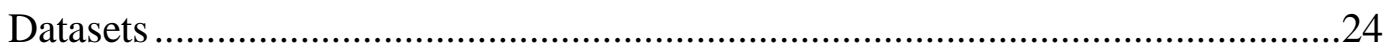

Google Earth Engine Data Processing ......................................................27

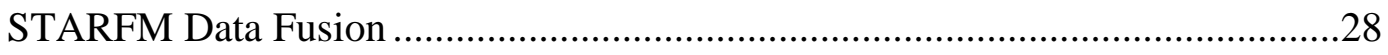

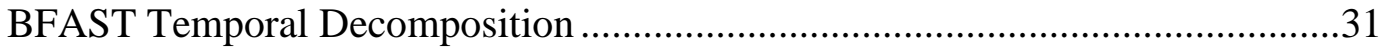

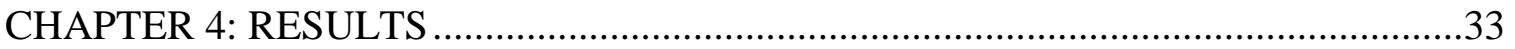

Comparison with Vegetation Outside the Study Areas .....................................43

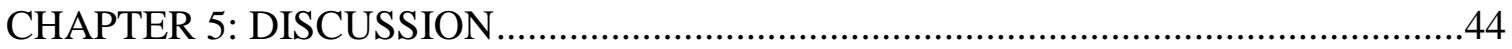


STARFM Data Fusion

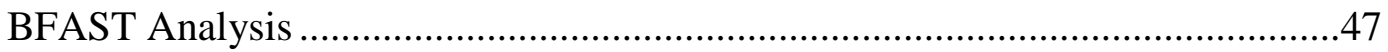

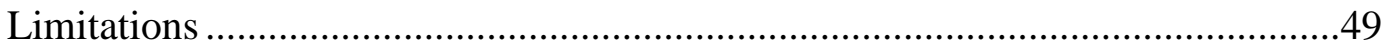

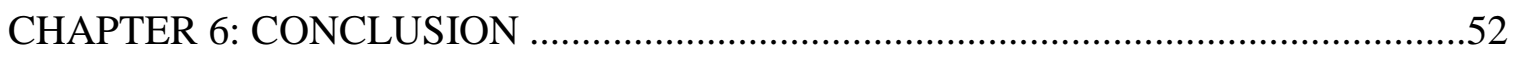

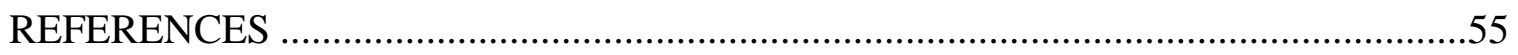

APPENDIX A: GOOGLE EARTH ENGINE CODE ...............................................61

APPENDIX B: R PROGRAMMING FOR STARFM .................................................68

APPENDIX C: R PROGRAMMING FOR BFAST ................................................

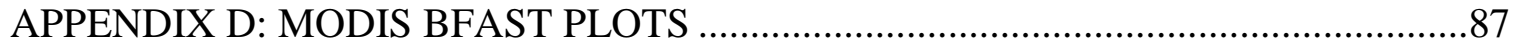

APPENDIX E: LANDSAT-SCALE BFAST PLOTS .................................................90

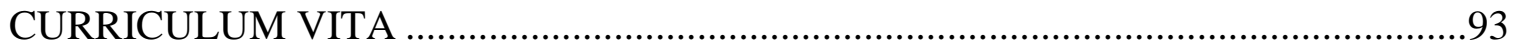




\section{LIST OF TABLES}

TABLE

PAGE

1. Comparison of Landsat and MODIS spectral bandwidths ....................................11

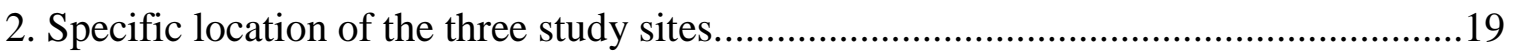

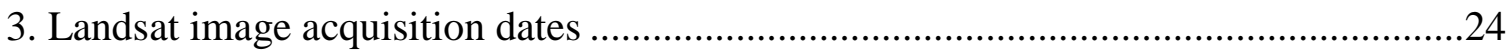

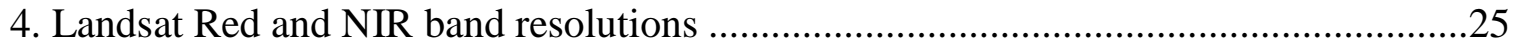

5. Breakdown of Landsat imagery used in the STARFM fusion process........................29

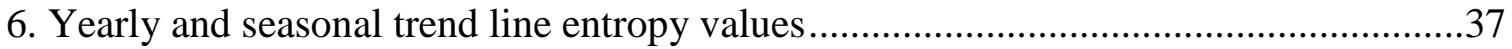

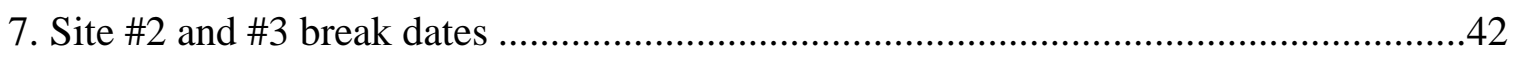

8. EDDMapS and NAWMA data collection standards ................................................53 


\section{LIST OF FIGURES}

$\begin{array}{lll}\text { FIGURE } & \text { PAGE }\end{array}$

1. Approximate boundary of a kudzu infestation in Illinois after the first freeze............2

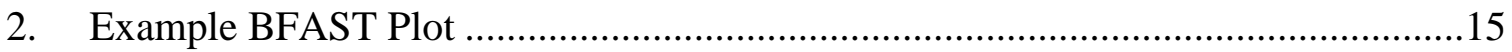

3. Location of kudzu infestation study sites in eastern Kentucky ..............................20

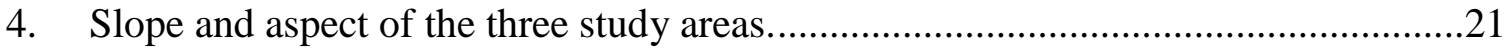

5. Site \#2 kudzu infestation KY 1096 looking southeast..........................................22

6. Site \#3 kudzu infestation KY 1096 looking north ............................................22

7. Placement of centroids and random points for each study sites. ............................24

8. Landsat images above and below the 5\% bad pixel threshold................................29

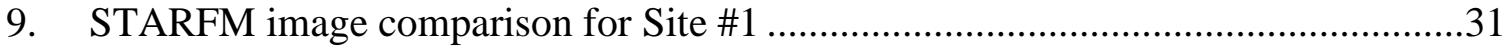

10. Site \#1 times series for MODIS, Landsat, STARFM, and Fused datasets ................34

11. Site \#2 times series for MODIS, Landsat, STARFM, and Fused datasets ................35

12. Site \#3 times series for MODIS, Landsat, STARFM, and Fused datasets ................36

13. Comparison of MODIS and filled image collections at Site \#1 .............................38

14. Comparison of MODIS and filled image collections at Site \#2 .............................39

15. Comparison of MODIS and filled image collections at Site \#3 ..............................40

16. Site \#2 spectral profile of kuzdu, forest and grass ............................................43

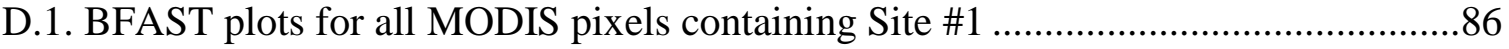

D.2 BFAST plots for all MODIS pixels containing Site \#2 .....................................87

D.3. BFAST plots for all MODIS pixels containing Site \#3 .......................................88 
E.1. Site \#1 BFAST plots using fused Landsat-scale data........................................89

E.2. Site \#2 BFAST plots using fused Landsat-scale data.........................................90

E.3. Site \#3 BFAST plots using fused Landsat-scale data............................................91 


\section{CHAPTER 1: INTRODUCTION}

Invasion of non-native plant species has had negative impacts on the environment and cost the United States upwards of $\$ 120$ billion to eradicate and control (Callen and Miller 2015; Hawthorne et al. 2015). Kudzu (Pueraria montana) is a woody, deciduous vine that has become one of the most invasive non-native species in the United States. It was introduced from Asia in 1876 at Philadelphia's Centennial Exposition in the form of seeds and marketed as a way to help with soil erosion in the southeastern region of the United States (Blaustein 2001).

Kudzu exhibits a diverse array of physiological traits that have adapted it to a wide range of climates. None the less, it does prefer certain conditions over others. Its bioclimatic requirements include at least $100 \mathrm{~cm}$ of precipitation per year and temperatures between $25^{\circ} \mathrm{C}$ and $30^{\circ} \mathrm{C}$ for maximum photosynthesis (Forseth et al. 2004; Lindgren et al. 2013). During peak periods of growth, this species has been known to elongate up to 1 foot per day (Smith 2010). It also has an extensive root system designed for optimal moisture and nutrient extraction. These growth habits often result in kudzu outcompeting other vegetation as it blankets any surface that it encounters. Growth can be stunted when exposed to low temperatures and decreased rainfall (Lindgren et al. 2013).

Many of the 32 states listed as containing kudzu infestations by the Early Detection and Distribution Mapping System (EDDMapS) (EDDMapS 2016) have dedicated 
managers monitoring the infestations, and in Kentucky this is overseen by The Kentucky Nature Preserves and Natural Areas (J. Bender, personal communication, 18 September 2015). This organization utilizes EDDMapS to track new and established kudzu infestations. With the help of public citizens, government agencies, and private companies, infestation data is uploaded to this site as point locations along with associated metadata. Because these data are volunteered it may be biased towards accessible and well frequented areas.

The Illinois Department of Natural Resources, uses airborne imagery after the first frost to analyze the extent of infestations throughout the state (J. Shimp, personal communication, 30 September 2015). This is an efficient method because kudzu foliage senesces after the first freeze, thus distinguishing it from other vegetation as seen in Figure 1.

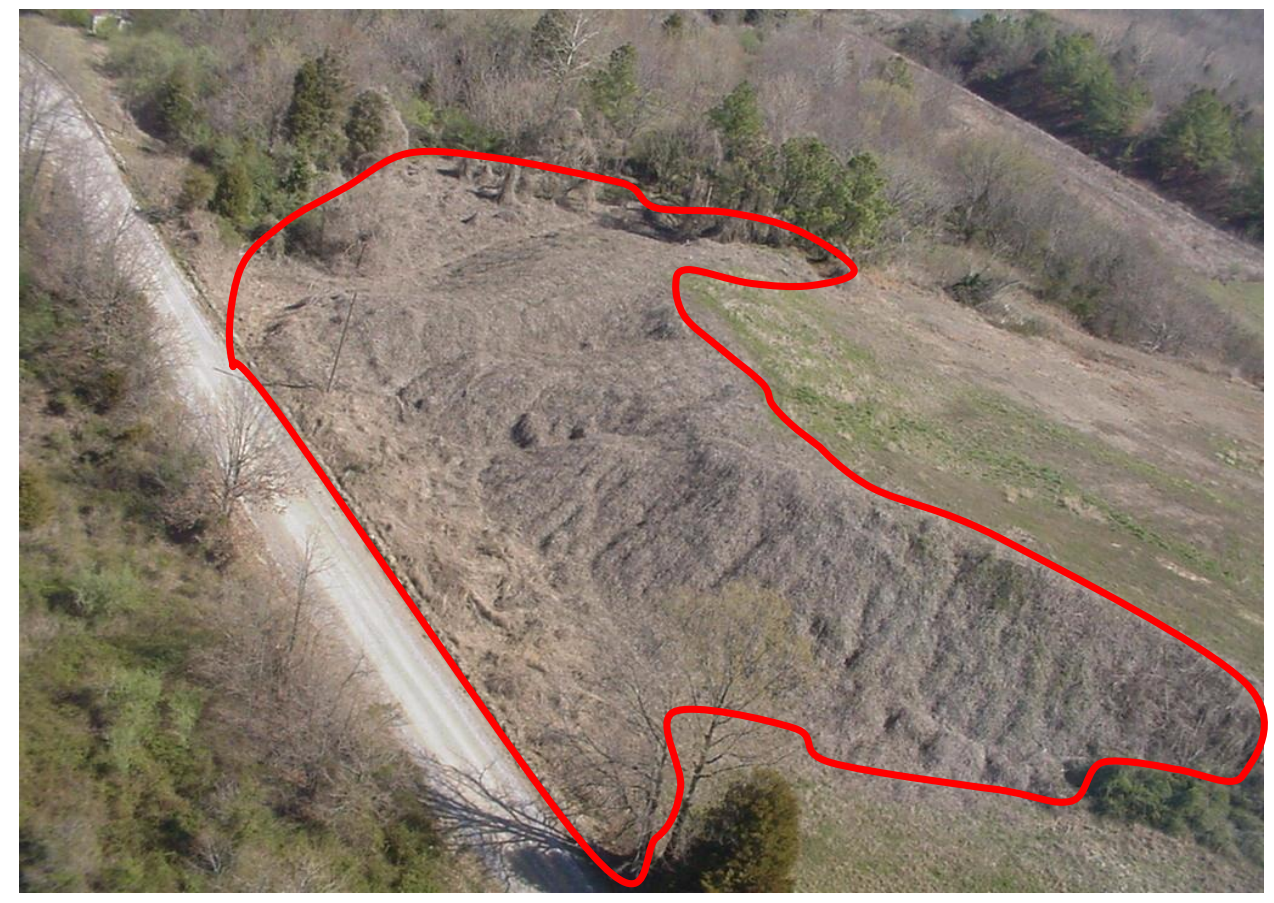

Figure 1. Approximate boundary of a kudzu infestation in Illinois after the first freeze. Courtesy of Jody Shimp IDNRDivision of Natural Heritage 


\section{Research Objectives and Hypotheses}

The positive correlation of fluctuations in kudzu biomass with the rate of photosynthesis via vegetation indices (Zhitao et al. 2014) builds the foundation of the research question conceived for this thesis project: "Can the analysis of vegetation indices from remotely sensed data be used to detect the spread and intensity of kudzu infestations?". The objective and associated hypotheses related to this broad question are as follows.

1. Assess if the density of kudzu's planophile leaf structure inhibits using NDVI for studying its phenology since NDVI has been known to saturate in high LAI areas. Hypothesis 1: Despite the high leaf area index values of kudzu, NDVI will not saturate at peak productivity, making NDVI a useful index for studying kudzu phenology.

2. Examine the robustness of fusing Landsat and MODIS imagery to create a time series of NDVI better suited to studying kudzu phenology. Hypothesis 2: Spatial extents and phenological dynamics of kudzu are better captured by $30 \mathrm{~m}$, Landsat-scale pixels, and higher temporal resolution of MODIS data, making STARFM Landsat-MODIS fused data better than either Landsat or MODIS data on their own for studying kudzu.

3. Assess the ability of vegetation indices as a reliable method to detect vegetation changes associated with kudzu infestation. Hypothesis 3: As kudzu infestations expand and intensify measurable vegetation phenology changes. These changes can be detected and measured using BFAST decomposition of NDVI time series. 


\section{Remote Sensing}

Remote sensing is the collection of data from a distance and an array of options are available when attempting to map attributes of non-native invasive species (Jensen 2016). Different sensors encompass varying spatial, spectral and temporal resolutions, which require consideration as to which is the most appropriate for mapping non-native invasive species (Cheng, Tom, and Ustin 2007; Hunt, Hamilton, and Everitt n.d.).

Commonly, aerial missions are employed to track infestations because of the availability of high spatial and spectral resolution data collected from airborne platforms. Aircraft are often outfitted with sensors like the hyperspectral Airborne Visible/Infrared Imaging Spectrometer (AVIRIS). It is able to detect spectral signatures in 10nm band increments between 380- 2570nm (Asner et al. 2008; Huang and Asner 2009). Collecting continuous data across the electromagnetic spectrum in hundreds of bands provides the opportunity to assign unique spectral signatures to individual species. When combined with the sensor's moderate to fine resolution, $1 \mathrm{~m}$ to $20 \mathrm{~m}$, an accurate representation of vegetation cover might be made. This approach has been used to detect kudzu with an $83.02 \%$ accuracy when validated with field data. The authors found that kudzu reflects the highest in the spectrum around 1100nm (Cheng, Tom and Ustin 2007). Drawbacks to using this type of data is that it has a low temporal resolution due to the availability only when a flight path has been tasked and the high cost of operation (Huang and Asner 2009).

Spaceborne multispectral platforms, such as MODIS and Landsat (Buheaosier et al. 2003; Huang \& Asner 2009) have been in use for decades monitoring vegetation. Multispectral sensors differ from hyperspectral in that they have considerably fewer 
bands across the electromagnetic spectrum over which data is collected. This prevents moderate resolution sensors from spectrally detecting individual plant species due to the spatial and spectral limitations.

The Landsat program began on July 23, 1972 (Jenson 2016) with the launch of Landsat 1 Multispectral Scanner (MSS) to monitor global agricultural practices. Since the maiden launch, sequentially named Landsat satellites have been put into service with the latest being Landsat 8 with the Operational Land Imager (OLI). Landsat 6 was launched in 1993 but did not achieve orbit. Aside from some sensor-to-sensor variation in spectral characteristics, developers have upheld the fundamental goal of the Landsat program which is to retain compatibility across sensors. Changes have included the addition of new bands, such as the coastal/aerosol band to Landsat 8, or band narrowing to assist in spectral differentiation (Jensen 2016). Landsat data was made free and publically available in 2008 through the United States Geological Survey (Wulder et al. 2012).

Landsat has a moderate spatial resolution of $30 \mathrm{~m}$ for all bands besides the panchromatic and thermal. The swath width is $185 \mathrm{~km}$ which provides ample representation of infestations on the surface (Jensen 2016). The temporal resolution of Landsat data is relatively coarse with a 16 day return time which is often extended due to cloud cover. In this study, climate in eastern Kentucky is prone to rain and snow showers in the spring and winter months (Hill and Mogil 2012) which add to the number of cloudy days. Consequently, a fast growing plant like kudzu would not be sufficiently monitored at a 32-day, or more, temporal resolution making Landsat inferior for detection purposes. 
The Moderate Resolution Imaging Spectroradiometer (MODIS), like the Landsat sensors, has been used extensively in the mapping of land surface phenology but is often constrained to the global scale due to the sensor specifications (Muchoney et al. 2000; Zhang et al. 2004; Chuvieco et al. 2013). It has been operational on the NASA based Terra and Aqua satellites since 2/24/2000. This is a sun-synchronous satellite with a swath width of $2330 \mathrm{~km}$ and is sinusoidally projected. The fine temporal resolution of one day makes it an ideal candidate for tracking vegetation changes. It is limited by the 250-500 m resolutions available on the bands related to land surface cover. If used on a localized scale there is almost certainly going to be the inclusion of mixed pixels in heterogeneous landscapes.

Huang and Asner (2009) suggest that to successfully use Landsat or MODIS sensors for invasive species detection an infestation site should be expansive and exhibit a phenology different than its surroundings. Privet (Ligustrum spp.) and honeysuckle (Lonicera spp.) are both non-native shrubs that have been successfully mapped using Landsat and MODIS (Salajanu and Jacobs 2009). These species have the phenological trait of dropping their leaves after most native deciduous trees which aids in distinguishing them from surrounding vegetation. In contrast, when non-native invasive species are obstructed by native vegetation Landsat and MODIS sensors are not as reliable (Huang and Asner 2009). One potential solution to studying localized and/or heterogeneous vegetation cover, which exhibits variation on a spatial scale too fine for MODIS but too rapidly for Landsat detection, is to use both datasets with the use of a data fusion method. 


\section{Vegetation Indices}

Kudzu is prone to overtake forest canopies, fields and any other surface it comes in contact with, which provides opportunities to be remotely detected. Vegetation indices (VIs) are utilized in the detection process (Blaustein 2001) because they provide a better representation of phenological changes verses basic spectral signatures, i.e. the green spectral signature. Slope based VIs, (Silleos et al. 2006), are commonly used for the detection of phenologic changes to vegetation and originate from the spectral "simple ratio" (SR), which is defined by the inverse relationship between the reflectance $(\rho)$ of the visible red and near infrared (NIR) portions of the electromagnetic spectrum (Birth and McVey 1968; Huete et al. 1997; Turner et al. 1999; Jensen 2016) .

$$
S R=\frac{\rho_{R E D}}{\rho_{N I R}}
$$

Healthier plants exhibit higher photosynthetic rates which results in a higher absorption in the visible red portion of the spectrum and higher reflectance in the NIR portion. This relational difference decreases in unhealthy or senescent plants. VIs are positively correlated with vegetation characteristics such as above ground biomass (Silleos et al. 2006), net primary productivity (NPP) (Rafique et al. 2016) and the level of leaf area index (LAI) (Jin and Eklundh 2014).

Invasive species are most easily detected via remote sensing when they possess a trait that exhibits reflectance properties that are different than their surroundings. Attributes may include earlier green-up time, leaf shape, or flowers (Hunt, Hamilton, and Everitt, n.d.). Kudzu has a noticeably higher LAI value and above ground biomass 10-15 times greater than deciduous forests and other planophile species (Forseth and Innis 2004; 
Lindgren et al. 2013). The planophile orientation of kudzu leaves allows it to reflect more in the NIR spectrum and absorb more in the red spectrum when compared to leaves that have an erectophile orientation (Turner et al., 1999). Since VIs are correlated with LAI and above ground biomass they provide a possible means of delineating kudzu from its surroundings.

Examples of VIs are the enhanced vegetation index (EVI) and the normalized difference vegetation index (NDVI). EVI is tailored to mask out atmospheric and soil noise which helps to reduce saturation of vegetation with high LAI values (Huete et al. 1997) . NDVI was first developed by Rouse et al. (1974) and has proven to be a reliable method for extracting phenologic trends across a wide variety of vegetation types. NDVI as a phenology indicator has been used to monitor vineyard growth (Johnson et al. 2003), Mediterranean forest monitoring (Maselli 2004) and the extent of Lonicera mackii growth in Cherokee Park, Louisville, KY (Shouse, Liang, and Fei 2013).

Like the SR, NDVI relies on the relative difference in reflectance of the visible red and NIR portions of the spectrum, Equation 2. It differs from the SR in that it normalizes the output value range to -1 to 1 , eliminating the effects of having a zero in the denominator.

$$
N D V I=\frac{\rho(\text { nir })-\rho(\text { red })}{\rho(n i r)+\rho(r e d}
$$

Normalization works by calculating the difference between the visible red and NIR bands which is then divided by the sum of the two values. Reducing the value range decreases the overall effect that the "Soil Line" has on NDVI values as a whole (Silleos et al. 2006). Compiling long term NDVI values into a time series has been found to be a useful 
method for detecting abrupt and gradual changes in vegetation over a long time period caused by many types of land cover disturbances.

\section{Google Earth Engine}

In 2008, after the USGS release of Landsat imagery, Google launched the cloudbased IDE (Integrated Development Environment) Google Earth Engine (GEE) to run the Earth Engine API (Application Program Interface), also commonly referred to as the Playground. JavaScript is the language of choice within this API. This does require the user have a background in JavaScript as this is not a GUI platform. GEE imagery includes the entire Landsat and MODIS catalogs as well as additional datasets (Padarian, Minasny, and McBratney 2015). All processing and computations are done on the fly (Hansen et al. 2013) which allows the computer to reproject and process data in close to real time. This process automatically does this for any available dataset on the global scale. Geospatial data can be converted to a fusion table, Google's method of geospatial data management, and then loaded into GEE to interact with other vector or raster data. Outputs from GEE analyses are able to be downloaded as georeferenced raster data.

Datasets with highly dimensional spatial and/or temporal resolutions are cumbersome and time consuming for desktop computers to acquire, process and export. GEE's thousands of computers wired in parallel and large collection of data make analyzing big data 40 - 100 times faster than a desktop computer (Padarian, Minasny, and McBratney 2015).

Although the provided data collection is large there are many dataset not available which has been noted as one of the platform's drawbacks. Hyperspectral data is among 
the unavailable datasets which limits studies requiring precise spectral classification such as those related to population (Patela et al. 2015), geology (Padarian, Minasny, and McBratney 2015) and forest (Hansen et al. 2013). Personal datasets can be upload to the Playground to offset this limitation but are limited by the $10 \mathrm{gb}$ available storage (Padarian, Minasny, and McBratney 2015).

Despite limitations, GEE has been used extensively and proven that a cloud-based remote sensing platform is necessary for research based on highly dimensional datasets. Patel et al. (2015) were able to classify urban extent on the global scale using the normalized difference spectral vector. Maize and soybean crop simulations from the United States were applied to Landsat data acquired via GEE to predict yields (Lobell et al. 2015). A break through global forest map was created by Hansen et al. (2013) that now used by Google to highlight the capabilities of GEE.

\section{Data Fusion Modelling}

The spatial and temporal adaptive reflectance fusion model (STARFM), (Gao et al. 2006), generates synthetic imagery by fusing Landsat data with MODIS data. By combining both datasets into one synthetic version so that both high temporal resolution and fine/moderate spatial resolution may be preserved (Gao et al. 2006; Zheng and Moskal 2009). The combination of both resolutions produces an environment that is robust enough to track phenologic productivity changes in vegetation cover while working with a spatial resolution fine enough for smaller, patchy invasive contexts (Gao et al. 2006; Walker et al. 2012; Wang, Gao, and Masek 2014; Schmidt et al. 2015). 
Landsat and MODIS data work well for data fusion because they have overlapping spectral bandwidths (Table 1) and similar flyover times which were developed to be comparable (Walker et al. 2012). This method has accurately tracked changes in vegetation dynamics on west Texas ranches (Yang et al. 2015) and after forest/grassland disturbances (Hilker et al. 2009; Schmidt et al. 2015).

\begin{tabular}{|c|c|c|c|c|c|c|c|}
\hline $\begin{array}{c}\text { TM } \\
\text { Bands }\end{array}$ & $\begin{array}{c}\text { TM } \\
\text { Bandwidths } \\
(\mathrm{nm})\end{array}$ & $\begin{array}{c}\text { ETM+ } \\
\text { Bands }\end{array}$ & $\begin{array}{c}\text { ETM+ } \\
\text { Bandwidths } \\
(\mathrm{nm})\end{array}$ & $\begin{array}{c}\text { OLI } \\
\text { Bands }\end{array}$ & $\begin{array}{c}\text { OLI } \\
\text { Bandwidths } \\
(\mathrm{nm})\end{array}$ & $\begin{array}{c}\text { MODIS } \\
\text { Bands }\end{array}$ & $\begin{array}{c}\text { MODIS } \\
\text { Bandwidths } \\
(\mathrm{nm})\end{array}$ \\
\hline 1 & $450-520$ & 1 & $450-515$ & 2 & $450-515$ & 3 & $459-479$ \\
\hline 2 & $520-600$ & 2 & $525-605$ & 3 & $525-600$ & 4 & $545-565$ \\
\hline 3 & $630-690$ & 3 & $630-690$ & 4 & $630-680$ & 1 & $620-670$ \\
\hline 4 & $760-900$ & 4 & $750-900$ & 5 & $548-885$ & 2 & $841-876$ \\
\hline 5 & $1550-1750$ & 5 & $1550-1750$ & 6 & $1560-1660$ & 6 & $1628-1652$ \\
\hline 7 & $2080-2350$ & 7 & $2080-2350$ & 7 & $2100-2300$ & 7 & $2105-2155$ \\
\hline
\end{tabular}

Table 1. Comparison of Landsat and MODIS spectral bandwidths

This fusion technique works by identifying two base pairs of Landsat and MODIS imagery across a time series that have the same or close to the same acquisition date to create a synthetic image of missing or bad Landsat data within a scene. A significant amount of overlapping, valid data realistically should be shared between image pairs in order to establish a relationship that can be used to generate synthetic imagery (Gao et al. 2006; Wang, Gao, and Masek 2014). Acceptable base pairs are chosen from a sliding window that temporally moves through the times series from iteration to iteration until two sound pairs are chosen. After establishing image pairs, a statistical model is utilized in the prediction of Landsat reflectance or Landsat-scale product derived from MODIS inputs. Predictions produced by the statistical model are used to match unpaired MODIS image dates with Landsat-scale images. 
Data introduced into the STARFM algorithm must be corrected and assume some basic principles (Gao et al. 2006). Atmospheric correction and resampling are required before input into the algorithm. First, surface reflectance is estimated prior to fusion processing requiring all MODIS and Landsat imagery to be atmospherically corrected using the same basic principles. Most commonly Landsat Ecosystem Disturbance Adaptive Surface Reflectance (LEDAPS) (Maiersperger et al. 2013; USGS 2016) is used for Landsat images because it is very similar to the correction algorithm applied in the Collection 6s approach for MODIS data (Gao et al. 2006; Maiersperger et al. 2013). Second, both datasets must have the same spatial resolution which requires all MODIS imagery to be resampled to $30 \mathrm{~m}$ to match that of Landsat.

An ideal study area to run through STARFM would provide the user with pure pixels, unchanging vegetation extent and uniform spectral reflectance (Gao et al. 2006). In the real world this does not exist and is accounted for in the STARFM algorithm by weighting pixels that neighbor a central pixel. Three factors are considered: spectral difference, temporal difference and location difference. The product of these weights make up the combined weight assigned to a pixel (Equation 4).

$$
C_{i j k}=S_{i j k} * T_{i j k} * D_{i j k}
$$

Where $C$ is the combined weight, $S$ is the spectral difference, $T$ is the temporal difference and $D$ is the location difference (Gao et al. 2006). $i, j, k$ refers to the $\mathrm{x} / \mathrm{y}$ coordinates and acquisition date of a pixel, respectively. All three exhibit an inverse relationship between what is measured and how heavily the pixel is weighted. The lower 
the measurement of the three variables, the higher the weight assigned to a pixel (Gao et al. 2006).

To increase the efficiency of this product, additional weights can be assigned to pixels based on the level of homogeneity in the study area. Spectral classification of pixels must be examined to ensure that correct weighting is assigned. Classification options include an unsupervised method or utilizing a threshold indicator built into the STARFM algorithm. The difference between the two is that the unsupervised method applies the rules over the entire study area while the second method only applies to the pixels that are of concern. Beyond this step bad pixels can be masked as they can create bias within the statistical predictions used to form the synthetic image.

\section{Temporal Decomposition}

NDVI estimates can be combined at the pixel level into time series which can then be decomposed in order to analyze underlying trends associated with phenologic change. Such are required to be relatively long periods, which in remote sensing terms translates to the numbers of images acquired for a distinct subset of land. Time series are classified as having high or low dimensionality depending on the amount of observations.

Dimensionality refers to the length and number of temporal observations within a dataset. For example, a dataset consisting of all available Landsat TM images would have high dimensionality versus a low dimensionality dataset consisting of only two Landsat TM images.

Low dimensional time series often use methods such as Principal Component Analysis or Fourier analysis (Verbesselt et al. 2010b). Both are transformation methods 
that aim to reduce the dimensionality of a dataset down to the components with the highest variance (Lhermitte et al. 2011). Most often such methods are used to assess change by partitioning variation into various subcomponents including large shifts. Transformation methods reduce underlying trends but typically mask them because they do not contribute a high amount to the total variance.

Datasets with high dimensionality benefit when seasonal and other trends are retained as the data is reduced. Breaks for Additive Seasonal and Trend (BFAST) (Verbesselt et al. 2010a; Forkel et al. 2013) does this by decomposing a time series into seasonal, linear and error components as illustrated in Figure 2. This means that all the decomposed parts when summed reconstruct the observations through time (Equation 3).

$$
Y t=S t+T t+e t
$$

Where $Y t$ is the observed trend, St is the seasonal trend component, $T t$ is the linear trend component and et is the error component.

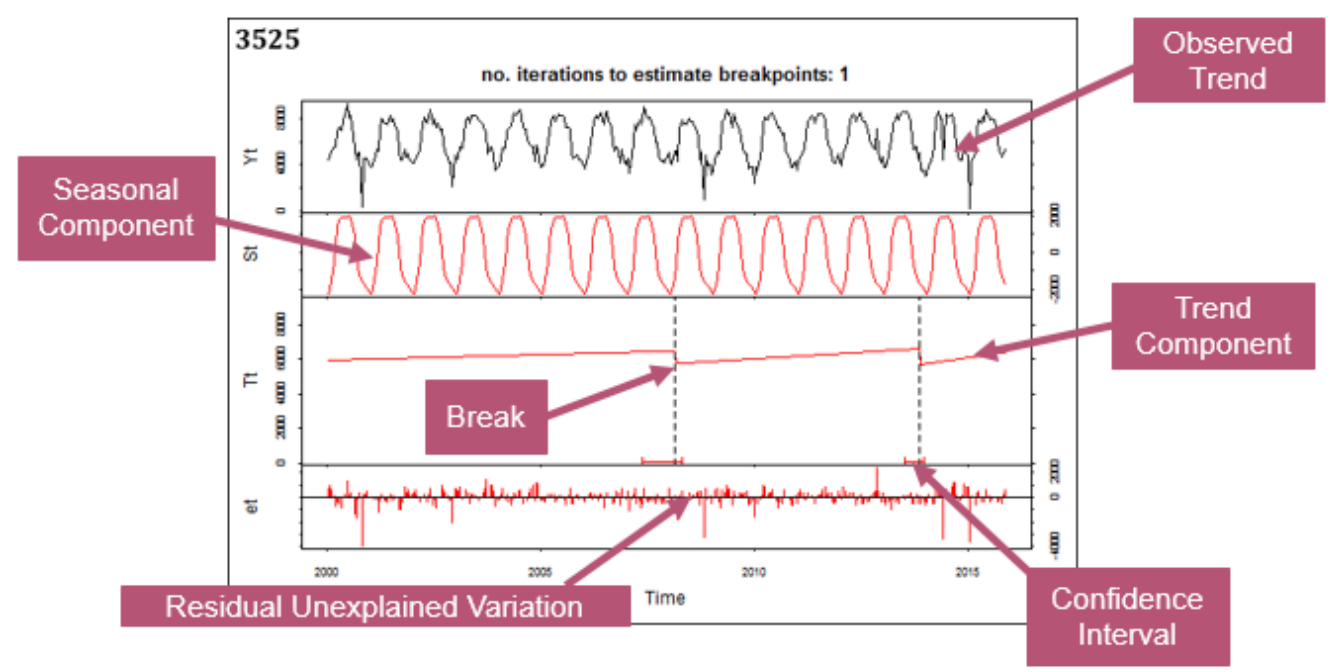

Figure 2. Example BFAST Plot 
A harmonic analysis is applied to decompose the observed seasonal trend from other more predictable parts of the series. This type of analysis is more robust than the "dummy" model method because it uses a continuous baseline for decomposition rather than discrete points (Verbesselt et al. 2010b; Hutchinson et al. 2015). Discrete points chosen for the dummy model express phenologically important dates such as green up or leaf drop thus obscuring what occurs between these chosen points. The combination of multiple sinusoidal waves comprise a harmonic analysis which varies based on changes to the amplitude and phase of the wave (Jakubauskas, Legates, and Kastens 2001).

Abrupt or gradual changes in vegetation can be detected after decomposition by applying breaks to the linear trend to better fit detected errors. This is accomplished by analyzing any remaining trends leftover from the initial decomposition process (Hutchinson et al. 2015; Verbesselt et al. 2010a) by specifying the acceptable number of breaks that can be added to the linear trend. A set number of iterations is chosen for the BFAST algorithm to complete before selecting the best fit for breaks along the linear trend. The linear trends connecting breaks are useful in characterizing duration of disturbances, as well as the nature of vegetation dynamics pre- and post- break. A level of uncertainty bounds the breaks meaning that the true date of disturbance may lie before or after the break date. These break dates correspond to remote sensing acquisition dates which will vary based on the temporal resolution of the sensor being used. 


\section{CHAPTER 2: SIGNIFICANCE}

The objective of this project is to produce a method incorporating satellite imagery that management officials can use to assess kudzu (Pueraria montana) infestations. The study sites were chosen in Kentucky because of the location along the northern edge of the North American kudzu extent and the presence of smaller, localized infestations. Monitoring and management methods should display that that they are effective at assessing the kudzu phenologic dynamics in a variety of infestation site sizes and be economical to implement.

The Kentucky Transportation Cabinet (KYTC) District 10 is currently working with the University of Kentucky to test chemical and mechanical methods to control kudzu. The current method being used to monitor the effectiveness of these applications is ground-based field collection. This method is labor intensive and may not provide the coverage and scale needed to accurately monitor the efficacy of eradication methods. A method like the one proposed in this study would reduce the labor time and cost as well as compliment the ongoing field-based monitoring system that is currently in place.

The proposed method could also be applied to a broader spectrum of kudzu infestations outside of Kentucky as well as other non-native vine species inside and outside of the state. Vines such as porcelain berry, Ampelopsis glandulosa, exhibit characteristic similar to that of kudzu that both threaten ecosystems and are difficult to eradicate and or control. 


\section{CHAPTER 3: METHODS AND DATA}

Landsat and MODIS imagery was incorporated into the STARFM data fusion algorithm to produce the most accurate series of images to apply the BFAST temporal decomposition model to. This process aimed to produce a dataset with sufficient temporal and spatial resolution to assess productivity change using decomposed NDVI time series of kudzu infestations in three study sites. Similarities between both datasets and their accessibility through open source data archives made Landsat and MODIS an ideal choice for this project. Google Earth Engine (GEE) was employed to acquire, process and export both sets of imagery because of its immense on the fly processing power of individual Landsat and MODIS scenes. The RStudio interface provided a platform to run both the STARFM and BFAST algorithms which fused and temporally decomposed the imagery, respectively.

\section{Study Area}

Infestation sites were chosen based on a set list of criteria. According to the United States Department of Agriculture (USDA) the smallest infestation site should be least 4 times as large as the image pixel (Hunt, Hamilton, and Everitt n.d.). The $30 \mathrm{~m}$ Landsat resolution determines that the smallest infestation should be larger than $3,600 \mathrm{~m}^{2}$. 
Study areas were supplied by the KYTC District 10 (D. R. Gumm, personal communication, 29 October 2015) and are clustered in the eastern portion of Kentucky in Breathitt and Perry counties (Table 2 and Figure 3). All sites were delineated using Google EarthPro ${ }^{\mathrm{TM}}$ on 6/13/2014 and saved as a. $\mathrm{kml}$ file which was later converted to a .shp file using ArcMap 10.3.1.

\begin{tabular}{|c|c|c|c|c|c|}
\hline Site & Latitude & Longitude & Area $\left(\mathrm{m}^{2}\right)$ & $\begin{array}{c}\text { Elevation } \\
(\mathrm{m})\end{array}$ & $\begin{array}{c}\text { Site } \\
\text { Location }\end{array}$ \\
\hline$\# 1$ & $37^{\circ} 32^{\prime} 8.26 " \mathrm{~N}$ & $83^{\circ} 32^{\prime} 36.25^{\prime \prime} \mathrm{W}$ & $\begin{array}{c}52,936 \\
(13 \mathrm{acres})\end{array}$ & 281.94 & $\begin{array}{c}\text { KY } 2469 \\
\text { Athol, KY }\end{array}$ \\
\hline$\# 2$ & $37^{\circ} 13^{\prime} 13.83^{\prime \prime} \mathrm{N}$ & $83^{\circ} 10^{\prime} 37.72^{\prime \prime} \mathrm{W}$ & $\begin{array}{c}34,459 \\
(8.51 \mathrm{acres})\end{array}$ & 369.72 & $\begin{array}{c}\text { KY1096 } \\
\text { Hazard, } \\
\text { KY }\end{array}$ \\
\hline$\# 3$ & $37^{\circ} 12^{\prime} 11.84 " \mathrm{~N}$ & $83^{\circ} 11^{\prime} 33.10^{\prime \prime} \mathrm{W}$ & $\begin{array}{c}28,777 \\
(7.11 \mathrm{acres})\end{array}$ & 541.02 & $\begin{array}{c}\text { KY1096 } \\
\text { Hazard, } \\
\text { KY }\end{array}$ \\
\hline
\end{tabular}

Table 2. Specific Location of the three study sites. 


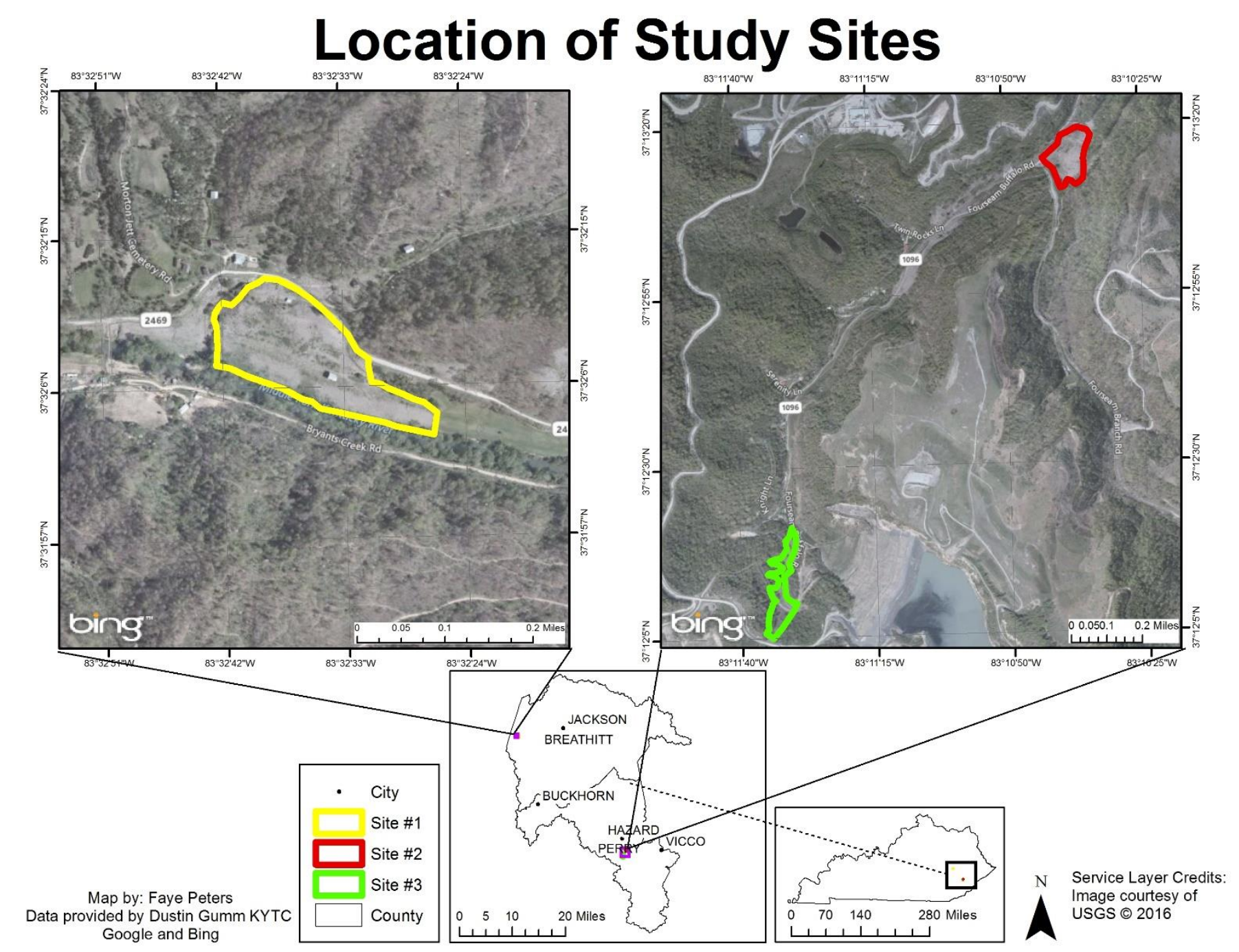

Figure 3. Location of kudzu infestation study sites in eastern Kentucky. 
The study areas are located in the Cumberland Plateau region of eastern Kentucky.

Forested, rolling hills intertwined with rivers and creeks cover this landscape. The actual sites sit at lower elevations (Figure 4) than the surrounding landscape and do not exhibit one slope aspect over another.

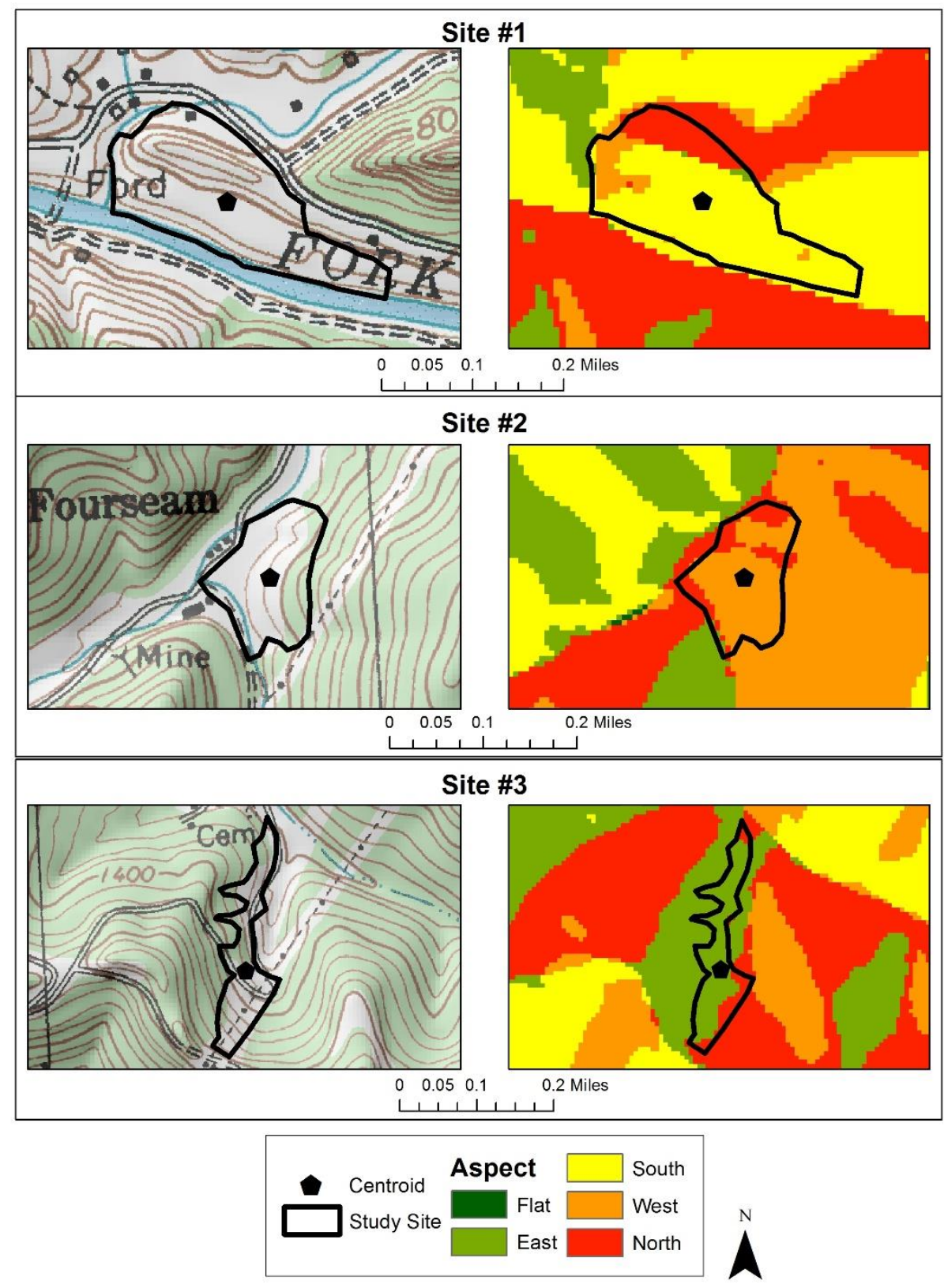

Figure 4. Slope and aspect of the three study areas. 
Disturbed edges are prime environments for kudzu to thrive due to greater sunlight for photosynthesis and other factors (Blaustein 2001; Smith 2010; Lindgren et al. 2013). Disturbance sources include, the eastern Kentucky coal fields, which can be clearly seen in images from Perry County. Images acquired from Google Street View display the robust and aggressive nature of this vine (Figure 5 and Figure 6).

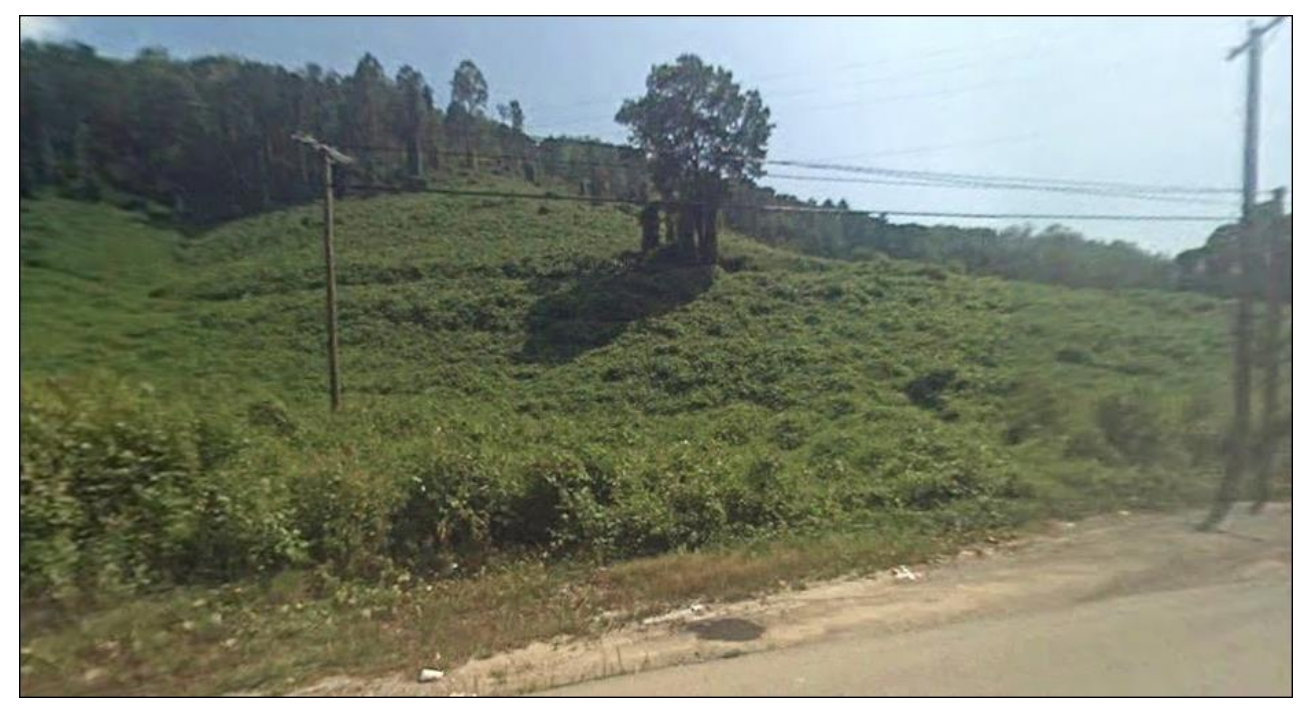

Figure 5. Site \#2 kudzu infestation KY 1096 looking southeast. Image: Google EarthPro ${ }^{\mathrm{TM}}(4 / 10 / 2016)$

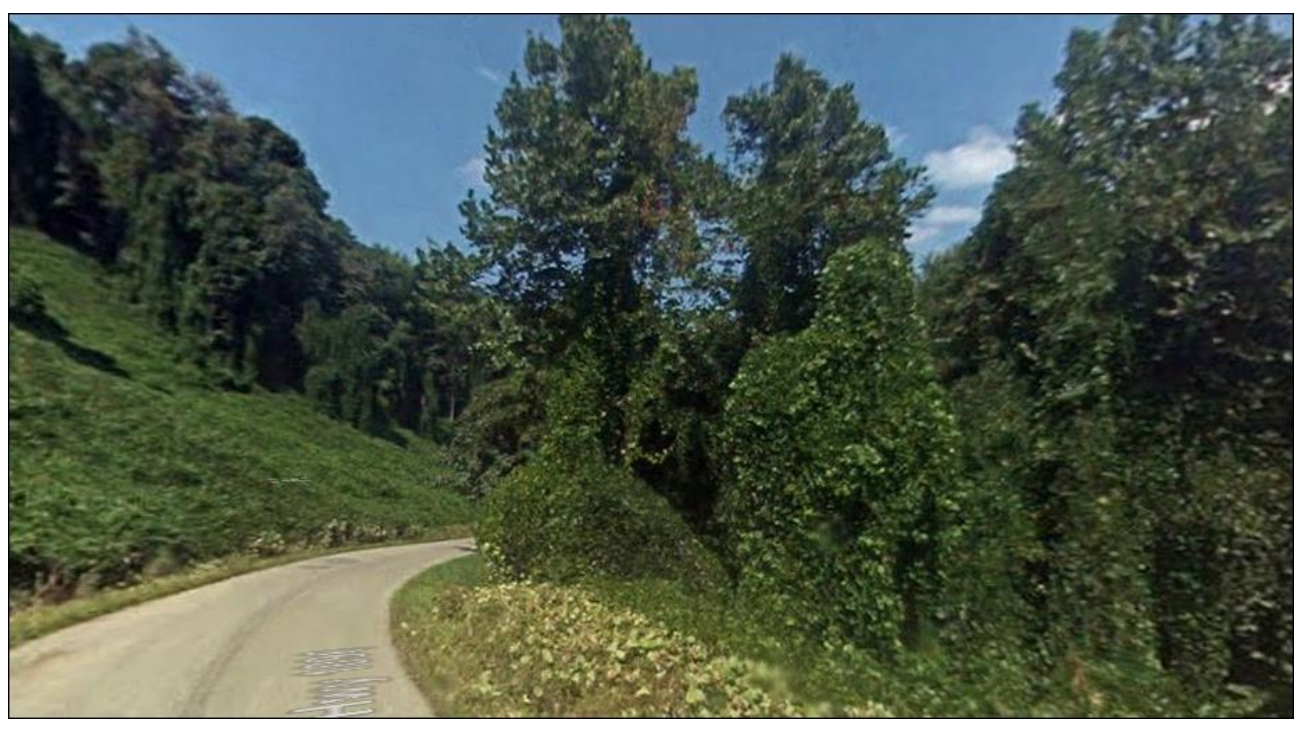

Figure 6. Site \#3 kudzu infestation KY 1096 looking north. Image: Google EarthPro ${ }^{\mathrm{TM}}(4 / 10 / 2016)$ 
Centroid pixels were used to compare productivity trends between the three sites to determine whether a NDVI time series "signature" exists for kudzu infestations like those commonly encountered in Kentucky. Centroids were calculated in ArcMap 10.3.1 using the Feature to Point tool in the Data Management Toolbox. The centroid for Site \#3 was shifted south to ensure that the pixel was completely contained within the site. NDVI values from the pixel containing the centroid from the MODIS and synthetic data were used to generate the time series and subsequent BFAST temporal decompositions.

A series of random points were created in each study area to determine if the trends detected near the centroids were representative of the entire area or if it was an isolated occurrence. These extra points were generated randomly using the Create Random Points tool within the ArcMap Data Management toolbox as illustrated in Figure 7. Five points were selected with a minimum allowable distance of $30 \mathrm{~m}$. Before running the BFAST on any of these points it was made sure that none were located within the same $30 \mathrm{~m}$ pixel or in a pixel not completely contained within the study area. 


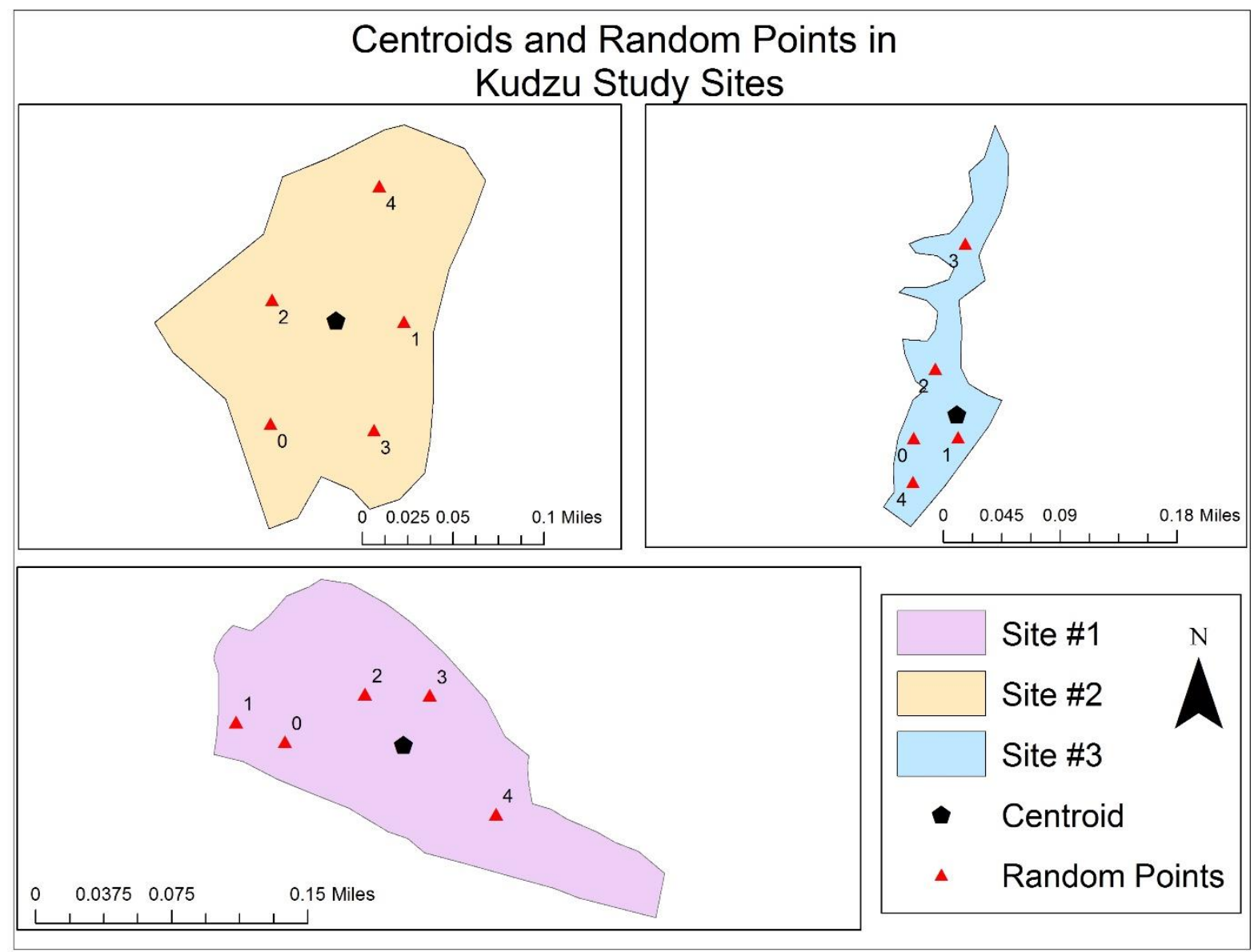

Figure 7. Placements of centroids and random points in each of the study sites.

\section{Datasets}

Both Landsat and MODIS datasets were acquired and processed using the GEE, cloud-based API. The JavaScript-based GEE interface script that subset, resampled and exported all MODIS and Landsat data used in the study is included in Appendix A. All Landsat images were acquired from the GEE archive where surface reflectance estimates were calculated on the fly via the LEDAPS algorithm for dates ranging from 2/18/2000 to 12/31/2015 along Path 19 Row 34 (Table 3). This time frame was chosen to coincide with all possible MODIS imagery through the end of 2015. 


\begin{tabular}{|c|c|}
\hline SENSOR & ACQUISITION DATES \\
\hline Landsat 5-TM & $3 / 12 / 2000$ to $11 / 6 / 2011$ \\
\hline Landsat 7-ETM+ & $\begin{array}{c}10 / 1 / 2007 \text { to } 12 / 31 / 2007 \\
4 / 1 / 2011 \text { to } 6 / 30 / 2013\end{array}$ \\
\hline Landsat 8-OLI & $4 / 11 / 2013$ to $12 / 31 / 2015$ \\
\hline
\end{tabular}

Table 3. Landsat Image Acquisition Dates

Landsat 7 ETM+ experienced a scan line corrector (SLC) failure on May 31 ${ }^{\text {st }}, 2003$ (Gu and Wylie 2015) resulting in images with strips of data missing due the sensor not being able to compensate for movement during data acquisition. Considerations were made to remove these data but would have resulted in a time gap measuring a few months between the SLC off date and the launch of Landsat 8 (Goward et al. 2006) as well as a period in 2007 when TM went offline. Due to the rapid phenological changes of kudzu and the need for continuous data for BFAST to work most efficiently, it was decided to include all ETM+ images for possible matches with MODIS/Landsat image pairs.

The spectral resolutions between Landsat sensors varies slightly, so all Landsat products were resampled to the standard $30 \mathrm{~m}$ during the GEE export process (Appendix A) (Irons, Dwyer, and Barsi 2012). The visible red and NIR bands were used to calculate the NDVI for the study areas (Table 4)) at each image date which were then processed into a single multiband image (Appendix A). Cubic convolution resampling was used during image resampling and data was projected to UTM Zone 17N (WGS84) in GEE (Appendix A). 


\begin{tabular}{|c|c|c|c|}
\hline & Red Band & NIR Band & Spatial Resolution \\
\hline Landsat 5 TM & $630-690 \mathrm{~nm}$ & $760-900 \mathrm{~nm}$ & $30 \mathrm{~m}$ \\
\hline Landsat 7 ETM+ & $630-690 \mathrm{~nm}$ & $780-900 \mathrm{~nm}$ & $30 \mathrm{~m}$ \\
\hline Landsat 8-OLI & $640-670 \mathrm{~nm}$ & $850-880 \mathrm{~nm}$ & $30 \mathrm{~m}$ \\
\hline
\end{tabular}

Table 4. Landsat Red and NIR Band Resolutions

The MODIS MOD13Q1 Vegetation Indices 16-Day Global $250 \mathrm{~m}$ product was used to construct an NDVI time series. This dataset was collected from the MODIS sensor aboard the Terra platform. These data were acquired and processed via GEE for the time period of $2 / 24 / 2000$ to $12 / 31 / 2015$ for all three study sites using tile h11v05. These data provide EVI, NDVI and surface reflectance from which NDVI was estimated. Quality assurance mask bands were used for the exclusion of bad pixels below the lowest level of decreasing quality as specified in the MOD13Q1 data description (Appendix A) (LP DAAC 2014). Dates assigned to this image collection correspond to the first day of each 16 day period.

Beginning in 2015 the $6^{\text {th }}$ version of the processing algorithm for the MOD13Q1 dataset was released, which needs to be used for all analyzed data (Gao et al. 2006). This algorithm estimates surface reflectance via atmospheric correction using bi-directional reflectance, and is similar to the Landsat LEDAPS method of atmospheric correction which adds to the comparability between Landsat and MODIS datasets (Walker et al. 2012; Wang, Gao, and Masek 2014) 


\section{Google Earth Engine Data Processing}

TM, ETM+ and OLI image collections were filtered for only those available within the date range of MODIS images. To reduce the file size of final time series, data from each of the three study areas was acquired and assembled into separate multiband image stacks. A $5000 \mathrm{~m}$ buffer was included so that all pixels overlaying the study sites were extracted for both MODIS and Landsat datasets and to provide potential areas to be used in a land cover comparison.

The STARFM algorithm is most efficient when then percentage of bad pixels is kept to a minimum (Gao et al. 2006). For this reason everything besides clear and water pixels were masked from each Landsat image and if that accounted for more than 5\% of the total number of pixels then the image was not included in the fusion process. From this point forward the term "bad" in reference to the quality of images used in this study will be defined as those with $>5 \%$ bad pixels.

As explained in the methods and GEE code (Appendix A), NDVI was calculated for each image collection. Separate lines of code were constructed for the TM/ETM+ and OLI image collections as the band numbering is different between these sensors. After the filtering process was complete, all Landsat images were merged into one Landsat multiband image. Each band contained either good and/or masked pixels.

The merged Landsat collection was matched against the merged MODIS imagery by image date. MODIS NDVI values are stored in GEE as integers which does not correspond with Landsat's floating point estimates of NDVI. Thus, Landsat NDVI values were multiplied by 10,000 to convert them to integer values. At which point, two complete and comparable multiband images were saved for all three study sites for every 
MODIS 16-day composite date between February 2000 and December 2015. In addition, summary tables recording the composite dates and percentage of bad pixels for each site were exported and saved.

\section{STARFM Data Fusion}

The STARFM data fusion algorithm was used for this study to synthesize the high temporal resolution of MODIS 16-day composites with the higher spatial resolution of Landsat data (30m) (Gao et al. 2006). The STARFM v.1.2.1 algorithm was run from command line tools downloaded from the USDA Agricultural Research Service website (United States Department of Agriculture 2016) but executed using the R statistical environment (R Core Team 2016). The series of STARFM commands used in the study is documented and provided in Appendix B.

Before the implementation of data fusion, a threshold of $5 \%$ bad pixels was set to define which MODIS and Landsat pairs would be used in the process. Any pixel within the buffered area or the border surrounding it containing clouds, snow or shadow were masked and considered "bad." Any masked pixel within the $5000 \mathrm{~m}$ buffered area was counted and the percentage of the total area these pixel comprised was calculated. If the number of "bad" pixels inside the border region exceeded $5 \%$ of the total the image was defined as "bad" and it was not used to create "good" MODIS/Landsat pairs. The total number of images used in the fusion process are shown in (Table 5

Table 5) and graphically in (Figure 8). 


\begin{tabular}{|c|c|c|c|c|}
\hline \multicolumn{5}{|c|}{ Landsat (TM, ETM+, \& OLI) Image Contribution } \\
\hline Site & $\begin{array}{c}\text { Good Images } \\
(\leq 5 \% \text { Bad Pixels })\end{array}$ & $\begin{array}{c}\text { Bad Images } \\
(>5 \% \text { Bad Pixels })\end{array}$ & $\begin{array}{c}\text { Missing Images } \\
\text { (All Bad Pixels) }\end{array}$ & $\begin{array}{c}\text { Total } \\
\text { Images }\end{array}$ \\
\hline$\# 1$ & 76 & 162 & 127 & 365 \\
\hline$\# 2$ & 52 & 75 & 238 & 365 \\
\hline$\# 3$ & 55 & 79 & 231 & 365 \\
\hline
\end{tabular}

Table 5. Breakdown of Landsat Imagery used in the STARFM fusion process.

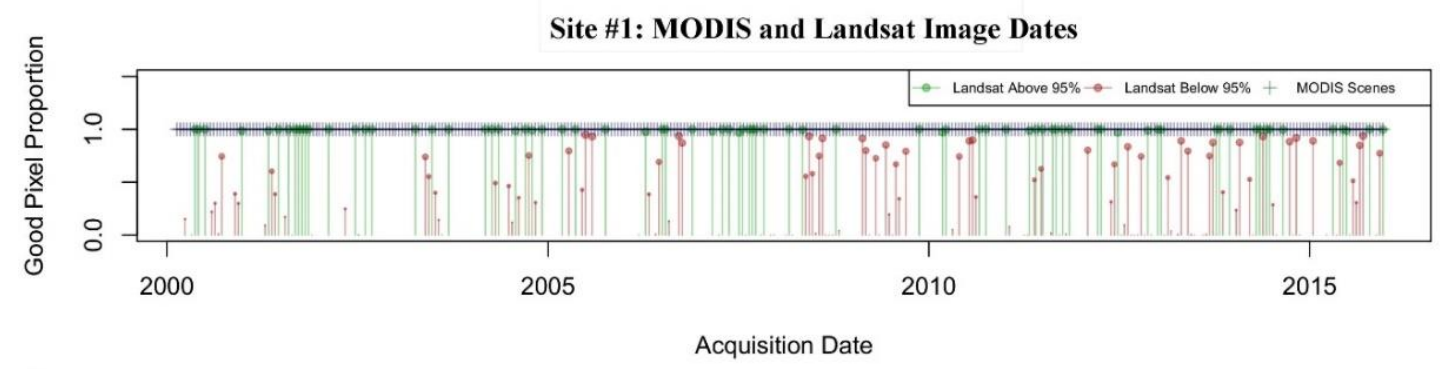

(a)

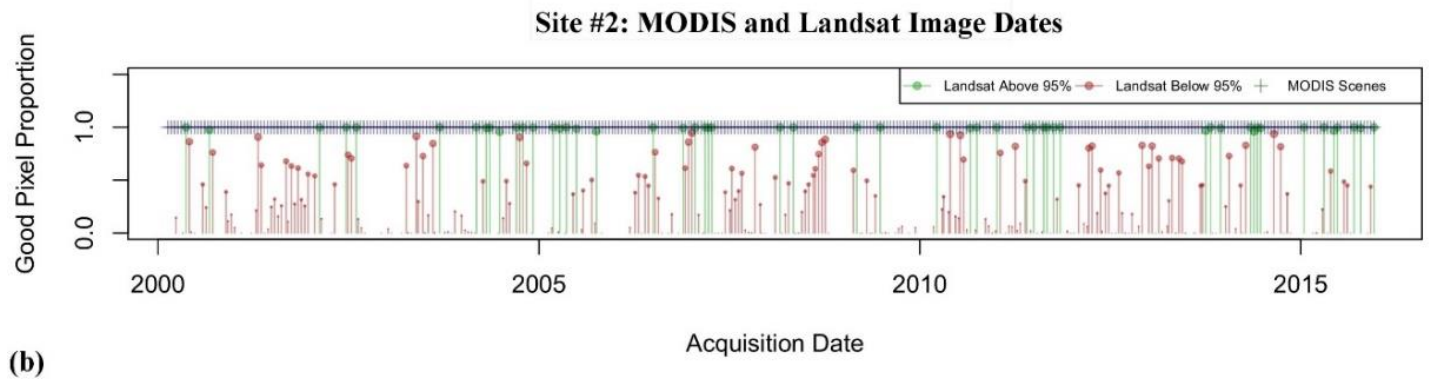

(b)

Site \#3: MODIS and Landsat Image Dates

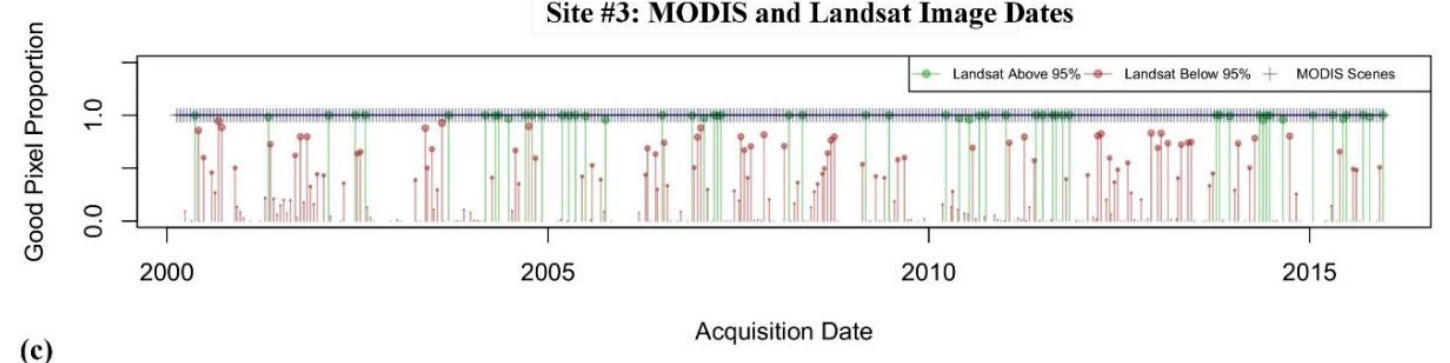

(c)

Figure 8. Graphical representation of Landsat images above and below the 5\% bad pixel threshold. No percentage correlates to no image. MODIS images along the 1.0 lines representing all good imagery from that collection. Site \#1 (a), Site \#2 (b), Site \#3 (c) 
For each MODIS 16-day image date STARFM used a moving window to locate the first Landsat/MODIS image pair containing at least $95 \%$ good pixels directly before and after it. The purpose of these image pairs was to simulate a Landsat spatial scale estimate of NDVI at the MODIS image date between the identified paired images. The outcome of this process was a synthetic time series of Landsat-scale data for each MODIS image date. Upon completion of the fusion process, any masked Landsat pixel was replaced with the Landsat-scale synthetic data produced at the corresponding MODIS image date. This method retained the most original Landsat data by compiling a Landsat-scale image stack comprised of original, filled and completely synthetic estimated NDVI images of which was used in the BFAST analysis. This process is featured in Figure9. 


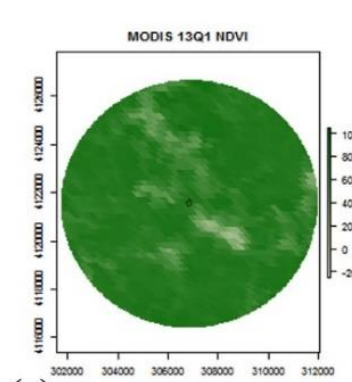

(a)
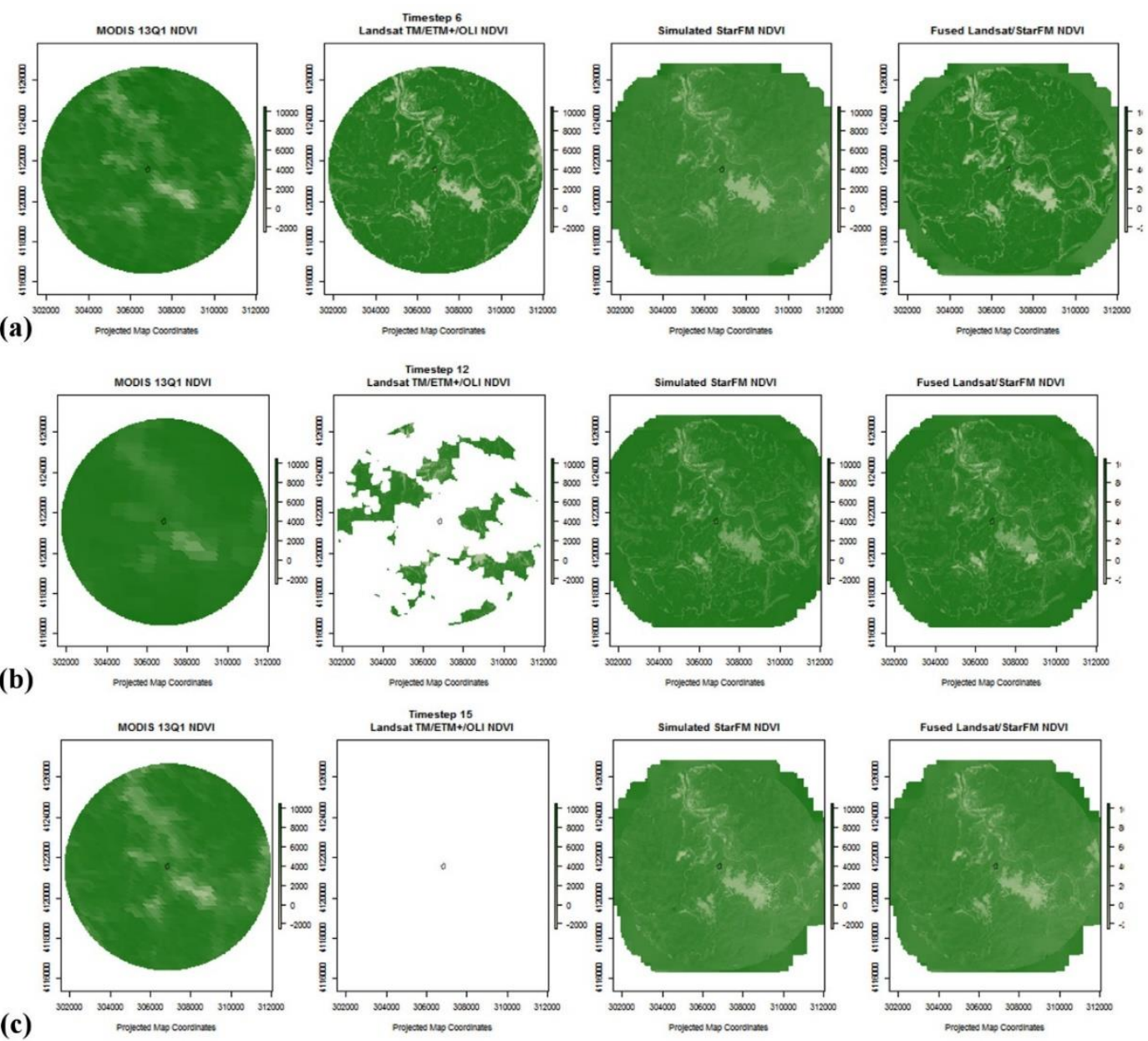

Figure 9. STARFM image comparison from Site \#1. From left to right: MODIS, Landsat, Synthetic, Filled. Image sequence (a) time step six which contains Landsat image with no missing data, (b) date twelve contains masked pixels that are filled with synthetic data, (c) date fifteen, which contains no valid Landsat pixels and which is replaced with a complete, synthetic or simulated set of pixels images.

\section{BFAST Temporal Decomposition}

Following the fusion process, all non-missing Landsat data was filled in with synthetic, STARFM data to produce a complete time series at a $30 \mathrm{~m}$ spatial resolution. The BFAST package for R (Verbesselt et al. 2010a; Verbesselt et al. 2010b) was used to process and decompose the time series for each infestation site, Appendix C. A total of 
six pixels were evaluated by compiling their NDVI values into a time series. These included the pixel corresponding to the centroid and five additional pixels for each site. The resulting series of decompositions shows phenological variance and change measured by NDVI (Appendix E). 


\section{CHAPTER 4: RESULTS}

The fused Landsat time series assembled from Landsat-derived and STARFM synthetic data proved to be a better scale to evaluate the productivity of kudzu in all three study sites compared with one composed strictly of MODIS data. All final Landsat-scale images were combined into an estimated NDVI time series. It was important to derive a complete time series for the time range of this study to avoid any temporal gaps but consequently cloud, shadow, snow, SLC-off errors and other contaminates were included. Figure 0 - Figure 2 highlight the range of gaps in the Landsat data, red line, and how those gaps were replaced with filled and synthetic imagery.

Evaluation of the differences between MODIS and Landsat-scale pixel resolution was made by comparing the results of BFAST plots from MODIS only data and fused time series. From all kudzu study area centroids and points, time series were extracted and decomposed with the BFAST algorithm (Appendices D and E). 


\section{Site \#1}

MODIS, Landsat, StarFM, and Fused Time Series

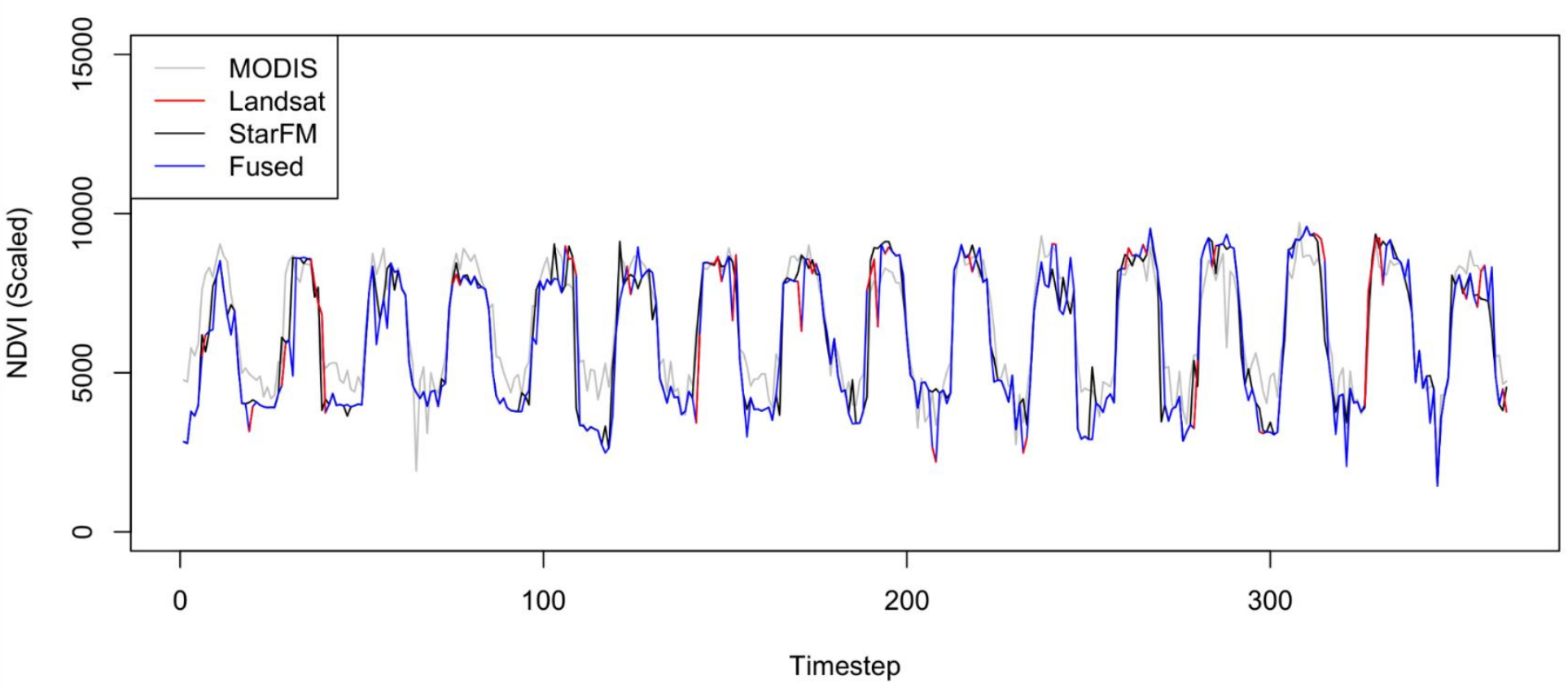

Figure 10. Site \#1 times series for MODIS, Landsat, STARFM, and Fused datasets. The red line represent available good Landsat data and the prevalence of gaps in that image collection. 


\section{Site \#2}

MODIS, Landsat, StarFM, and Fused Time Series

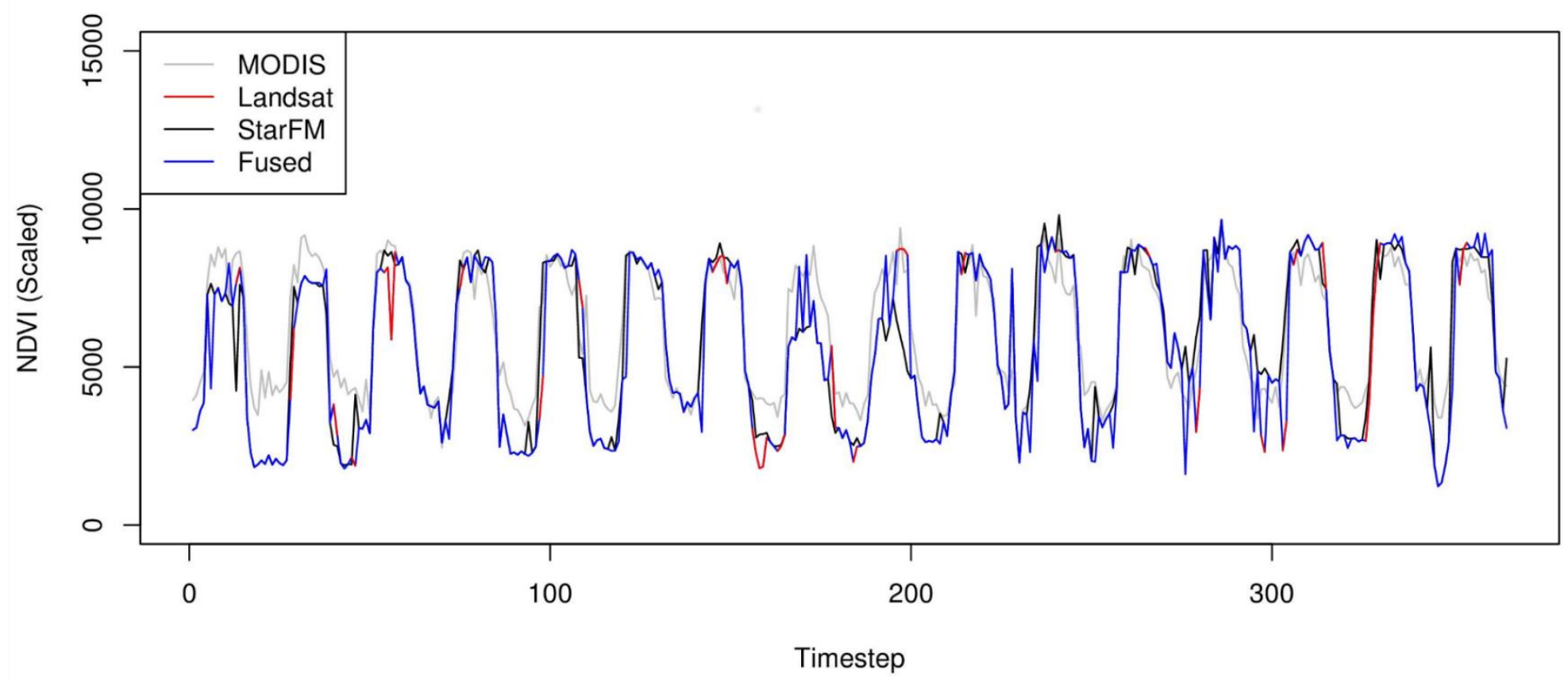

Figure 11. Site \#2 times series for MODIS, Landsat, STARFM, and Fused datasets. The red line represents available good Landsat data and the prevalence of gaps in that image collection. 


\section{Site \#3}

MODIS, Landsat, StarFM, and Fused Time Series

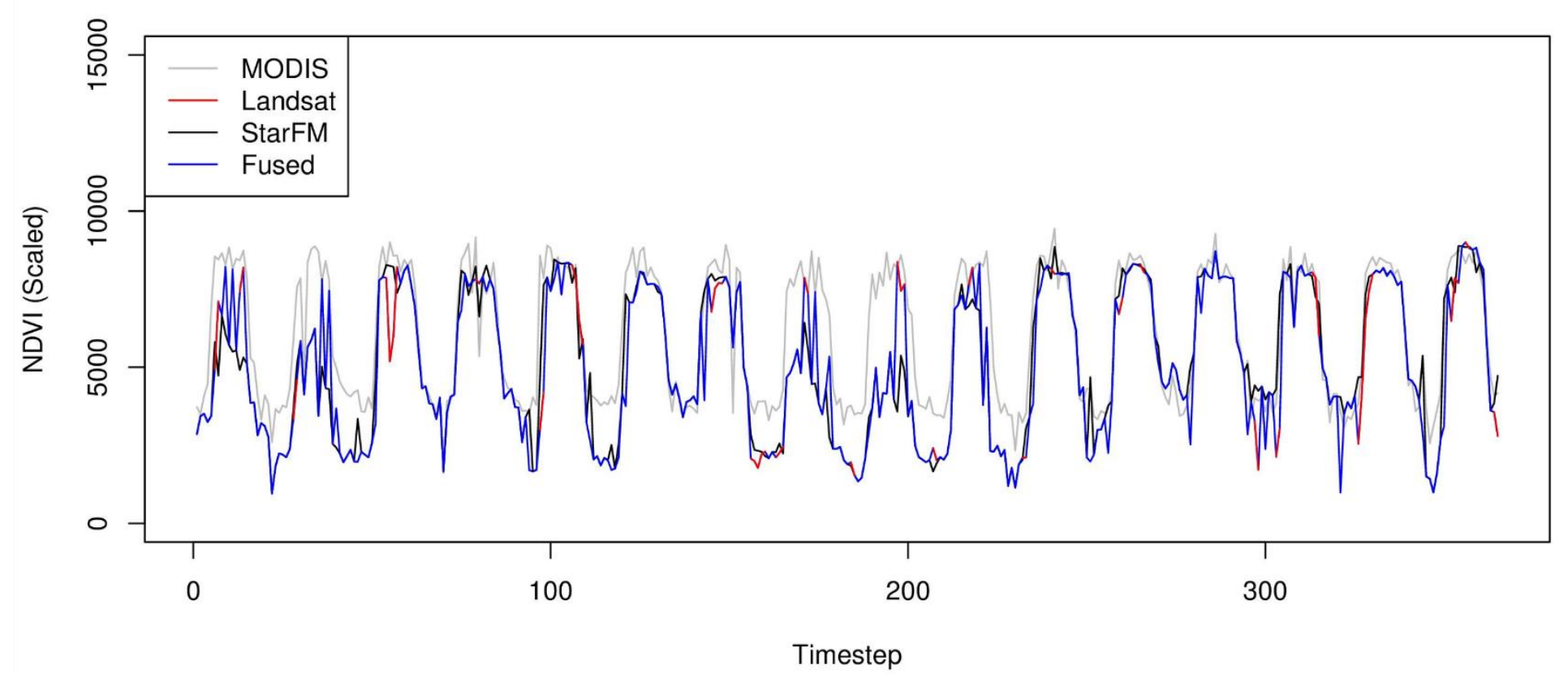

Figure 12. Site \#3 times series for MODIS, Landsat, STARFM, and Fused datasets. The red line represent available good Landsat data and the prevalence of gaps in that image collection. 
Entropy values for both the yearly and seasonal trends expose the complexity of seasonal trends in the data. The lower the entropy value the more order present in the trend line. Comparisons of BFAST results across sites show minimal difference between locations and sensors. These differences are listed in Table 6.

\begin{tabular}{|r|c|c|c|c|c|c|}
\hline \hline & \multicolumn{3}{|c|}{ Yearly Entropy } & \multicolumn{3}{c|}{ Seasonal Entropy } \\
\hline & Site \#1 & Site \#2 & Site \#3 & Site \#1 & Site \#2 & Site \#3 \\
\hline \hline \multicolumn{7}{|c|}{ (a)MODIS } \\
\hline Centroid & 0.4521 & 0.3346 & 0.3638 & 0.2290 & 0.2554 & 0.2511 \\
\hline \hline \multicolumn{7}{|c|}{ (b) Landsat } \\
\hline Centroid & 0.4042 & 0.4040 & 0.4714 & 0.2451 & 0.2412 & 0.2392 \\
\hline 0 & 0.4662 & 0.3996 & 0.4140 & 0.2474 & 0.2419 & 0.2434 \\
\hline 1 & 0.4179 & 0.4147 & 0.4440 & 0.2394 & 0.2424 & 0.2430 \\
\hline 2 & 0.3595 & 0.3787 & 0.4111 & 0.2438 & 0.2422 & 0.2380 \\
\hline 3 & 0.3880 & 0.4200 & 0.4153 & 0.2512 & 0.2385 & 0.2446 \\
\hline 4 & 0.5430 & 0.4454 & 0.3795 & 0.2384 & 0.2429 & 0.2464 \\
\hline Average & 0.4298 & 0.4104 & 0.4226 & 0.2442 & 0.2415 & 0.2424 \\
\hline \hline
\end{tabular}

Table 6. Yearly and seasonal trend line entropy values for (a) MODIS and (b) Landsat-scale, Fused Data time series.

The fused data did exhibit breaks in the seasonal trend (St) at Site \#1 which was not observed in the coarser MODIS data. This was observed at time step 97 which correlates with the date 4/22/2004. Unlike the other two sites where the estimated seasonal trend was consistent across time, and similar between MODIS and fused imagery, the identification of this difference could be a signal of disturbance or shift in established vegetation at Site \#1. Comparisons between the similar seasonal trends (St) are illustrated in BFAST analyses for each site provided in Figure 13 - 15. 


\section{BFAST:Study Site \#1}

MODIS GRID 3701 250m Resolution

no. iterations to estimate breakpoints: 1

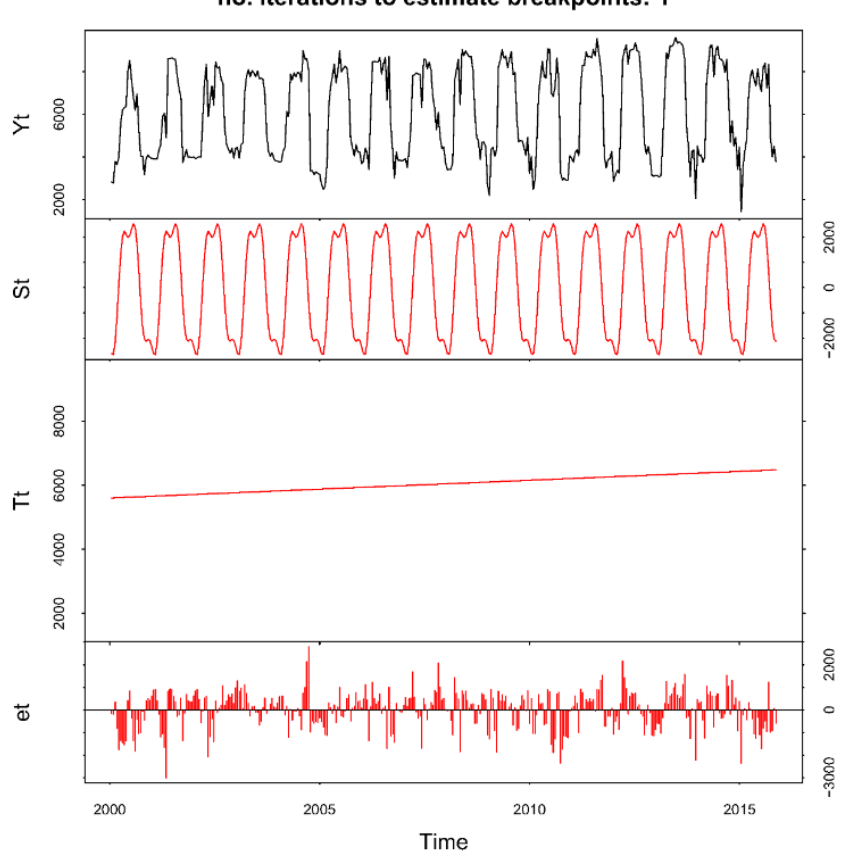

Filled Images 30m Resolution

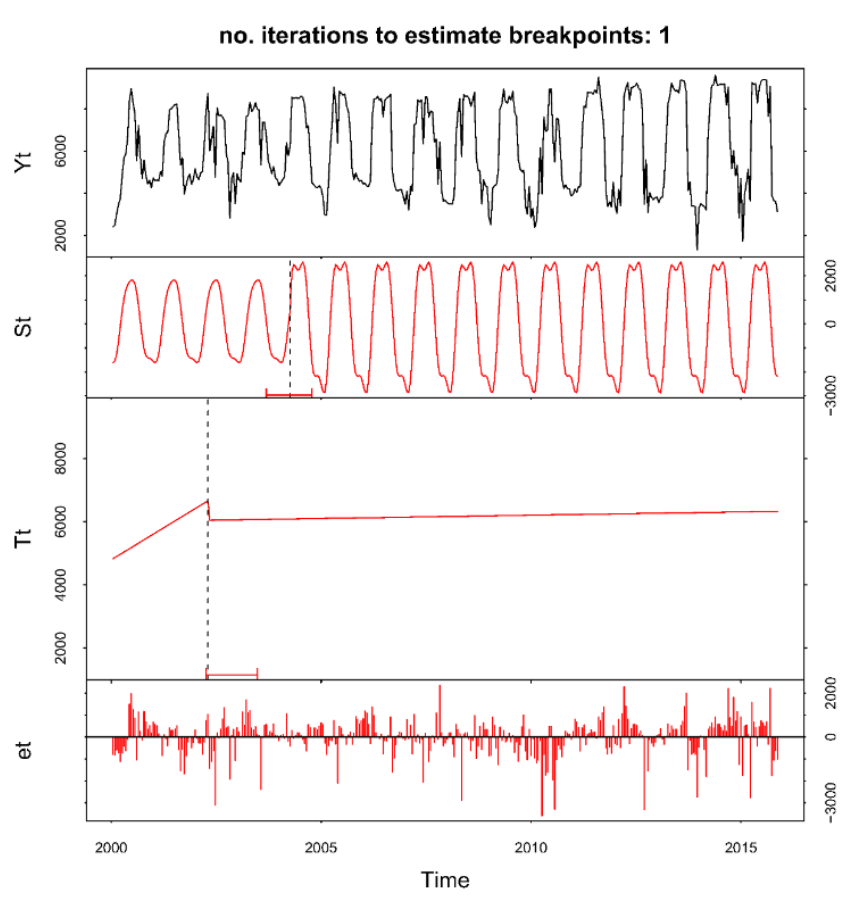

Figure 13. Comparison of the BFAST plots for the MODIS (left) and filled image collection (right) pixels that contain the centroid of Site \#1. 


\section{BFAST:Study Site \#2}

\section{MODIS GRID 28852 250m Resolution}

no. iterations to estimate breakpoints: 1

\section{Filled Images} 30m Resolution

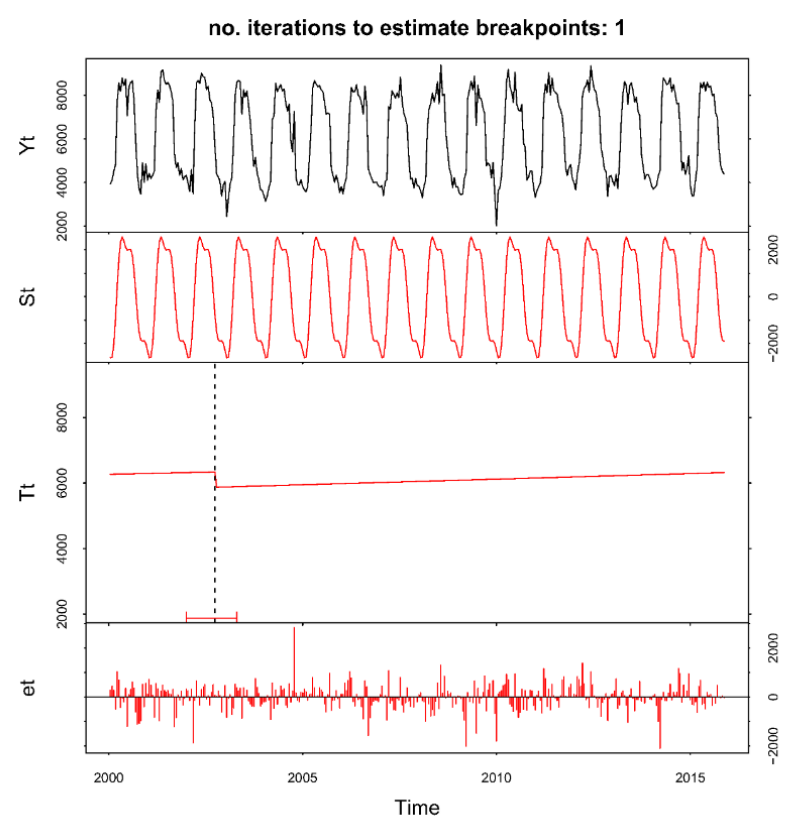

no. iterations to estimate breakpoints: 1

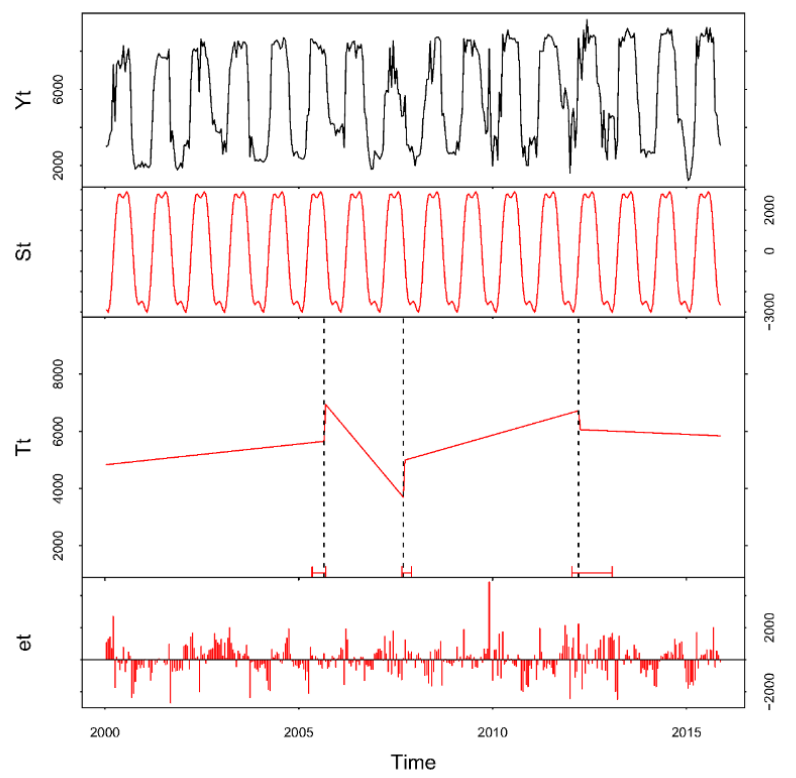

Figure 14. Comparison of the BFAST plots for the MODIS (left) and filled image collection (right) pixels that contain the centroid of Site \#2 


\section{BFAST:Study Site \#3}

MODIS GRID 30246

250m Resolution

no. iterations to estimate breakpoints: 1

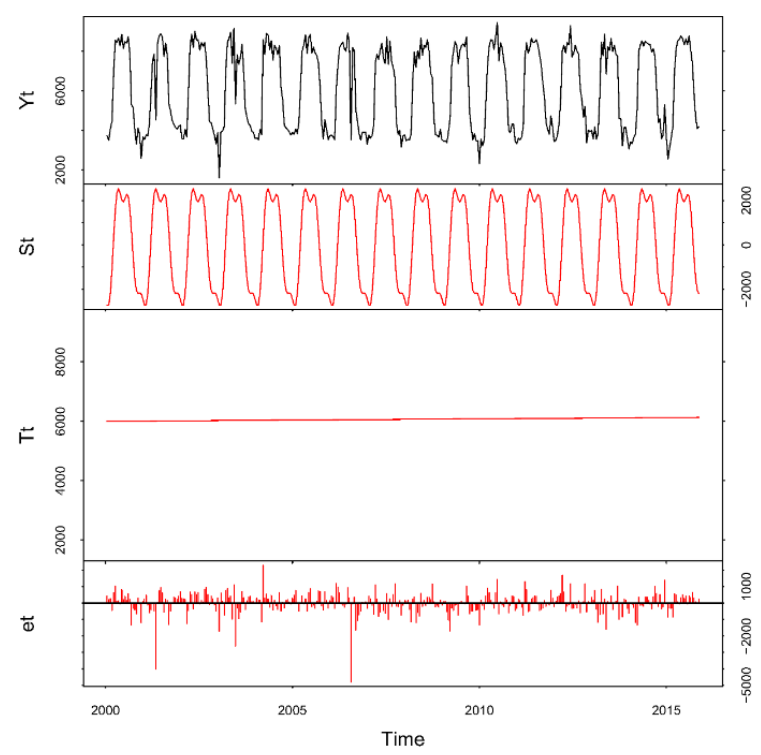

Filled Images 30m Resolution

no. iterations to estimate breakpoints: 1

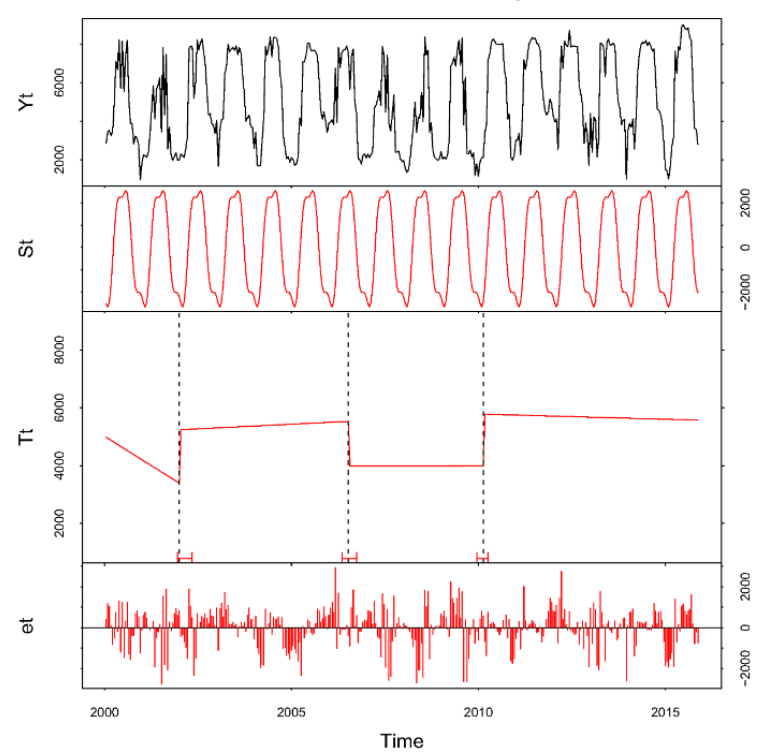

Figure 15. Comparison of the BFAST plots for the MODIS (left) and filled image collection (right) pixels 
From the BFAST plots generated at each of the 6 points there are trends within each study area, Appendix E. With the exception of one point, Site \#1 exhibited no breaks and a positive linear trend over time. Sites \#2 and \#3 produced BFAST plots similar to the one produced for each centroid. Three breaks in the long term, linear trend (Tt) are estimated at Sites \#2 and \#3 with the BFAST algorithm. These sites are located close to one another along Kentucky State Road 1096. Site \#2, point 1 exhibited two breaks compared to three for the rest of the points, Table 7. The date of the second break better coincides with the timing of the third break. For this reason this break was moved to the Break 3 column.

With a slight margin of error at the beginning and ending date of each break can be estimated by using the image band located at the break as a reference point. It is approximated because the date that it is referring to is also the date for which each MODIS MOD13Q1 16-day composite is labelled. The break is also approximate with regards to the disturbance or change in phenology that generates it since the effect measured in vegetation index may lag the cause of that change. The first break shows the most consistency between the two sites and was detected at 10/16/2005 as the approximate date highest frequency of same date breaks in NDVI (Table 7). The second and third breaks show a lower amount of overlap that also falls in the later months of the year. 


\begin{tabular}{|c|c|c|c|c|c|c|}
\hline \multicolumn{7}{|c|}{ Site \#2 } \\
\hline Point & Break 1 & $\begin{array}{c}\text { MODIS } \\
\text { Date }\end{array}$ & $\begin{array}{c}\text { Break } \\
2\end{array}$ & $\begin{array}{c}\text { MODIS } \\
\text { Date }\end{array}$ & $\begin{array}{c}\text { Break } \\
3\end{array}$ & MODIS Date \\
\hline Centroid & 131 & $10 / 16 / 2005$ & 178 & $11 / 1 / 2007$ & 282 & $5 / 8 / 2012$ \\
\hline 0 & 131 & $10 / 16 / 2005$ & 178 & $11 / 1 / 2007$ & 283 & $5 / 24 / 2012$ \\
\hline 1 & 154 & $10 / 16 / 2006$ & N/A & N/A & 318 & $12 / 3 / 2013$ \\
\hline 2 & 47 & 2/18/2002 & 154 & 10/16/2006 & 283 & $5 / 24 / 2012$ \\
\hline 3 & 131 & $10 / 16 / 2005$ & 178 & $11 / 1 / 2007$ & 316 & $10 / 16 / 2013$ \\
\hline 4 & 154 & $10 / 16 / 2006$ & 237 & $5 / 25 / 2010$ & 283 & $11 / 1 / 2013$ \\
\hline
\end{tabular}

(a)

\begin{tabular}{|r|c|c|c|c|c|c|}
\hline \multicolumn{7}{|c|}{ Site \#3 } \\
\hline Point & Break 1 & $\begin{array}{c}\text { MODIS } \\
\text { Date }\end{array}$ & $\begin{array}{c}\text { Break } \\
2\end{array}$ & $\begin{array}{c}\text { MODIS } \\
\text { Date }\end{array}$ & Break 3 & $\begin{array}{c}\text { MODIS } \\
\text { Date }\end{array}$ \\
\hline Centroid & 47 & $2 / 18 / 2002$ & 151 & $8 / 29 / 2006$ & 234 & $4 / 7 / 2010$ \\
\hline 0 & 131 & $10 / 16 / 2005$ & 178 & $11 / 1 / 2007$ & 270 & $11 / 1 / 2011$ \\
\hline 1 & 47 & $2 / 18 / 2002$ & 131 & $10 / 16 / 2005$ & 197 & $8 / 28 / 2008$ \\
\hline 2 & 131 & $10 / 16 / 2005$ & 197 & $8 / 28 / 2008$ & 287 & $7 / 11 / 2012$ \\
\hline 3 & 131 & $10 / 16 / 2005$ & 197 & $8 / 28 / 2008$ & 258 & $4 / 23 / 2011$ \\
\hline 4 & 57 & $7 / 28 / 2002$ & 151 & $8 / 29 / 2006$ & 318 & $12 / 3 / 2013$ \\
\hline
\end{tabular}

(b)

Table 7. Break location by band and the corresponding break start date based on the MODIS MOD13Q1 16-day composite dates for Sites \#2 (a) and \#3 (b) 


\section{Comparison with Vegetation Outside the Study Area}

Beyond the study area are forest stands and fields. To compare any similarities and contrasts that may exist between kudzu and another vegetation cover a simple spectral profile was created using NDVI values for three types of vegetation: kudzu, forest and grass. Site \#2 was used for this portion of analysis as results are assumed to be similar for the same types of vegetation near the other two infestation sites. The spectral profile reveals that overall grass shows lower and smaller ranges in NDVI values compared to the other vegetation covers most likely caused by its erectophile leaf structure (Turner et al. 1999). Forest and kudzu have similar entropy patterns with forest cover peaking with slightly higher NDVI values at both peaks and troughs. These variations are illustrated in Figure 16.

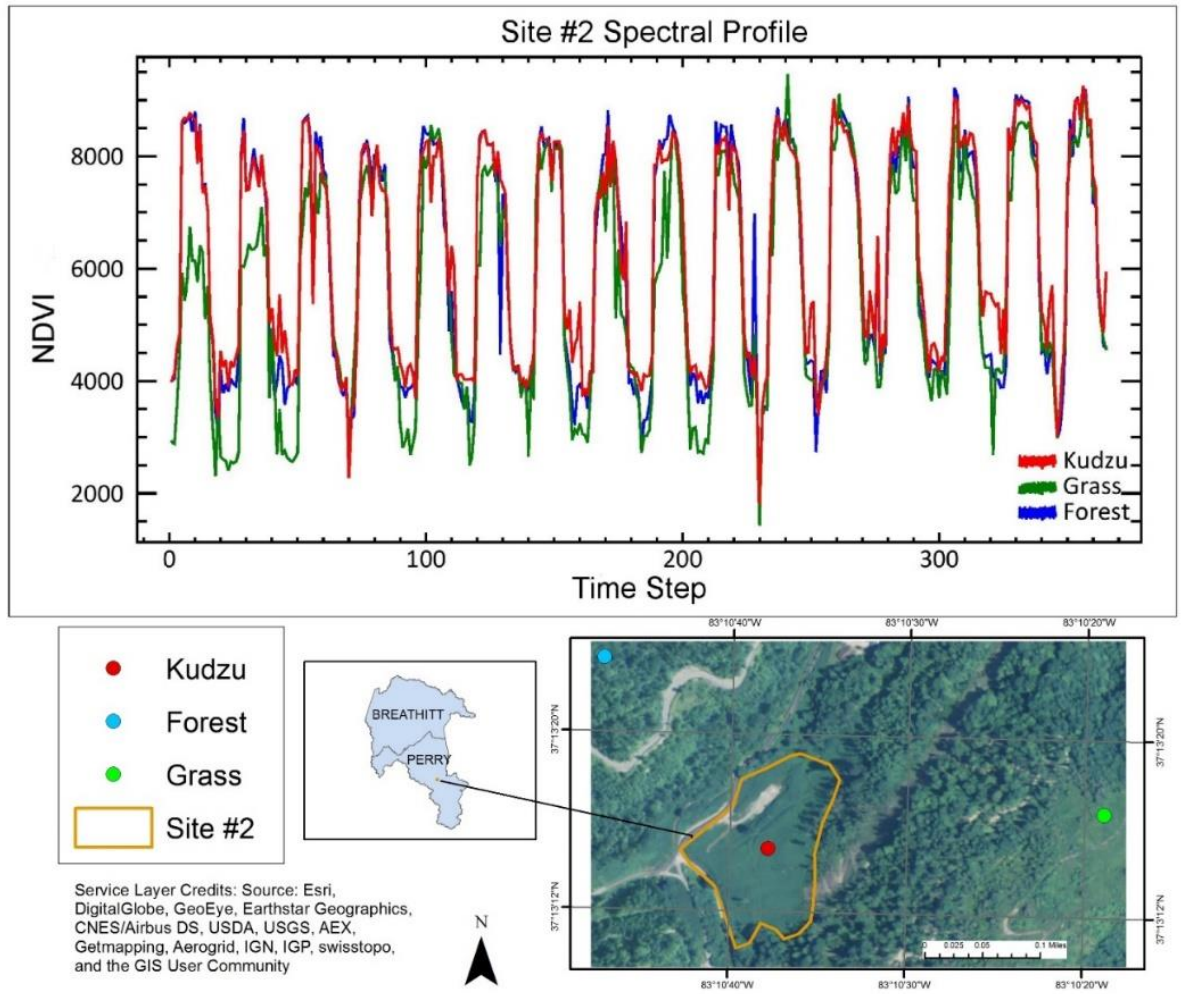

Figure 16. Spectral profile representing kudzu, grass and forest cover in and around Site \#2. 


\section{CHAPTER 5: DISCUSSION}

Results from this study show that original and decomposed time series indicate that estimated NDVI values for kudzu do not oversaturate and can be used as a resource to analyze the phenology dynamics of this plant. Analysis of the results also show that combining imagery into a fused image collection, filling temporal gaps in Landsat-scale NDVI with MODIS-derived, and synthetic data increase the applicability of this type of data to detect long-term trends and changes. Being a fast-growing and high biomass species (Forseth and Innis 2004; Lindgren et al. 2013) we assumed that this method would have successfully detected expansion and intensity of kudzu infestations from the surrounding vegetation. However, the scales used in this study were not fine enough to positively distinguish growth patterns within the three study sites.

\section{STARFM Data Fusion}

The STARFM data fusion algorithm excelled at creating a complete Landsat resolution time series at the MODIS temporal scale. These time series also showcase that NDVI did not oversaturate due to the LAI range at these study sites. If saturation had been present, clipping would have existed in some or all of the peaks within the trend line. Clipping refers the flattening of wave peaks caused by values that exceed the intended range. Such results show that NDVI is an acceptable vegetation index to use when monitoring and measuring kudzu phenology changes. 
Due to the potentially high LAI values of kudzu, 3.7 - 7.8 (Forseth and Innis 2004), the validity of NDVI as a sufficient method of kudzu monitoring should be compared with other VIs such as EVI. Like NDVI, EVI is based on the simple ratio with adjustments expressed in Equation 4.

$$
E V I=G \frac{\rho(\text { nir })-\rho(\text { red })}{\rho(\text { nir })+C_{1} \rho(\text { red })-C_{2} \rho(\text { blue })+L}
$$

This is a more robust VI compared to NDVI because of the inclusion of the constants $C_{1}$ and $C_{2}$ along with the soil coefficient L (Jensen 2016). The two constants adjust for atmospheric scattering and absorption in the red and blue bands respectively. $\mathrm{L}$ is derived based on the type of soil underlying the vegetation and accounts for many of its reflection. These coefficients adjust for any background canopy noise associated with leaf litter, snow, etc (Huete et al. 2002).

Kudzu expands in a blanketing nature which partially or completely replaces any type of canopy that it consumes. The increased presence of chlorophyll increases the sensitivity of NDVI thus potentially producing over estimation of kudzu productivity (Huete et al. 2002). By comparing the NDVI time series produced in this study with that of EVI a conclusion can be made if these value are indeed accurate or have been inflated due to the phenologic and physiologic attributes of kudzu.

Combining "good" and unmasked Landsat-derived NDVI with filled and synthetic imagery aided in preserving the most Landsat data possible as seen in (Schmidt et al. 2015). All three image series represent the progression of the fusion process with (1) MODIS image, (2) Landsat image with mask applied, (3) synthetic Landsat-scale image 
derived from the fusion process and (4) the final Landsat-scale image classified as either original, filled or synthetic.

The BFAST algorithm works best when presented with a complete set of data. This is because it is an additive decomposition model which functions by using the sum of the seasonal, linear and error components to express the observed trend (Verbesselt et al. 2010b; Schmidt et al. 2015). If there is a portion of the observed trend missing, and later inputted, then the additive trends will be skewed due to the lack of data.

Reliance on Landsat data alone would have produced a time series that exhibits numerous points of missing data caused by its unreliable 16-day temporal resolution as displayed in Figures $10-12$. Interpolation between good pixels and images to produce a complete time series could have potentially been misleading based on the number of missing pixels. Incorporating MODIS data with the STARFM algorithm provided good pixels correlating with missing Landsat pixels to produce synthetic imagery.

With this brings uncertainty due to the spatial resolution of the MODIS pixels in relation to the area of each study site. As none of the sites were large enough to contain a complete MODIS pixel, the synthetic Landsat-scale pixels within the study sites were derived from mixed MODIS pixels containing spectral signatures from surrounding vegetation. Gao et al. (2006) does mention that the accuracy of detecting phenology changes using STARFM is dependent on the size of the study area. Locating pure coarse resolution pixels representing the land cover in question increases the accuracy of the synthetic data for similar but smaller areas. Without a land cover classification it is not clear if a pure kudzu pixel was used in the STARFM algorithm. Future studies could 
incorporate a land cover classification to clarify this questions and if the absence of a pure kudzu MODIS scale pixel effects the results of this study.

\section{BFAST Analysis}

Results from the BFAST analyses substantiate the use of the STARFM fusion algorithm to produce a much more robust image collection compared to one that is composed only of Landsat or MODIS data. Analysis of these plots show a distinct difference in the phenologic dynamics observed at $250 \mathrm{~m}$ compared to those made at 30 $\mathrm{m}$ spatial resolutions. The increase in the number of breaks produced from the $30 \mathrm{~m}$ filled dataset shows that finer resolution is better at detecting phenologic change at the local level. Each break calculated by the BFAST algorithm was matched with the corresponding image, or band, in the filled image collection. This was possible because each image correlates to a MOD13Q1 composite.

Site \#1 did not present as many breaks as was recorded for Sites \#2 and \#3. A number of approaches were made to determine the cause of these breaks but a concrete answer was not reached. Perry and Breathitt counties are both host to numerous wildfires every year which range in size from 10 acres to over 500 acres according to the Kentucky State Department of Forestry (M. Harp and R. Boggs, personal communication, 21 March 2016). A firsthand account offered by the KYTC District 10 (D. R. Gumm, personal communication, 16 March 2016) was that at least one fire in early 2014 disturbed part of the Kudzu infestation at Site \#1. At this same time the KYTC, in collaboration with a team from the University of Kentucky, began studying the western section of this site by 
sectioning it off into $30 \mathrm{ft}$. $x 30 \mathrm{ft}$. plots to test chemical and mechanical methods of kudzu eradication.

The 2014 fire hampered their project because it allowed a patch of ragweed to take hold. Unfortunately these disturbances were not able to be detected as a statistically significant break most likely due to its position near the end of the time series not allowing enough data to accurately predict breaks. Our inability to confirm when kudzu was established also prohibits the detections of a kudzu signal. A finer spatial resolution image collection could also be used to better match that of the study plots to reduce the presence of mixed pixels especially for experimental control methods.

According to the Kentucky Wildland Forest Management fall fire season ranges from October to December correlating with deciduous species dropping their leaves. This also happens to the be the time in which both Sites \#2 and \#3 exhibited overlapping breaks in 2005 and 2007. The distance separating the two sites along KY Highway 1096 is approximately 1.5 miles making it possible that both could have been impacted by the same fire events. Site \#1 is 30 miles northwest, possibly isolating it from these fire events and explain the lack of breaks during this period. A lack of consistent recording of each fire and of burn scar extent made this data too inconsistent to definitively know if a fire consumed any portion of these two sites.

Fires in eastern Kentucky are most often caused by arsonists and human carelessness and is exacerbated by periods of sustained, reduced rainfall and high temperatures (Maingi and Henry 2007). Changes in the weather can also affect how efficiently kudzu grows. As mention earlier this plant prefers temperatures ranging from $25^{\circ} \mathrm{C}$ and $30^{\circ} \mathrm{C}$ and precipitation of at least $100 \mathrm{~cm}$ per year (Forseth and Innis 2004; Lindgren et al. 
2013). Future studies could potentially correlate temperature and precipitation fluctuations with trends and breaks detected using the BFAST analysis. For example, years with early freeze dates or sustained drought may provide reasoning as to why a low estimated NDVI value for kudzu was observed. Including burn scar maps using the methods described by Maingi (2005) using Landsat ETM+ data in this area of the state may also prove to be useful by providing spatial and temporal clues as to the cause of vegetation disturbance observed by breaks in the linear trend.

\section{Limitations}

A number of limitations were considered when attempting to explain why the methods used in this study did not adequately detect changes to the extent and intensity of kudzu infestations. Landsat and MODIS are both multispectral sensors that are calibrated to detect fewer than 20 bands within the electromagnetic spectrum. Hyperspectral sensors collect 100s of bands that are narrower and have the ability to accurately assign specific spectral signatures to individual plant species, (He et al. 2011). The approach taken in this study is limited by assessing only the visible red and NIR bands of the electromagnetic spectrum via the NDVI which was assumed to present a unique spectral signature for kudzu compared to surrounding vegetation. The results do not provide concrete evidence that this is a sound method and that finer spectral resolution combined with a fine temporal resolution may be necessary for detection.

A previous study that was successful in detecting kudzu utilized the hyperspectral airborne AVIRIS sensor, (Cheng, Tom, and Ustin 2007), with a spatial resolution of $4 \mathrm{~m}$. The combination of higher dimensionality within the visible red and NIR bands, along 
with the spatial resolution, could produce a more sensitive NDVI-like estimate better tailored to kudzu. This method could be employed in conjunction with the Illinois Department of Resources (J. Shimp, personal communication, 30 September 2015) technique of monitoring kudzu after the first freeze when is browns. This approach has the potential to be problematic because the sensor collects data only when specified and at a significant cost, and not on a continual basis. Long term time series could not be assembled using this data because of the lack of temporal continuity. Attaching a sensor to a UAV could potentially reduce these limitations but would require someone trained in using the machinery and software.

This study is also limited by the absence of field-collected reference data and collection of in situ data related to site specific kudzu growth, presence, absence, and disturbances. This reduces the ability to explain the results from the time series and BFAST analyses. Similar approaches involving other vegetation types include the measurement of cheatgrass extent detected with the use a combination of land cover classification in the Great Basin and field observations made at over 600 locations in the study area (Bradley and Mustard 2005). This method models a more in depth approach to monitoring this invasive species because it creates a detailed land cover classification to validate remotely sensed spectral signatures of vegetation types.

Creating a land cover classification for the area within the $5000 \mathrm{~m}$ buffered area could also be beneficial as suggested by the results from the simple spectral. This is because of the presences of slight overall variations in individual spectral profiles present between vegetation types. These results combined with those from the BFAST analysis do show that NDVI is a valid indicator of vegetation phenology change overtime due to the slight 
variations between vegetation and kudzu. Referring back to Figure 12, kudzu and forest exhibit similar patterns in estimated annual NDVI values but forest cover tends to show more extreme values at both peaks and troughs. This signals suggests that this variation is a characteristics that could be used to distinguish the two species and verified with a land cover classification map. 


\section{CHAPTER 6: CONCLUSION}

This research was conducted to explore the efficacy of synthetic imagery as a method for measuring and monitoring kudzu infestations in eastern Kentucky. The position of Kentucky along the northern edge of the North American kudzu extent makes this a study area ripe for understanding the phenological characteristics that allow kudzu to propagate so aggressively. With the use of data acquisition scripts written for GEE this research was able to acquire and process high dimensional Landsat and MODIS image collections. By fusing these two image collections together via STARFM a multiband image was produced containing the Landsat $30 \mathrm{~m}$ spatial resolution and MODIS 16-day temporal resolution.

Results showed that the finer spatial resolution of the synthetic data was better at detecting within site disturbances in the vegetation dynamics compared to using MODIS data alone. Sites \#2 and \#3 both exhibited 2-3 breaks for each of the six pixels examined from within each site. At the scale of these kudzu infestations MODIS data is too spatially coarse which potentially hides kudzu vegetation dynamics within spectral signatures from neighboring vegetation. MODIS pixels may not show similar breaks because of mixing in the coarser resolution pixels.

Adding a field component may have significantly increased the chance of firmly addressing the phenologic trend of these kudzu infestations. The outcome did produce a set of script that could be reused in future studies to handle big data for processing time 
series decomposition of kudzu and other vegetation. As time goes on and the temporal dimensionality extends for Landsat and MODIS which will further increase the need for a robust time series decomposition method as presented here.

In situ data collection would aid in the validation of the STARFM and BFAST results, especially as it relates to invasive species monitoring. In order to collect the most effective data the collection process might follow the guidelines posed by EDDMapS which provides collectors with required data fields that must be completed before submitting any observation to their open source site. These standards are taken from the North American Weed Management Association's (NAWMA) Invasive Plant Mapping Standards Following these standards during the data collection process will ensure the comparison to existing data on other kudzu infestations. Table 8

Table 8 lists NAWMA's standards that are required when collecting data.

\begin{tabular}{|c|c|c|}
\hline \multicolumn{3}{|c|}{ Data Collection Standards } \\
\hline Reporter & Canopy Closure & Datum \\
\hline Date Entered & Latitude & Ownership \\
\hline Pest & Longitude & Location Description \\
\hline Observation Date & $\begin{array}{c}\text { Infested Area Size } \\
\text { (sq.m) }\end{array}$ & Images \\
\hline State and County & & \\
\hline
\end{tabular}

Table 8. EDDMapS and NAWMA Data Collection Standards

Refinement of this study with the addition of field work, more refined approach to BFAST pixel selection within the buffered areas and possibly different image collections results might aid land managers when detecting and formulating kudzu management plans. The process developed in this study showcases the importance of big data 
processing, such as Google Earth Engine, for acquiring and processing large amounts of raster-based and remotely sensed data. It highlights the efficiency of allowing massive computer networks to carry out these steps on the fly at a global scale using highly dimensional datasets.

This study also illustrates how the STARFM algorithm is used to create a derived continuous Landsat-scale time series of estimated NDVI for the use in monitoring kudzu and other types of vegetation phenology dynamics. Although this technique combined with the BFAST analysis is highly technical it would be improved upon with the addition of field-based research. Remote sensing and other geospatial techniques do make research of local and global phenomenon accessible away from the source but there is still a need to validate such results with field data. By combining both data collecting techniques a more complete picture of kudzu phenologic dynamics can be made which will make monitoring and eradication for efficient. Understanding how to use and interpret remotely sensed data requires substantial training which does limit its use and would require collaboration on mitigation efforts if needed. Kudzu will continue to threaten landscapes, economies and communities and this is another step towards a solution to the problem. 


\section{REFERENCES}

Asner, G. P., D. E. Knapp, T. Kennedy-Bowdoin, M. O. Jones, R. E. Martin, J. Boardman, and R. F. Hughes. 2008. Invasive species detection in Hawaiian rainforests using airborne imaging spectroscopy and LiDAR. Remote Sensing of Environment 112 (5):1942-1955.

Bender, J. personal communication. 18 Spetember 2015.

Blaustein, R. J. 2001. Kudzu's invasion into Southern United States life and culture. The Great Reshuffling: Human Dimensions of Invasive Species. 55-62.

Birth, G. S., and G. R. McVey. 1968. Measuring the color of growing turf with a reflectance spectrophotometer. Agronomy Journal. 60 (6): 640-643.

Bradley, B. A., and J. F. Mustard. 2005. Identifying land cover variability distinct from land cover change: Cheatgrass in the Great Basin. Remote Sensing of Environment. 94 (2):204-213.

Buheaosier, K., Tsuchiya, M. K. and S. J. S. 2003. Comparison of Image Data Acquired with AVHRR, MODIS, ETM+ and ASTER over Hokkaido, Japan. Advances in Space Research. 32 (11):2211-2216.

Callen, S. T., and A. J. Miller. 2015. Signatures of niche conservatism and niche shift in the North American kudzu ( Pueraria montana) invasion. Diversity and Distributions. 21 (8):853-863.

Cheng, Y. B., E. Tom, and S. L. Ustin. 2007. Mapping an invasive species, kudzu (Pueraria montana), using hyperspectral imagery in western Georgia. Journal of Applied Remote Sensing. 1 (1):013514.

Chuvieco, E., S. Opazo, W. Sione, H. Valle, J. Anaya, D. Bella, I. Cruz, L. Manzo, G. López, N. Mari, F. González-alonso, F. Morelli, A. Setzer, I. Csiszar, J. A. Kanpandegi, A. Bastarrika, R. Libonati, S. E. Applications, and N. Jan. 2013. Global Burned-Land Estimation in Latin America Using Modis Composite Data. Ecological Applications. 18 (1):64-79.

EDDMapS. 2016. Early Detection \& Distribution Mapping System. The University of Georgia - Center for Invasive Species and Ecosystem Health. Available online at http://www.eddmaps.org/; (last accessed 20 March 2016).

ESRI. 2014. ArcGIS Desktop v10.3.1. Redlands, CA.: Environmental Systems Research Institute. 
Forkel, M., N. Carvalhais, J. Verbesselt, M. D. Mahecha, C. S. R. Neigh, and M. Reichstein. 2013. Trend Change detection in NDVI time series: Effects of interannual variability and methodology. Remote Sensing. 5 (5):2113-2144.

Forseth, I. N., and A. F. Innis. 2004. Kudzu (Pueraria montana): History, Physiology, and Ecology Combine to Make a Major Ecosystem Threat. Critical Reviews in Plant Sciences. 23 (5):401-413.

Gao, F., J. Masek, M. Schwaller, and F. Hall. 2006. On the blending of the landsat and MODIS surface reflectance: Predicting daily landsat surface reflectance. IEEE Transactions on Geoscience and Remote Sensing. 44 (8):2207-2218

Google EarthPro. Google

Goward, S., T. Arvldson, D. Williams, J. Faundeen, J. Irons, and S. Franks. 2006. Historical record of landsat global coverage : Mission operations, NSLRSDA, and international cooperator stations. Photogrammetric engineering and remote sensing 72 (10):1155-1169.

Gu, Y., and B.K. Wylie. Develeoping a 30-m grassland productivity estimation map for central Nebraska using 250-m MODIS and 30-m Landsat-8 observations. Remote Sensing of Environment. 171:291-298.

Gumm, D. R., personal communication. 29 October 2015.

Gumm, D. R., personal communication. 16 March 2016.

Hansen, M. C., P. V Potapov, R. Moore, M. Hancher, S. A. Turubanova, and A. Tyukavina. 2013. High-Resolution Global Maps of 21st Century Forest Cover Change. Science. 342 (6160):850-853.

Harp, M. and R. Boggs. personal communication. 21 March 2016.

Hawthorne, T. L., V. Elmore, A. Strong, P. Bennett-Martin, J. Finnie, J. Parkman, T. Harris, J. Singh, L. Edwards, and J. Reed. 2015. Mapping non-native invasive species and accessibility in an urban forest: A case study of participatory mapping and citizen science in Atlanta, Georgia. Applied Geography. 56:187-198.

He, K. S., D. Rocchini, M. Neteler, and H. Nagendra. 2011. Benefits of hyperspectral remote sensing for tracking plant invasions. Diversity and Distributions. 17 (3):381-392.

Hilker, T., M. A. Wulder, N. C. Coops, J. Linke, G. McDermid, J. G. Masek, F. Gao, and J. C. White. 2009. A new data fusion model for high spatial- and temporalresolution mapping of forest disturbance based on Landsat and MODIS. Remote Sensing of Environment. 113 (8):1613-1627.

Hill, J and H. M. Mogil., 2012. The Weather and Climate of Kentucky. Weatherwise. 65 (5):26-32. 
Huang, C., and G. P. Asner. 2009. Applications of Remote Sensing to Alien Invasive Plant Studies. Sensors. 9 (6):4869-4889.

Huete, A. R., H. Q. Liu, K. Batchily, and W. Van Leeuwen. 1997. A comparison of vegetation indices over a global set of TM images for EOS-MODIS. Remote Sensing of Environment. 59 (3):440-451.

Huete, A., K. Didan, T. Miura, E. P. Rodriguez, X. Gao, and L. G. Ferreira. 2002. Overview of the radiometric and biophysical performance of the MODIS vegetation indices. Remote Sensing of Environment. 83 (1-2):195-213.

Hunt, R., R. Hamilton, and J. Everitt. n.d. What Weeds Can Be Remotely Sensed?. United States Department of Agriculture: United States Forest Service. 1 - 5.

Hutchinson, J. M. S., A. Jacquin, S. L. Hutchinson, and J. Verbesselt. 2015. Monitoring vegetation change and dynamics on U.S. Army training lands using satellite image time series analysis. Journal of Environmental Management. 150:355-366.

Irons, J. R., J. L. Dwyer, and J. A. Barsi. 2012. The next Landsat satellite: The Landsat Data Continuity Mission. Remote Sensing of Environment. 122:11-21.

Jakubauskas, M. E., D. R. Legates, and J. H. Kastens. 2001. Harmonic analysis of time series AVHRR NDVI data. Photogrammetric Engineering and Remote Sensing. 67 (4):461 - 470.

Jensen, J. R. 2016. Introductory Digital Image Processing: A Remote Sensing Perspective. Pearson Education Inc.

Jin, H., and L. Eklundh. 2014. A physically based vegetation index for improved monitoring of plant phenology. Remote Sensing of Environment. 152:512-525.

Johnson, L. F., D. E. Roczen, S. K. Youkhana, R. R. Nemani, and D. F. Bosch. 2003. Mapping vineyard leaf area with multispectral satellite imagery. Computers and Electronics in Agriculture. 38 (1):33-44.

Lhermitte, S., J. Verbesselt, W. W. Verstraeten, and P. Coppin. 2011. A comparison of time series similarity measures for classification and change detection of ecosystem dynamics. Remote Sensing of Environment. 115 (12):3129-3152.

Lindgren, C. J., K. L. Castro, H. A. Coiner, R. E. Nurse, and S. J. Darbyshire. 2013. The Biology of Invasive Alien Plants in Canada. Pueraria montana var. lobata (Willd.). Canadian Journal of Plant Science. 93 (1):71-95.

Lobell, D.B., D, Thau, C. Seifert, E. Engle, and B. Little. A scalable satellite-based crop yield mapper. Remote Sensing of Environment. 164: 324-333.

LP DAAC. 2014. Vegetation Indices 16-Day L3 Global 250m. https://lpdaac.usgs.gov/dataset_discovery/modis/modis_products_table/mod13q1. (last accessed 5 April 2016). 
Maiersperger, T. K., P. L. Scaramuzza, L. Leigh, S. Shrestha, K. P. Gallo, C. B. Jenkerson, and J. L. Dwyer. 2013. Characterizing LEDAPS surface reflectance products by comparisons with AERONET, field spectrometer, and MODIS data. Remote Sensing of Environment. 136:1-13.

Maingi, J. K. 2005. Mapping Fire Scars in a Mixed-Oak Forest in Eastern Kentucky, USA, Using Landsat ETM+ Data. Geocarto International 20 (3):51-63.

Maingi, J. K., and M. C. Henry. 2007. Factors influencing wildfire occurrence and distribution in eastern Kentucky, USA. International Journal of Wildland Fire. 16 (1):23-33.

Maselli, F. 2004. Monitoring forest conditions in a protected Mediterranean coastal area by the analysis of multiyear NDVI data. Remote Sensing of Environment. 89 (4):423-433.

Muchoney, D., J. Borak, H. Chi, M. Friedl, S. Gopal, J. Hodges, N. Morrow, and A. Strahler. 2000. Application of the MODIS global supervised classification model to vegetation and land cover mapping of Central America. International Journal of Remote Sensing. 21 (6-7):1115-1138.

Padarian, J., B. Minasny, and A. B. McBratney. 2015. Using Google's cloud-based platform for digital soil mapping. Computers \& Geosciences. 83:80-88.

Patel, N. N., E. Angiuli, P. Gamba, A. Gaughan, G. Lisnini, F. R. Stevens, A. J. Tatem, and G. Trianni. 2014. Multitemporal settlement and population mapping from Landsat using Google Earth Engine. International Journal of Applied Earth Observation and Geoinformation. 35: 199-208.

R Core Team. 2016. R: A Language and Environment for Statistical Computing. http://www.r-project.org/ (last accessed 4 April 2016).

Rafique, R., F. Zhao, R. de Jong, N. Zeng, and G. Asrar. 2016. Global and Regional Variability and Change in Terrestrial Ecosystems Net Primary Production and NDVI: A Model-Data Comparison. Remote Sensing 8 (3):177.

Rouse Jr, J.W., R. H. Haas, J. A. Schell, and D. W. Deering. Monitoring vegetation systems in the Great Plains with ERTS. NASA special publication. 351 (1974): 309.

Salajanu, D., and D. M. Jacobs. 2009. Using Forest Inventory Plot Data and Satellite Imagery From Modis and Landsat-Tm To Model Spatial Distribution Patterns of Honeysuckle and Privet. In USDA Forest Service.

Schmidt, M., R. Lucas, P. Bunting, J. Verbesselt, and J. Armston. 2015. Multi-resolution time series imagery for forest disturbance and regrowth monitoring in Queensland, Australia. Remote Sensing of Environment. 158:156-168.

Shimp, J. personal communication. 30 September 2015. 
Shouse, M., L. Liang, and S. Fei. 2013. Identification of understory invasive exotic plants with remote sensing in urban forests. International Journal of Applied Earth Observation and Geoinformation 21:525-534.

Silleos, N. G., T. K. Alexandridis, I. Z. Gitas, and K. Perakis. 2006. Vegetation Indices: Advances Made in Biomass Estimation and Vegetation Monitoring in the Last 30 Years. Geocarto International. 21 (4):21-28.

Smith, C. 2010. Invasive Exotic Plants of North Carolina: Pueraria montana (Kudzu). N.C. Department of Transportation. Raleigh, NC. (08):1-2.

Turner, D. P., W. B. Cohen, R. E. Kennedy, K. S. Fassnacht, and J. M. Briggs. 1999. Relationships between leaf area index and Landsat TM spectral vegetation indices across three temperate zone sites. Remote Sensing of Environment. 70 (1):52-68.

United States Department of Agriculture. 2016. STARFM. Software Download. http://www.ars.usda.gov/services/software/download.htm?softwareid=432. (last accessed 5 April 2016).

USGS. 2016. PRODUCT GUIDE LANDSAT 4-7 CLIMATE DATA RECORD (CDR) SURFACE REFLECTANCE. Version 6.3 (March).

http://landsat.usgs.gov/documents/ledaps_release_notes.pdf (last accessed 4 April 2016).

Verbesselt, J., R. Hyndman, G. Newnham, and D. Culvenor. 2010a. Detecting trend and seasonal changes in satellite images time series. Remote Sensing of Environment (114):106-115.

Verbesselt, J., R. Hyndman, A. Zeileis, and D. Culvenor. 2010b. Phenological change detection while accounting for abrupt and gradual trends in satellite image time series. Remote Sensing of Environment 114 (12):2970-2980.

Walker, J. J., K. M. De Beurs, R. H. Wynne, and F. Gao. 2012. Evaluation of Landsat and MODIS data fusion products for analysis of dryland forest phenology. Remote Sensing of Environment. 117:381-393.

Wang, P., F. Gao, and J. G. Masek. 2014. Operational data fusion framework for building frequent landsat-like imagery. IEEE Transactions on Geoscience and Remote Sensing. 52 (11):7353-7365.

Wulder, M. A., J. G. Masek, W. B. Cohen, T. R. Loveland, and C. E. Woodcock. 2012. Opening the archive: How free data has enabled the science and monitoring promise of Landsat. Remote Sensing of Environment 122:2-10.

Yang, D. 2012. MODIS-Landsat Data Fusion for Estimating Vegetation Dynamics-A Case Study for Two Ranches in West Texas. 10th Annual TAMUS Pathways Student Research Symposium. 
Zhang, X., M. A. Friedl, C. B. Schaaf, and A. H. Strahler. 2004. Climate controls on vegetation phenological patterns in northern mid- and high latitudes inferred from MODIS data. Global Change Biology. 10 (7):1133-1145.

Zheng, G. and L.M. Moskal. 2009. Retrieving Leaf Area Index (LAI) Using Remote Sensing: Theories, Methods and Sensors. Sensors. 9(4):2719-2745.

Zhitao, Z., Y. Lan, W. Pute, and H. Wenting. 2014. Model of soybean NDVI change based on time series. International Journal of Agriculture and Biological Engineering. 7 (5):64-70. 


\section{APPENDIX A: GOOGLE EARTH CODE}

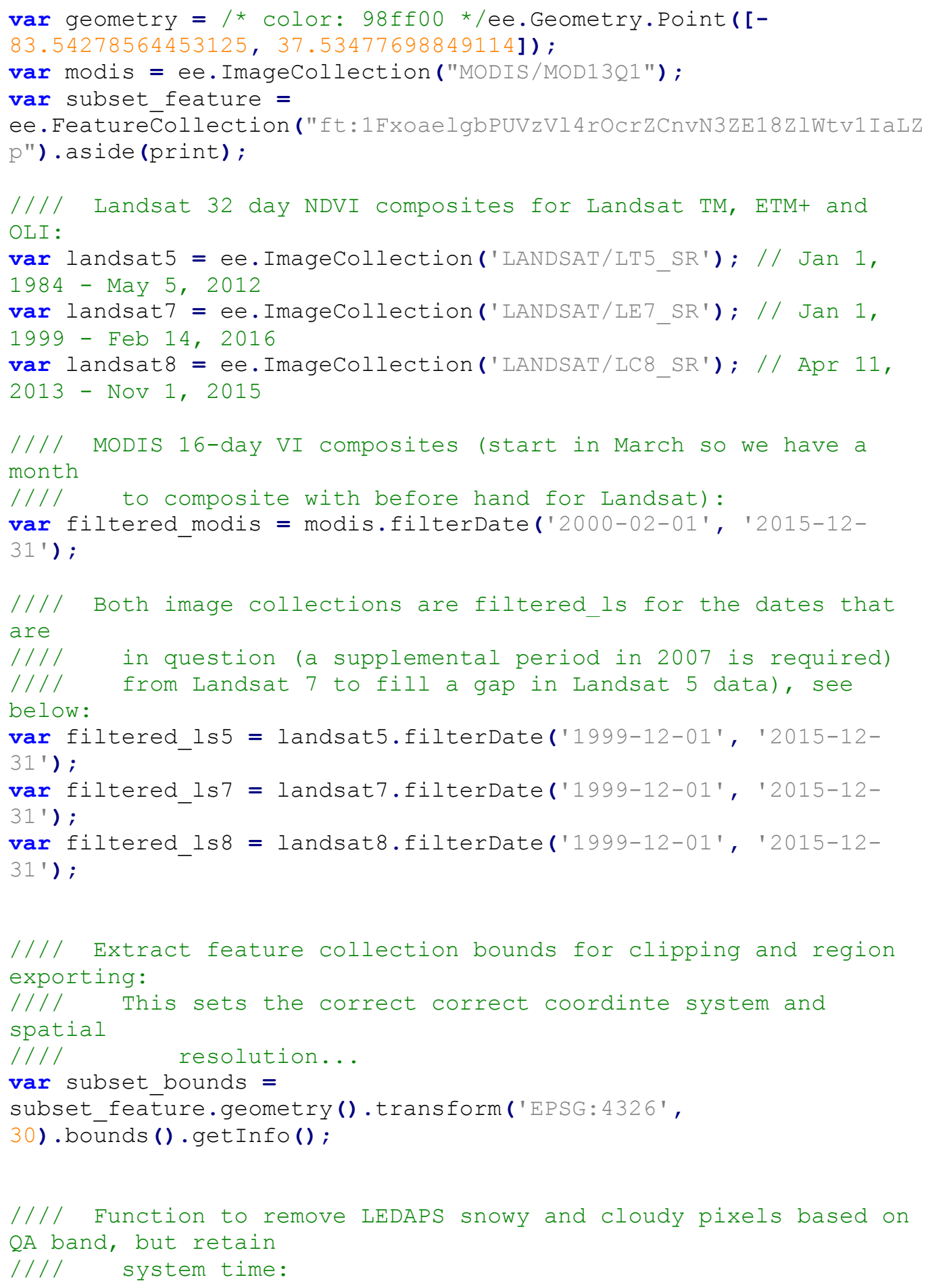


var removeBadobservations = function(image) \{

var valid_data_mask = ee.Image(image). select('Cfmask').lte(1);

var numberBandsHaveData $=$

image.mask ().reduce (ee.Reducer.sum ());

var allorNoBandsHaveData =

numberBandsHaveData.eq (0) .or (numberBandsHaveData.gte (9)) ;

var allBandsHaveData = allorNoBandsHaveData;

//Make sure no band is just under zero

var allBandsGT = image.reduce (ee. Reducer.min()).gt(-0.001)

var result $=$

ee. Image (image). mask (image.mask(). and (valid data mask). and (allBan dsHaveData) . and (allBandsGT)) ;

return

result.copyProperties (ee.Image (image), ['system:time_start']); \} ;

//// Functions to calculate NDVI for different sensors:

var getNDVI_tm = function(image) \{

var $n d v \bar{i}=$ ee.Image (image). normalizedDifference (['B4', 'B3']); return

ndvi.copyProperties (ee. Image(image), ['system:time start']);

\};

var getNDVI_oli = function(image) \{

$\operatorname{var} \mathrm{ndv} \bar{i}=$ ee.Image(image). normalizedDifference (['B5', 'B4']); return

ndvi.copyProperties (ee.Image (image), ['system:time start']);

\} ;

/// Filter the filtered_ls collecitons by the bound, remove bad pixels,

//// and calculate NDVI for all remaining images:

filtered $\operatorname{ls} 5=$

filtered_ls5.filterBounds (subset_bounds). aside (print) .map (removeB adobservations) . map (getNDVI_tm) ;

filtered $1 \mathrm{~s} 7=$

filtered_ls7.filterBounds (subset_bounds). aside (print) . map (removeB adobservätions) . map (getNDVI_tm) ;

filtered_ls $8=$

filtered_ls8.filterBounds (subset_bounds). aside (print) .map (removeB

adobservātions).map (getNDVI_oli) ;

//// Combine image collections across sensors:

var filtered_ls_ndvi = filtered_ls5;

//// Add on $\bar{y}$ select ranges of ETM+ data:

filtered_ls_ndvi $=$

filtered_ls_ndvi.merge(filtered_ls7.filterDate ('2007-10-01', '2007-12-31'));

filtered_ls_ndvi

filtered_ls_ndvi.merge(filtered_ls7.filterDate ('2011-04-01', '2013-06-30'));

filtered_ls_ndvi = filtered_ls_ndvi.merge(filtered_ls8);

104

105 
//// Convert polygon boundaries to raster by using the paint()

107 //// function on a non-existent property, and then add 1:

108 var subset_mask = ee.Image (). byte(). paint (subset_feature,

110

111

112

113

//// Process MODIS data to time series:

114

filtered modis $=$

filtered_modis.filterBounds(subset_bounds).aside (print);

115

var extract_modis_date $=$ function(row) \{

//// Pul' out the date:

var $\mathrm{d}=$ ee.Date (row.get ('system:time start'));

var $d 2=e \cdot$ Date.fromYMD (d.get('year'), $d \cdot \operatorname{get}($ 'month'),

d.get ('day'));

var result $=$ ee.Feature (null, $\left\{\right.$ 'date' $\left.^{\prime} \mathrm{d} 2\right\}$ );

result $=$ result. $\operatorname{set}\left(\left\{\right.\right.$ 'date' $\left.\left.^{\prime} \mathrm{d} 2\right\}\right)$;

return result;

\} ;

124

125

126

127

128

129

130

131

132

133

134

135

136

137

138

139

140

141

142

143

144

145

146

147

148

149

150

151

152

153

154

155

156

157

158

159

160

* A function that returns an image containing just the specified QA bits.

*

* Args:

* image - The QA Image to get bits from.

* start - The first bit position, 0-based.

* end - The last bit position, inclusive.

* name - A name for the output image.

* 1

var getQABits = function(image, start, end, newName) \{

//// Compute the bits we need to extract.

var pattern = 0 ;

for (var $i=$ start; $i<=$ end; $i++)\{$

pattern $+=\operatorname{Math} \cdot \operatorname{pow}(2, i)$;

$$
\text { \} }
$$

//// Return a single band image of the extracted QA bits, giving the band

//// a new name.

return image.select ([0], [newName])

.bitwiseAnd (pattern)

\} ;

.rightShift(start);

//// Process MODIS data, first subsetting and masking:

filtered_modis $=$ filtered_modis.map (function(image) \{

//// Check to see if the detailed QA bits 4-5 are both 11, indicating

//// bottom level of "Decreasing quality..." and set it to 1

if not

////

////

https://lpdaac.usgs.gov/dataset discovery/modis/modis products ta ble/mod13q1

var quality = getQABits (image.select(2), 4, 5, 'QAMask');

161 quality $=$ quality $\cdot$ eq( $(3) \cdot \operatorname{not}()$; 
163 image.clip (subset_bounds).mask(image.mask().multiply (subset_mask)

165 ) ) ;

166

//// We also have to select our Day of Year and NDVI:

var filtered modis day = filtered modis.select(10);

169

170

171

172

173

174

175

176

177

178

179

180

181

182

183

184

185

186

187

188

189

190

191

192

193

194

195

196

197

198

199

200

201

202

203

204

205

206

207

208

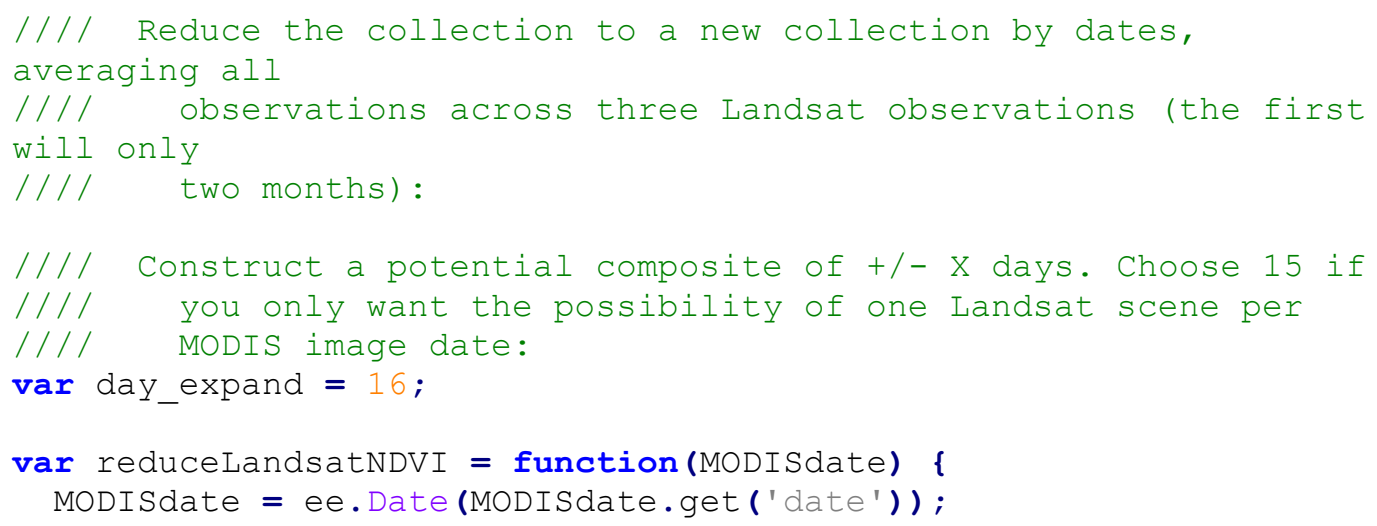


//// The MODIS time start represents the beginning of the MODIS composite

//// window. Therefore, to extract a Landsat scene that was captured

//// within the same composite period, we will not look before and after

/// that date:

$/ / \operatorname{var}$ ndvi subset $=$ ee.Imagecollection(filtered_ls_ndvi).filterDate ( 


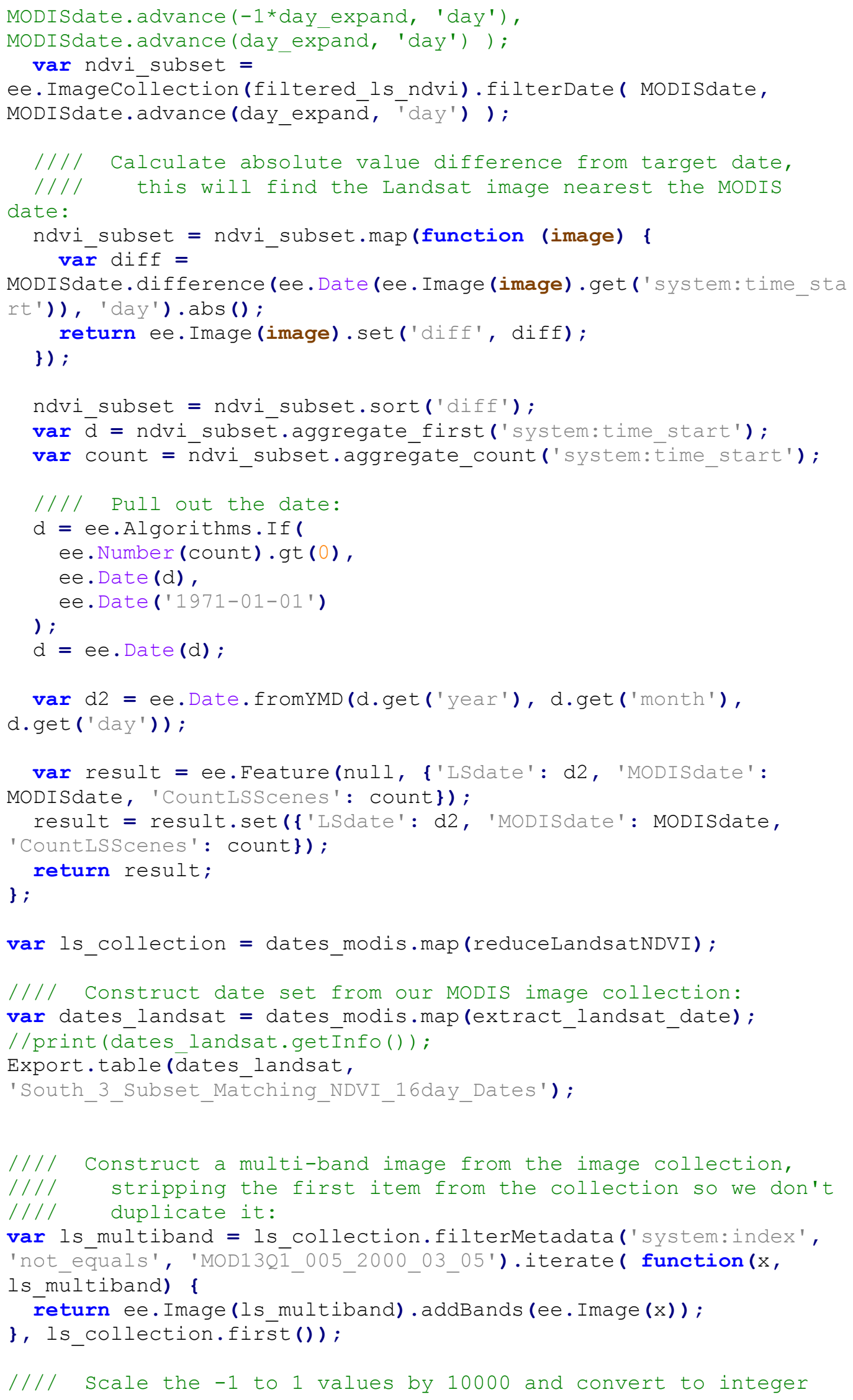


/// to match MODIS, then convert zeroes to missing (byproduct

334 //// of ND calculation and missing reducer values):

335 Is_multiband = ee.Image(ls_multiband).multiply(10000).int16();

336 is multiband $=$

337 ls_multiband.mask(ls_multiband.mask().multiply(ls_multiband.neq(0

338 ))

339

340

341

342

343

344

345

346

347

348

349

350

351

352

353

354

355

356

357

358

359

360

361

362

363

364

365

366

367

368

369

370

371

372

373

374

375

376

377

378

379

380

381

382

383

//// The multiband stack should now contain layers for each month

//// including the supplemental ones pulled from each sensor stack:

print (modis multiband);

print(ls_multiband);

/// NOTE: I'm exporting the MODIS at $30 \mathrm{~m}$ as well to match the Landsat

/// stack:

Export.image (modis_multiband, 'South_3_subset_MODIS_NDVI_16day', \{

Crs: 'EPSG:32617',

region:subset_bounds, scale: 30

\}) ;

Export.image (modis_day_multiband,

'South_3_Subset_MODIS_DoY_16day', \{ crs: 'E $\bar{P} S G: 326 \overline{1} 7$ ', region:subset_bounds, scale: 30

\}) ;

//// Exporting the image as a raster data set that can be opened in ENVI

Export.image(Is_multiband, 'South_3_Subset_Landsat_NDVI_16day' , \{

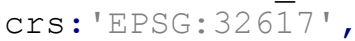
region:subset_bounds, scale:30

\}) ;

Map.addLayer(subset_feature, \{color: 'FF0000'\}, 'Subset');

//var coords =

ee.Feature (subset.first ()) . centroid().geometry(). coordinates();

//print (ee. Number (coords.get (1)));

Map.centerobject (subset_feature.first (), 12);

//Map.setCenter $(-83.54,-37.53,12)$;

Map.addLayer (ee.Image (modis_multiband), \{\}, 'MODIS NDVI

Composites') ;

Map.addLayer(ee.Image (modis_day_multiband), \{\} , 'MODIS Day of

Year Composites');

384 Map.addLayer(ee.Image(1s_multiband), \{\}, 'Landsat NDVI

385 Composites'); 


\section{APPENDIX B: R PROGRAMMING CODE FOR STARFM}

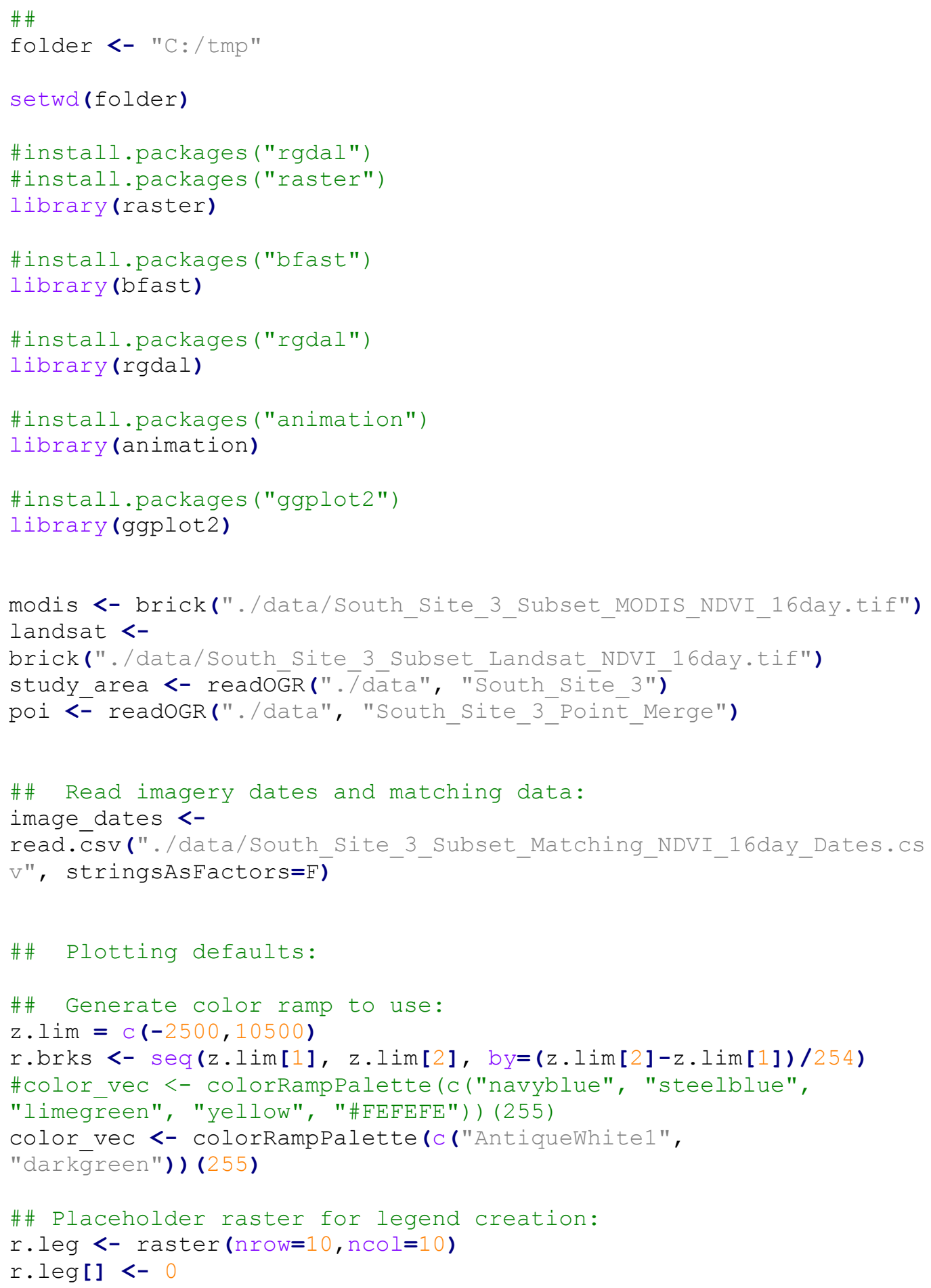


98 \#\# Threshold for "good" non-missing data that represents a

99 \#\# "matchable" Landsat scene (should be set to 10\% of non-

\#\# If data has already been processed, load the results: modis <- brick("./output/Subset_MODIS_NDVI_16day_masked.envi") landsat <- 


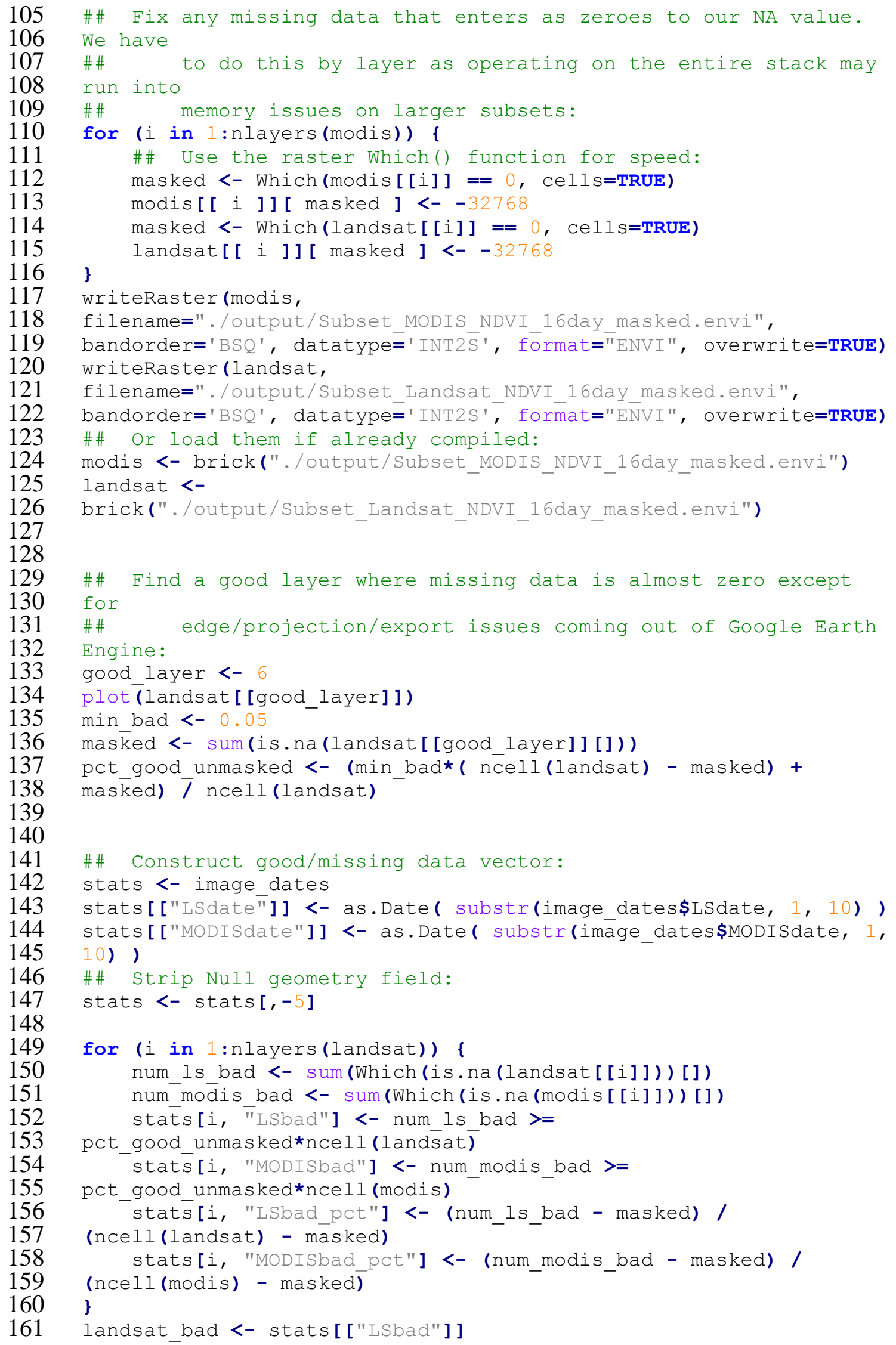


162

163

164

165

166

168

169

170

171

172

173

174

175

176

177

178

179

180

181

182

183

184

185

186

187

188

189

190

191

192

193

194

195

196

197

198

199

200

201

202

203

204

205

206

207

208

209

210

211

212

213

214

215

216

217

218

modis_bad <- stats[["MODISbad"]]

\#\# Save off compiled dates and stats for future use:

write.csv(stats, file="./output/Image_Date_Statistics.csv")

\#\# Construct time series out of LS and MODIS dates for plotting:

ls_plot <- stats [ stats\$LSdate > as.Date("2000-01-01"), ]

\#\# Quick and dirty way to plot MODIS irregularity:

\#plot (xts (stats_plot,

order.by=stats_plot\$MODISdate) \$MODISbad_pct, type="०")

\#\# Create a PDF plot of image dates from compiled MODIS and

Landsat scenes:

pdf(file=". / output/image_dates.pdf", width=10, height=3)

plot(1s_plot\$LSdate, 1 - ls_plot\$LSbad_pct, main="MODIS and

Landsat Image Dates", col=ifelse(!ls_plot\$LSbad, "\#00990066",

"\#99000066"), type="h", ylim=c(0,1.5),ylab="Good Pixel

Proportion", $x l a b=" A c q u i s i t i o n$ Date")

points(ls_plot\$LSdate, (1- ls_plot\$LSbad_pct),

col=ifelse(!) ls_plot\$LSbad, "\#00990066", "\#99000066"), pch=20, cex $\left.=\left(1-a s . n u m e r i c\left(1 s \_p l o t \$ L S b a d \_p c t\right)\right)\right)$

points (stats\$MODISdate, (1 - stats\$MODISbad_pct),

$\mathrm{col}=" \# 00004466 ", \mathrm{pch}=3, \mathrm{cex}=0.8$ )

legend (

"topright",

horiz=T,

legend=c ("Landsat Above 95\%", "Landsat Below 95\%", "MODIS

Scenes"),

COl=c("\#00990066", "\#99000066", "\#00440066"),

$\operatorname{lt}_{\mathrm{y}}=\mathrm{c}(1,1,0)$,

$\operatorname{pch}=c(20,20,3)$,

pt. $\operatorname{cex}=\mathrm{c}(1,1,0.8)$,

bg="white",

$\operatorname{cex}=0.6$

)

$\operatorname{dev}$. off()

\#\# If the above all works, then we run the following to loop over the

\#\# MODIS time steps, filling in Landsat output as we go:

landsat sim <- stack(modis)

landsat_sim[] <- NA

landsat_filled <- stack(modis)

landsat_filled[] <- NA

\#\# Or $\bar{l}$ oad it if we already ran it:

\#landsat sim $<-$

brick(".Toutput/Subset_Landsat_NDVI_16day_sim.envi")

\#\# Iterate and run StarFM for each MODIS date, choosing the

\#\# nearest pair of good MODIS/Landsat dates, one before and

\#\# one after the date being simulated where possible: 
pb <- pbCreate ((nlayers(landsat_sim)), "window", style=3,

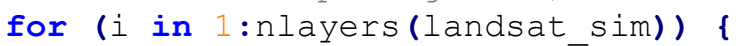




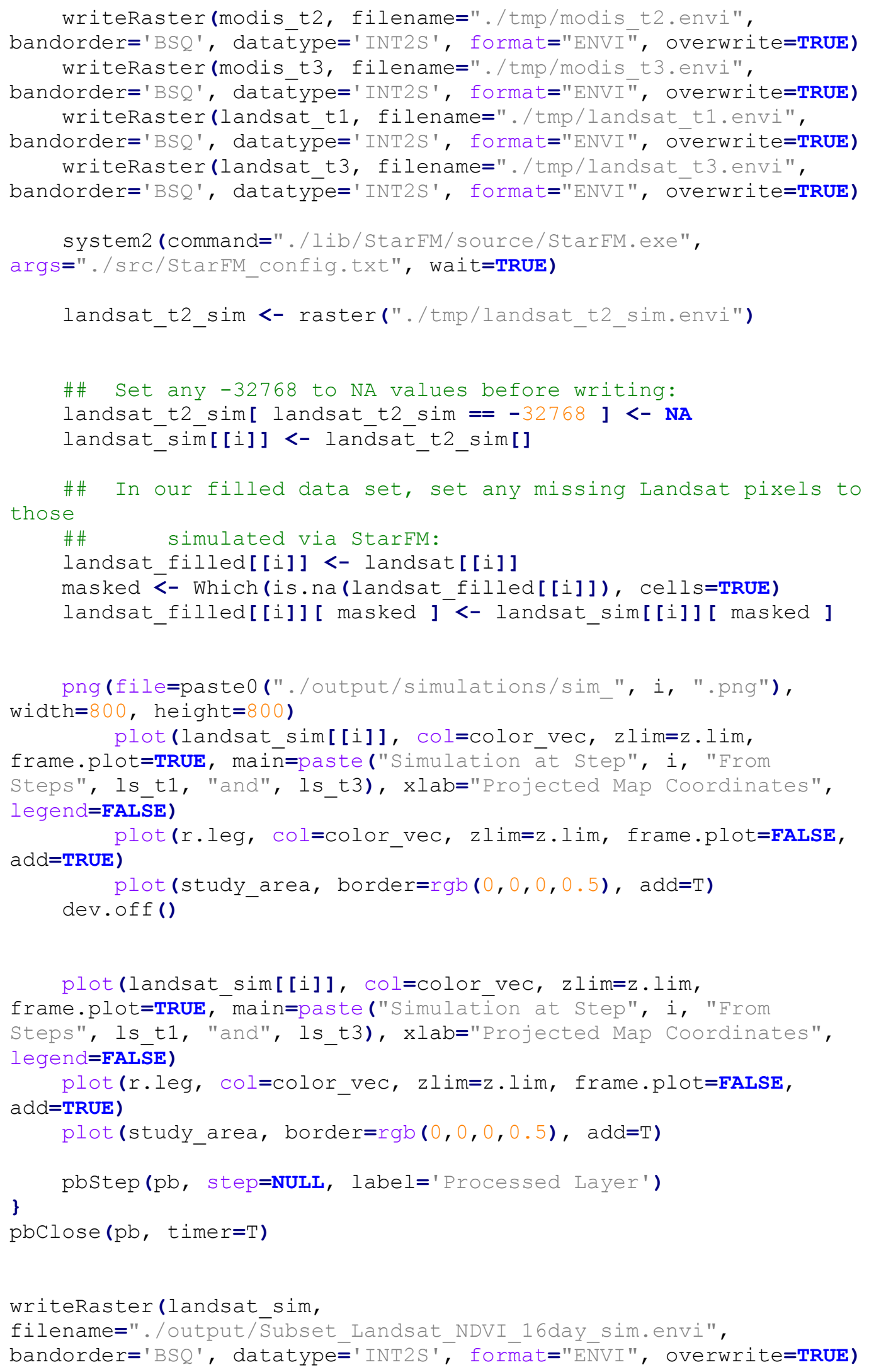


331

332

333

334

335

336

337

338

339

340

341

342

343

344

345

346

347

348

349

350

351

352

353

354

355

356

357

358

359

360

361

362

363

364

365

366

367

368

369

370

371

372

373

374

375

376

377

378

379

380

381

382

383

384

385

386

387

writeRaster(landsat_filled,

filename=" . / output/Subset_Landsat NDVI_16day_filled.envi", bandorder='BSQ', datatype='INT2S', format="ENVI", overwrite=TRUE) \#\# Or load them if already compiled:

landsat_sim <-

brick("-./output/Subset_Landsat_NDVI_16day_sim.envi")

landsat_filled <-

brick("- / output/Subset Landsat NDVI 16day filled.envi")

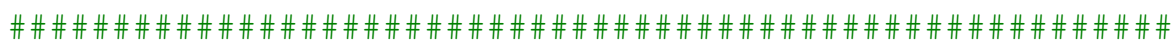

\#\# Optional, create animation of series over time:

old_wd <- getwd()

setwd("./output/animation")

saveHTML ( \{ $\operatorname{par}(\operatorname{mfrow}=\mathrm{C}(1,4))$

for ( $i$ in 1 :nlayers (landsat_sim)) \{ plot(modis[i]], col=color_vec, zlim=z.lim,

frame.plot=TRUE, main="\nMODIS $132 \overline{1}$ NDVI", $x l a b="$ Projected Map

Coordinates", legend=FALSE) add=TRUE)

plot(r.leg, col=color_vec, zlim=z.lim, frame.plot=FALSE,

plot (study_area, border $=r g b(0,0,0,0.5), \operatorname{add}=\mathrm{T}$ )

plot (landsat[[i]], col=color_vec, zlim=z.lim,

frame.plot=TRUE, main=paste ("Timestep", i, "\nLandsat TM/ETM+/OLI

NDVI"), xlab="Projected Map Coordinates", legend=FALSE) add=TRUE)

plot(r.leg, col=color_vec, zlim=z.lim, frame.plot=FALSE,

plot (study_area, border $=r g b(0,0,0,0.5), \operatorname{add}=\mathrm{T}$ )

plot(landsat sim[i]], col=color vec, zlim=z.lim,

frame.plot=TRUE, main=" \nSimulated StarF $\bar{M}$ NDVI", $x l a b=" P r o j e c t e d$ Map Coordinates", legend=FALSE)

add=TRUE)

plot(r.leg, col=color_vec, zlim=z.lim, frame.plot=FALSE,

plot (study_area, border $=r g b(0,0,0,0.5), \quad \operatorname{add}=\mathrm{T}$ )

plot(landsat filled[[i]], col=color_vec, zlim=z.lim,

frame.plot=TRUE, main=" \nFused Landsat/StarFM NDVI",

xlab="Projected Map Coordinates", legend=FALSE)

add=TRUE)

plot(r.leg, col=color_vec, zlim=z.lim, frame.plot=FALSE,

plot (study_area, border $=r g b(0,0,0,0.5), \operatorname{add}=\mathrm{T}$ )

ani.pause ( )

\} \},

img. name="ndvi",

imgdir=" . /images",

htmlfile = "./index.html",

autobrowse = FALSE,

title $=$ "Fused Landsat and MODIS NDVI Timeseries, February

2000 - December 2015",

description = "These data were extracted from Google Earth

Engine, and processed according to the script linked here.", 


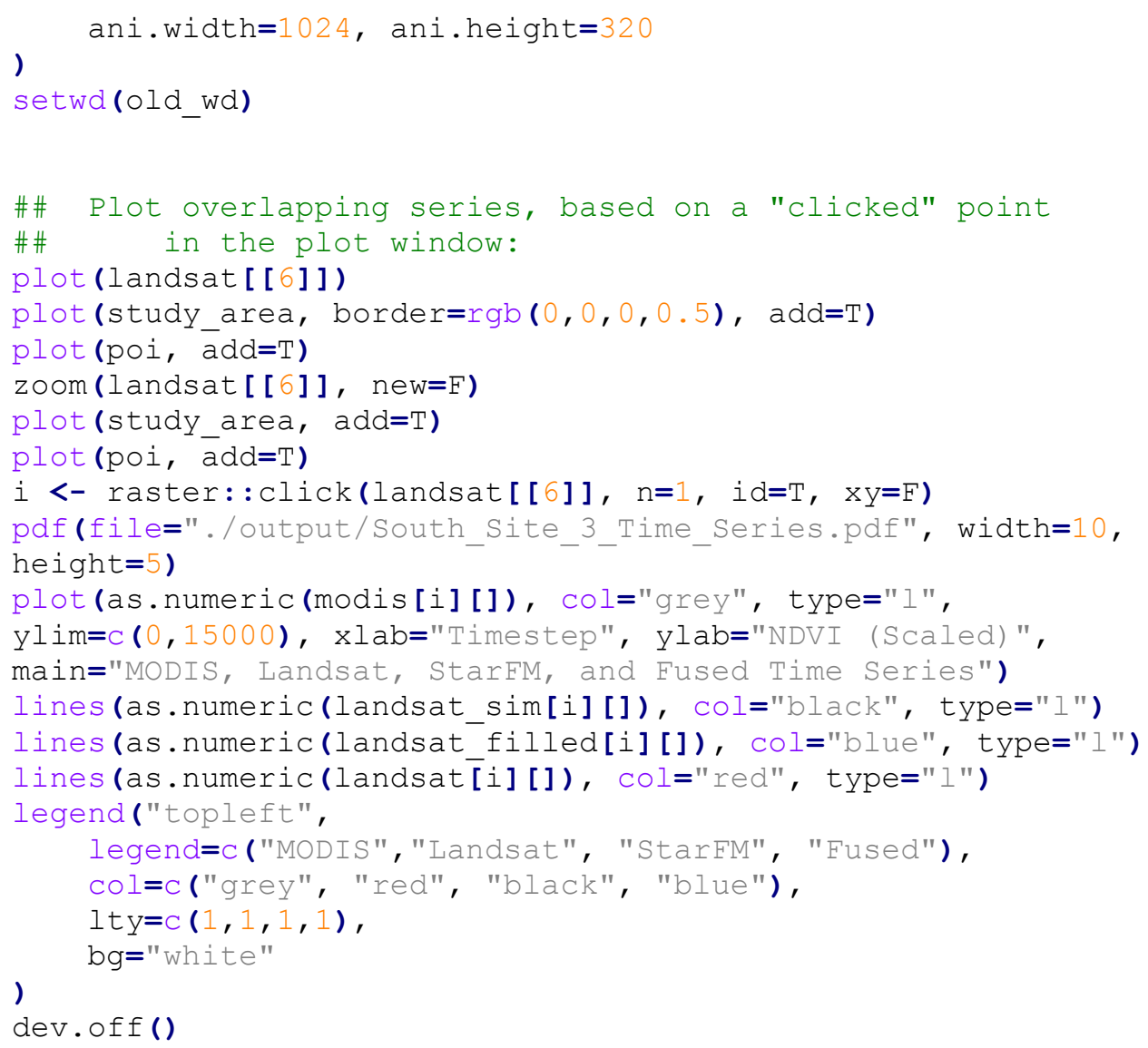

412

413

414

415

416 


\section{APPENDIX C: R PROGRAMMING CODE FOR BFAST}

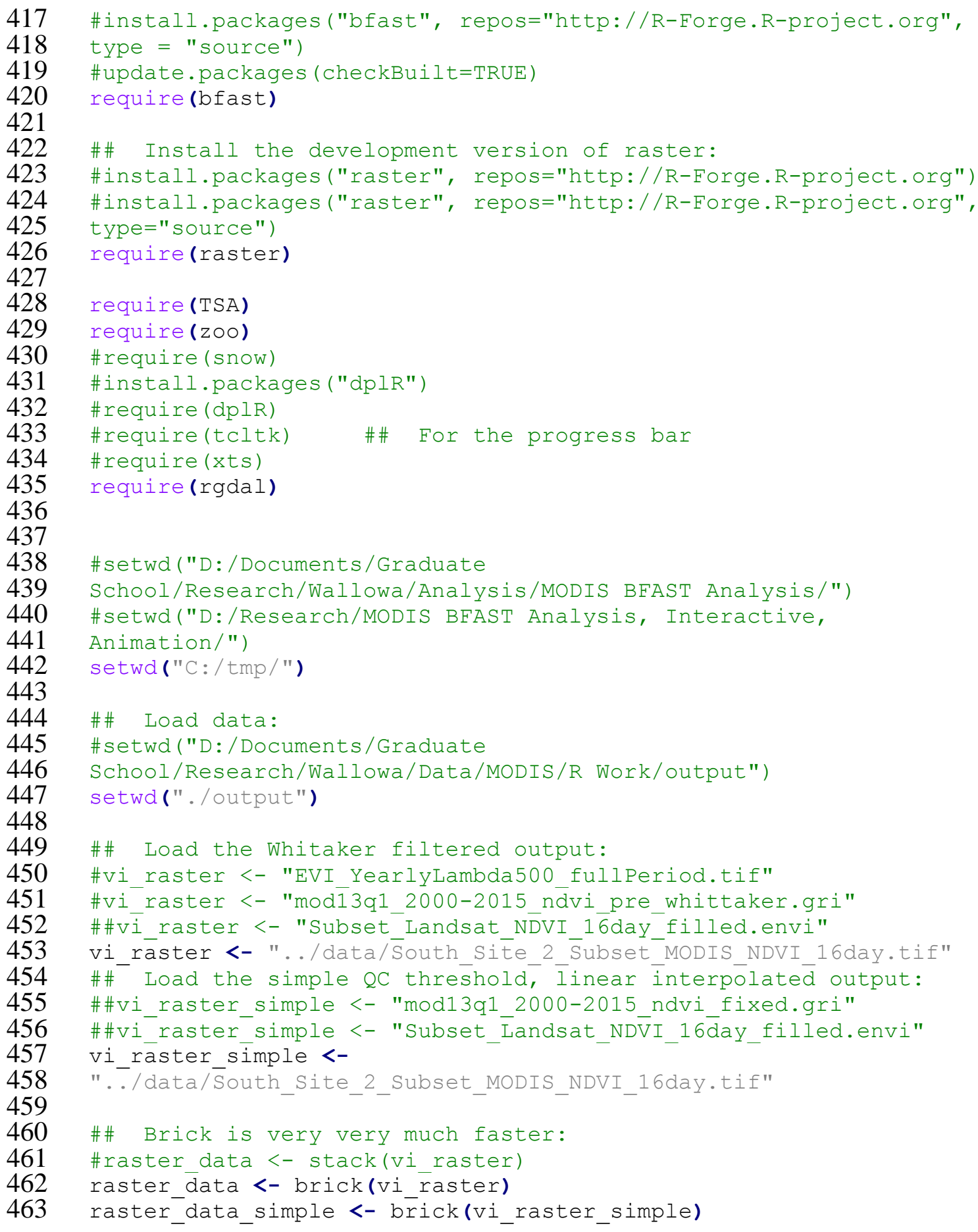


464

465

466

467

468

469

470

471

472

473

474

475

476

477

478

479

480

481

482

483

484

485

486

487

488

489

490

491

492

493

494

495

496

497

498

499

500

501

502

503

504

505

506

507

508

509

510

511

512

513

514

515

516

517

518

519

\#\# Write out a layer from the raster data converted to cell indices for 
layer names [(i)*num features+5]<- paste ("b", $i+1, "$ len", sep=" ")

522 layer names [(i)*num features+6] <- paste ("b", $i+1$," mean", sep=" ")

523 layer_names[(i)*num_features+7] <- paste ("b", i+1,"_slope", sep="")

\#\# Write out layer names for seasonal break detections:

$j=(i) *$ num features +7

layer names $\overline{[} j+1]<-$ "detected breaks seasonal"

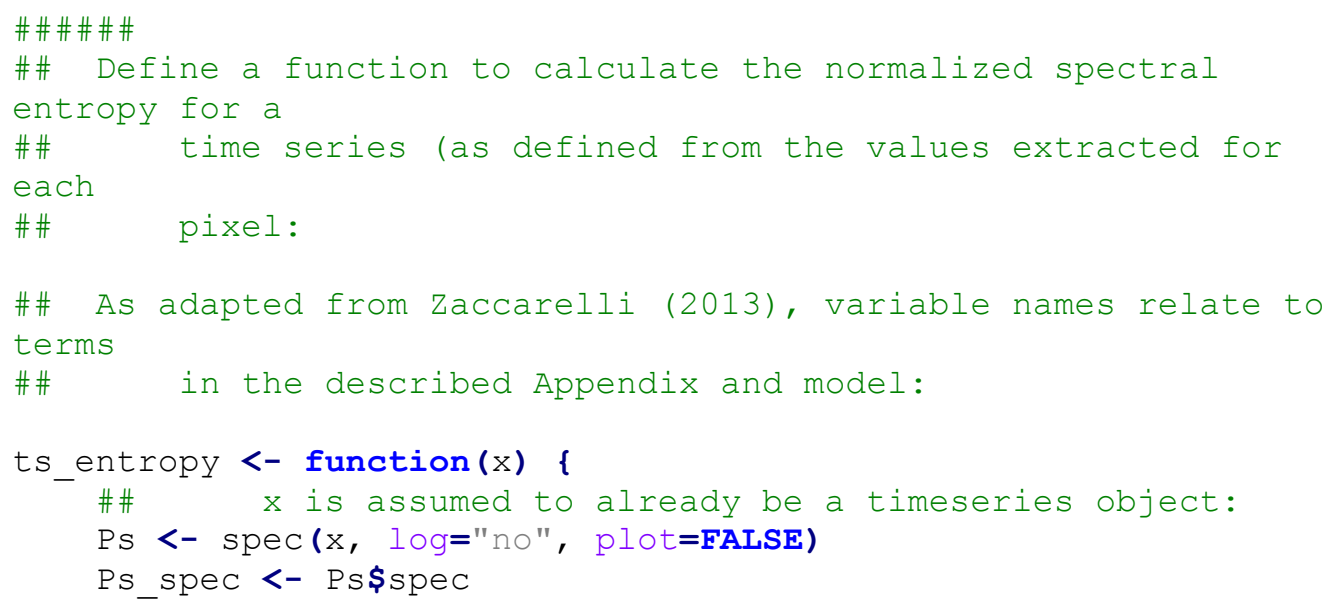




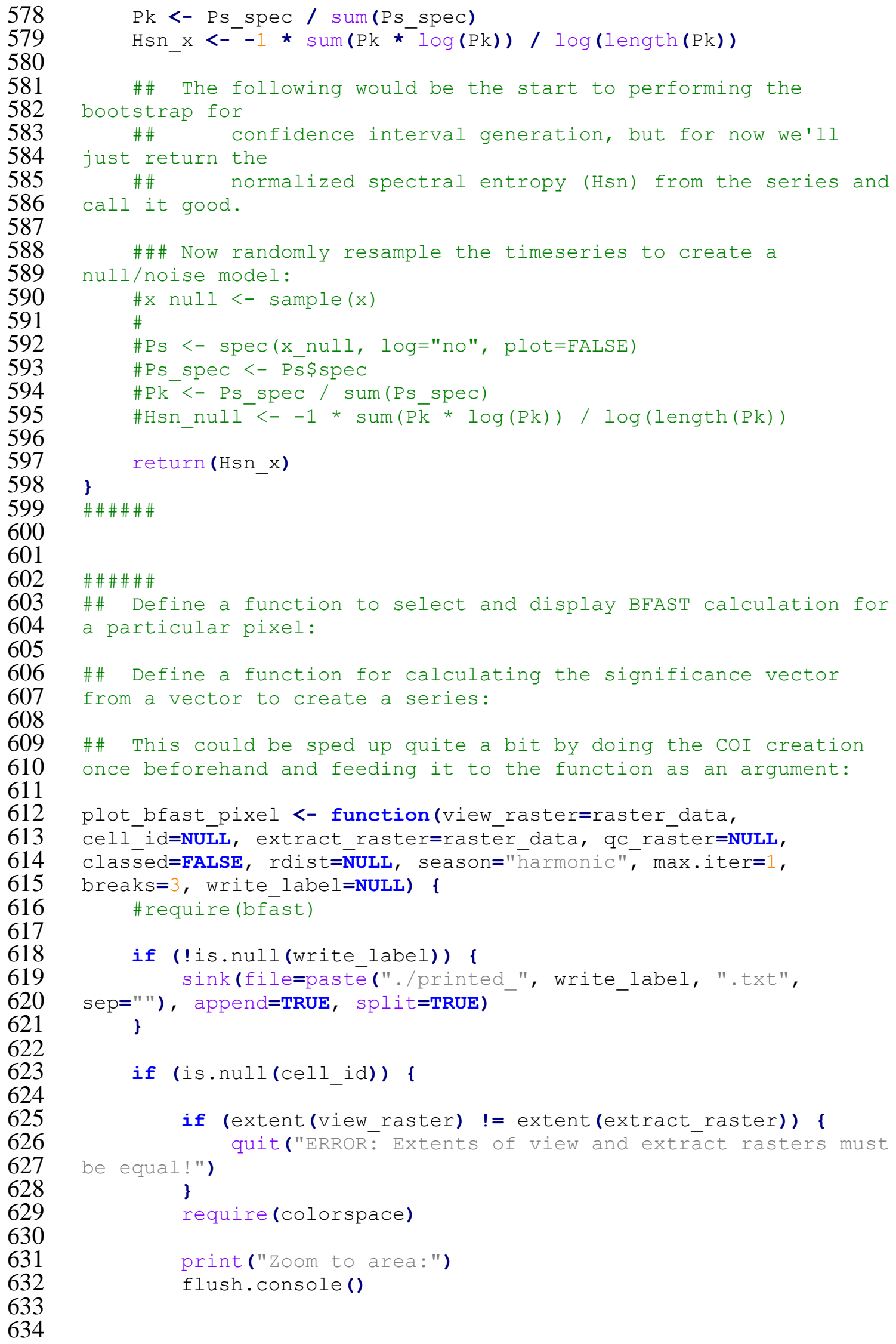




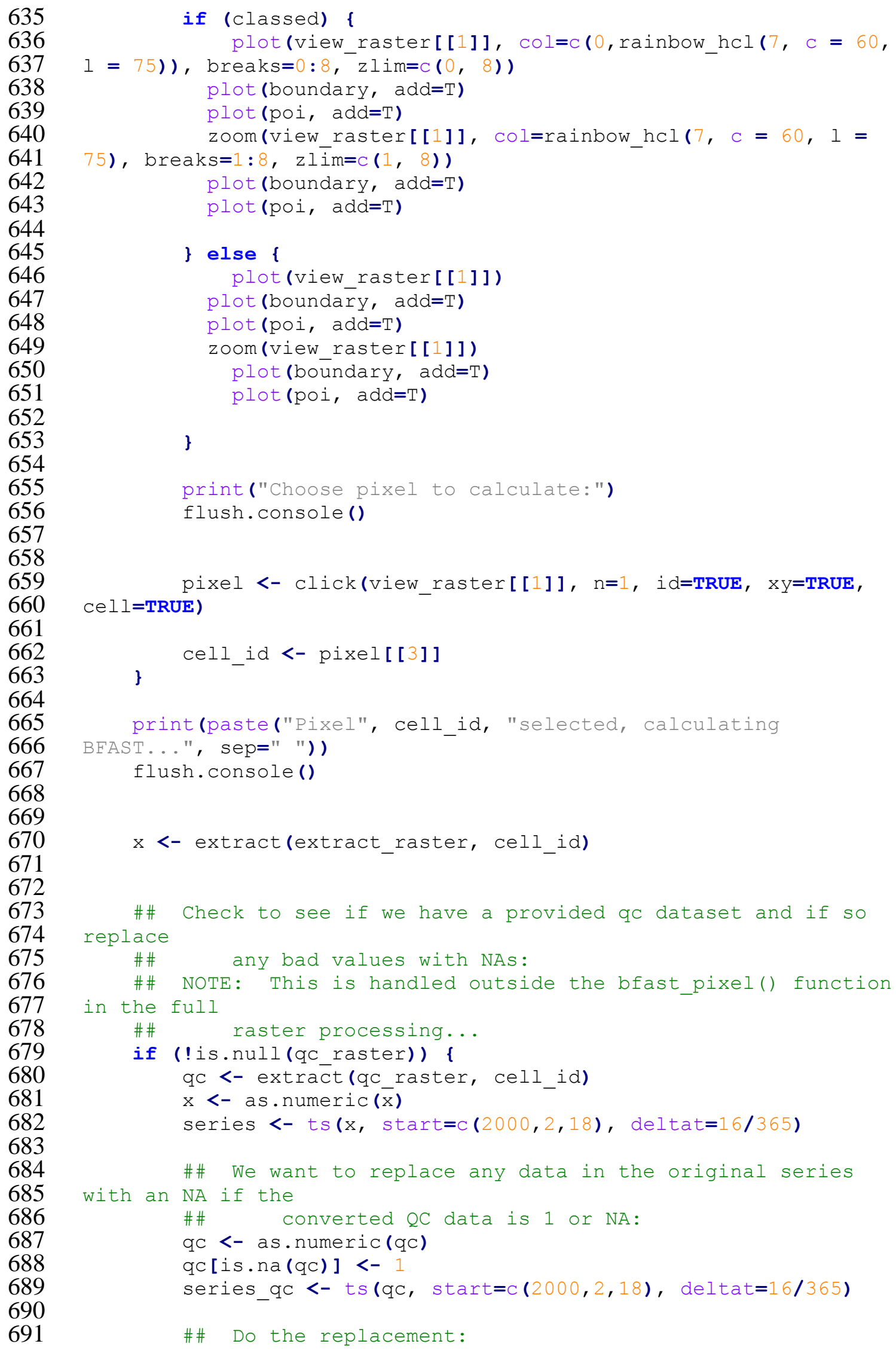




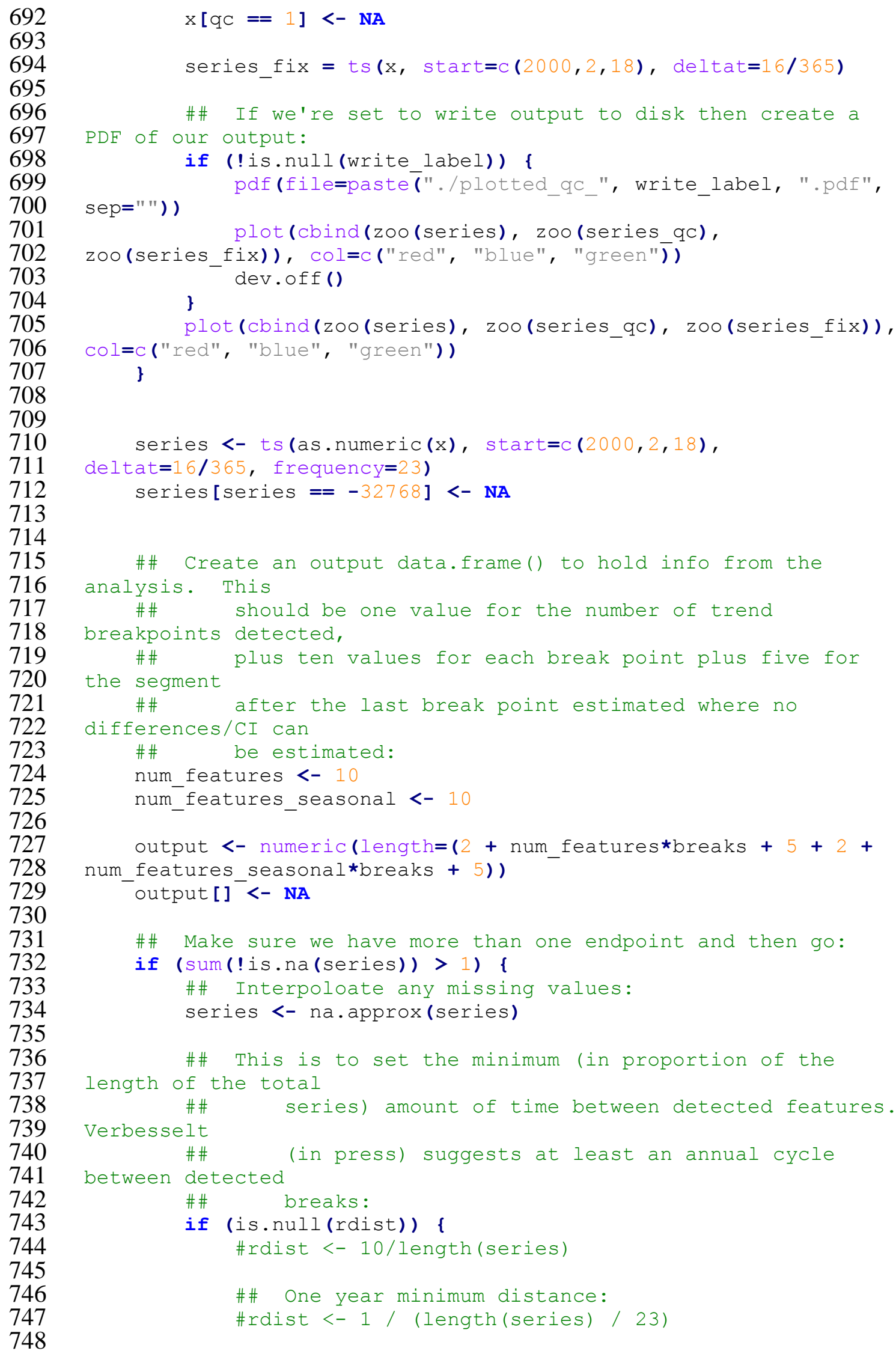




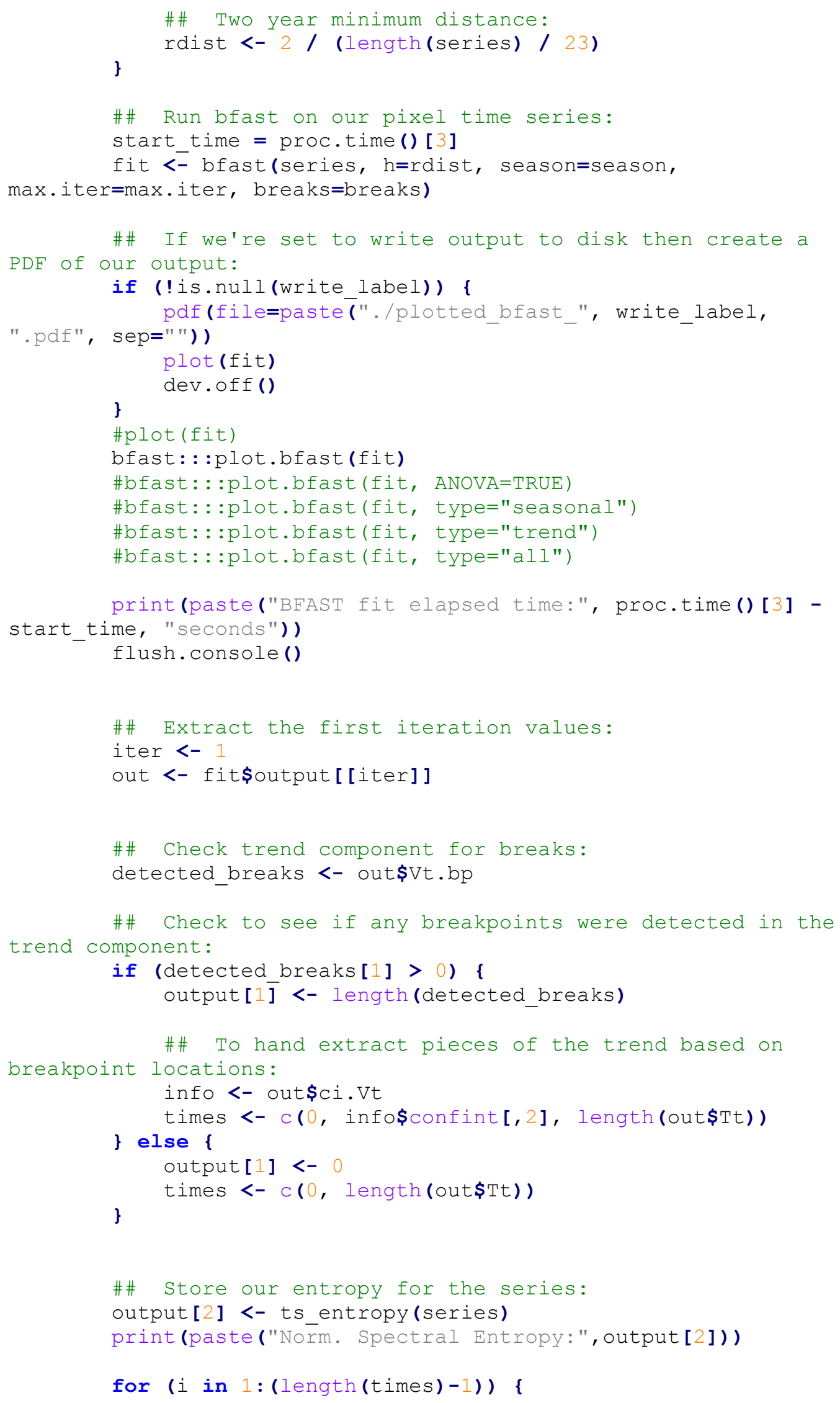




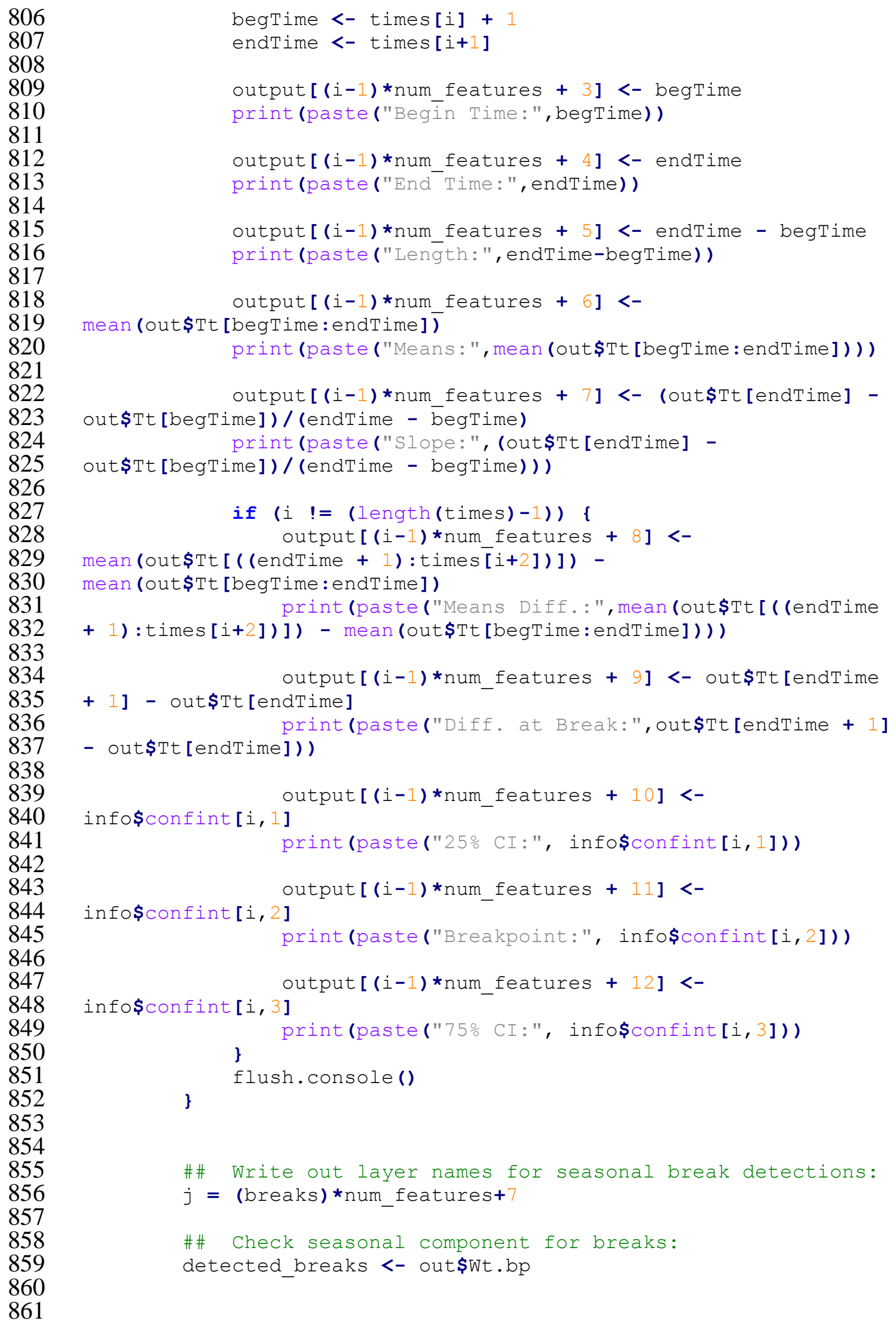




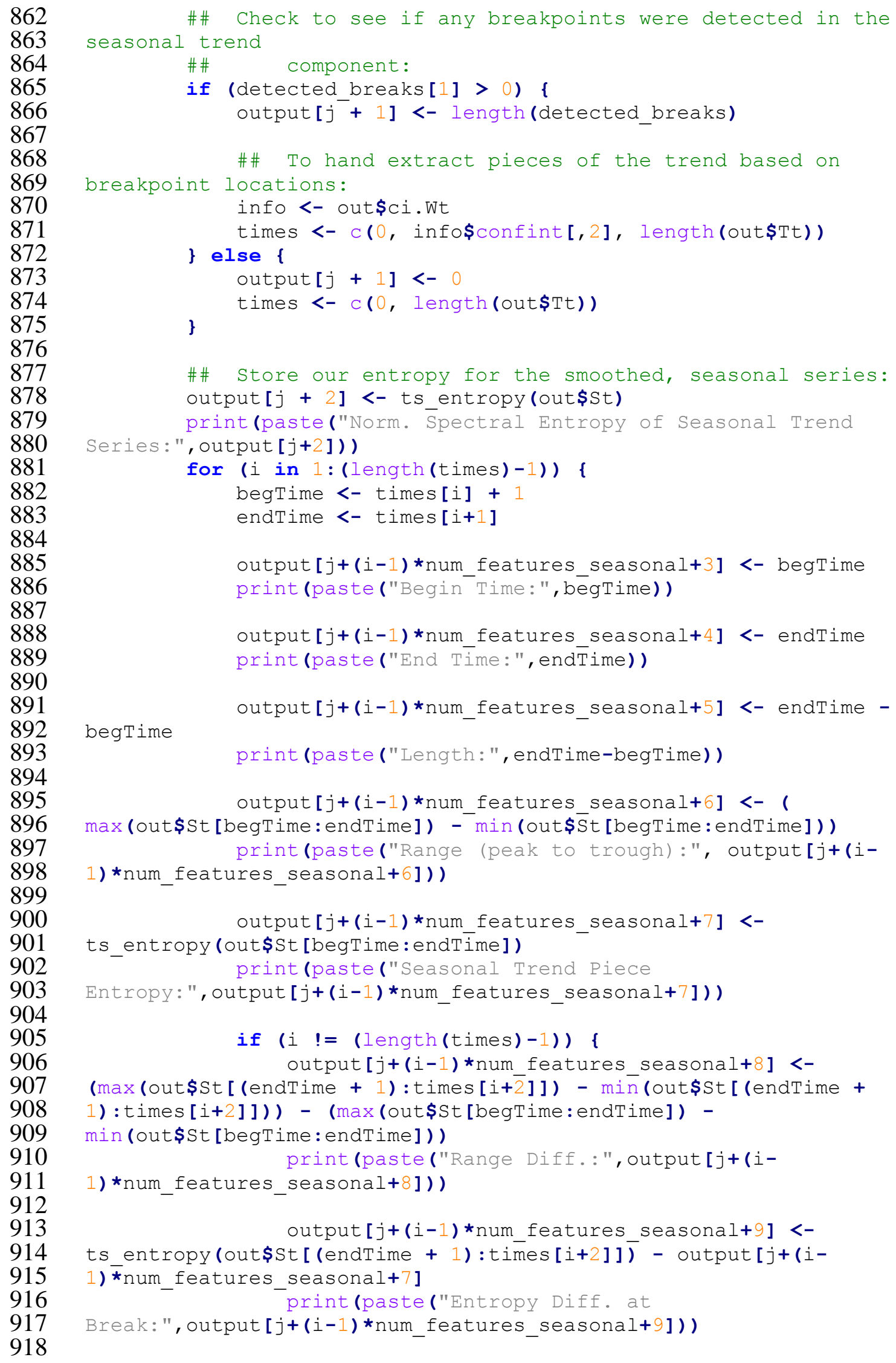




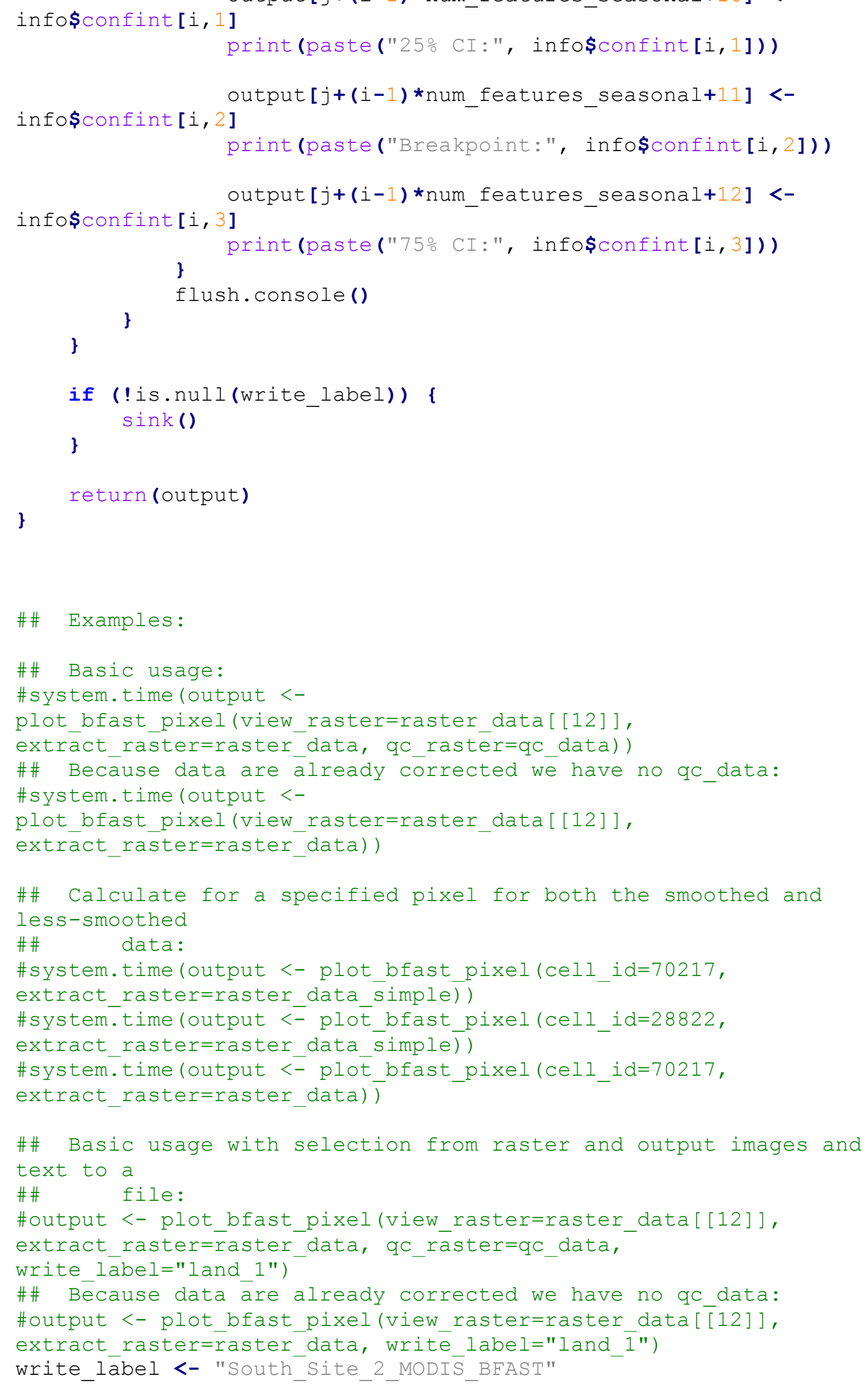


975 output <- plot_bfast_pixel(view_raster=raster_data_simple[[6]],

976 extract raster $=$ raste $\bar{r}$ data_simple, write_labe $\bar{l}=$ write_label)

977 output_ēf <- data.frame(t(as.matrix(output)))

978 names(output_df) <- layer_names

979 write.csv(output_df, file=pasteo(write_label, "_output.csv")) 


\section{APPENDIX D: MODIS BFAST PLOTS}

Site \#1: BFAST MODIS Plots
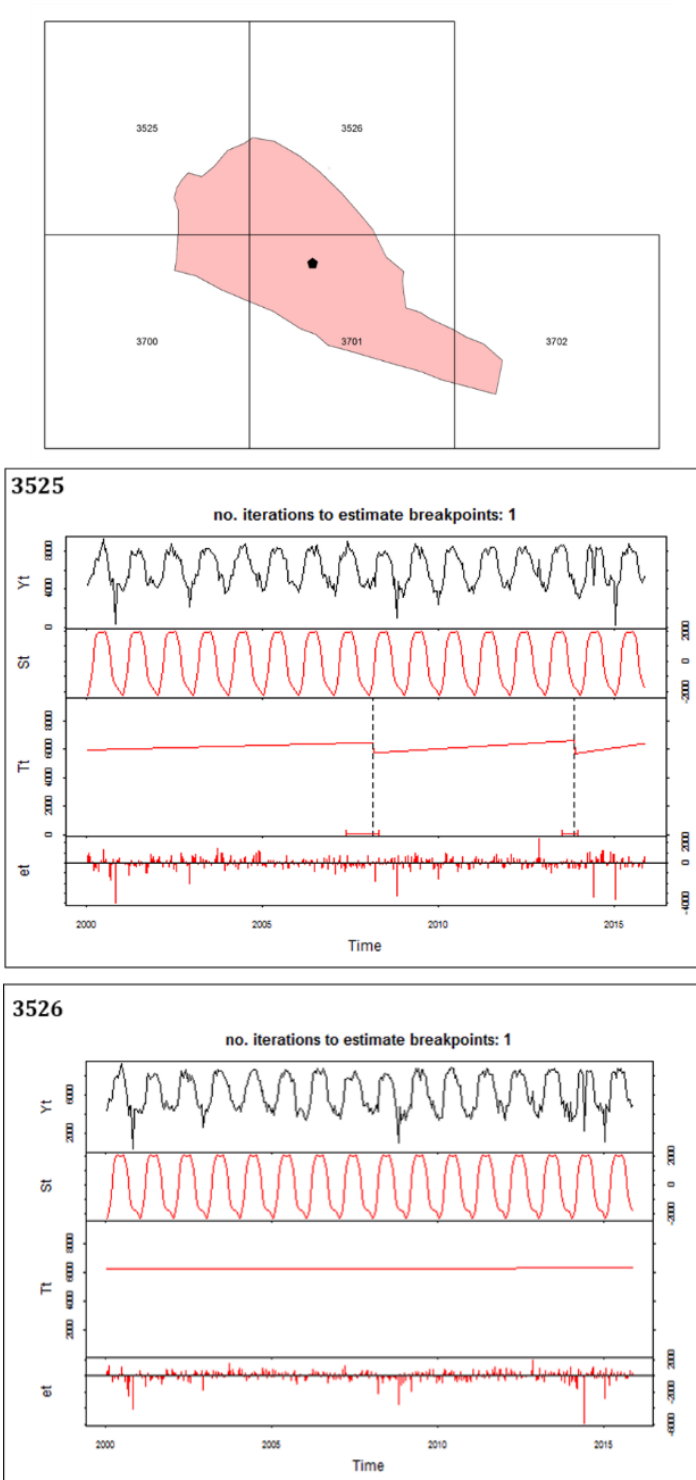
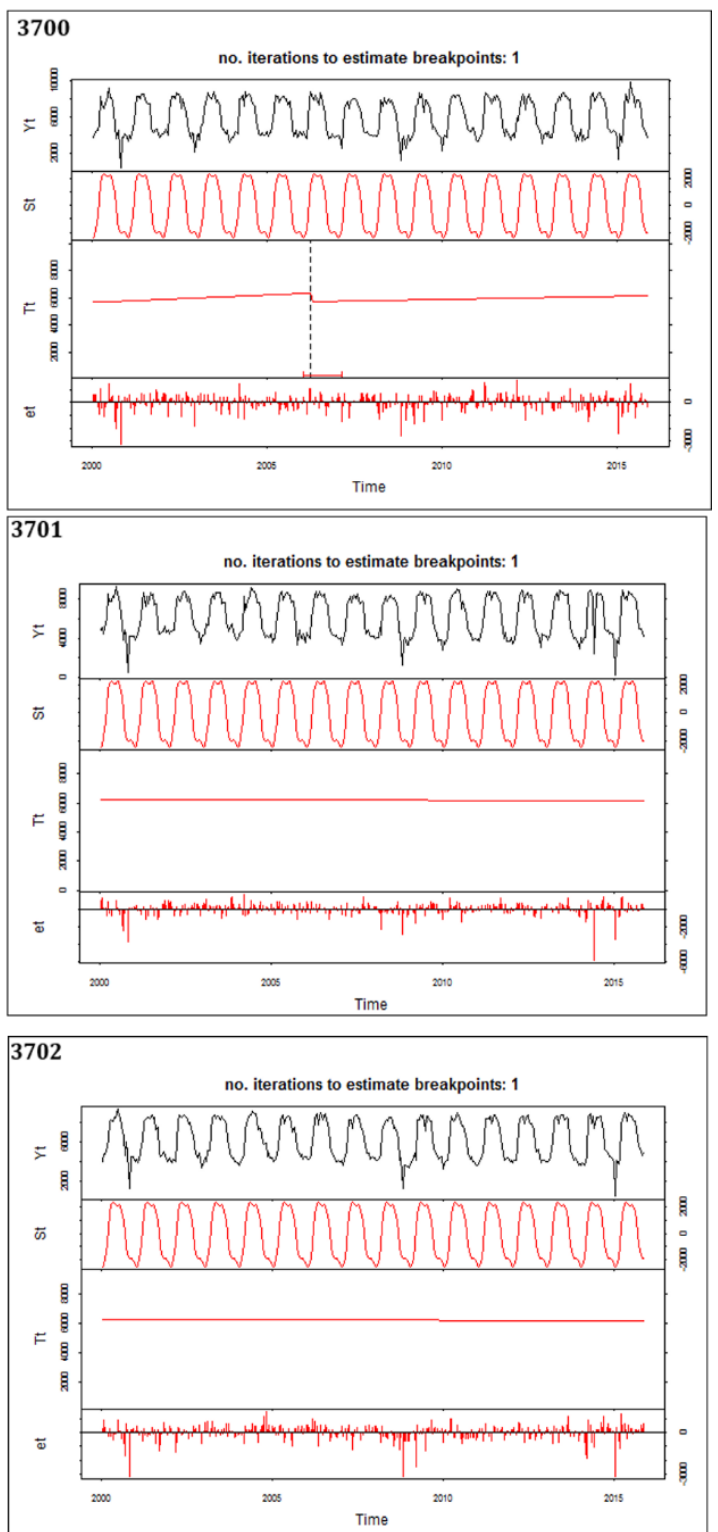

Figure D.1. BFAST plots for all MODIS pixels containing Site \#1. 
Site \#2: BFAST MODIS Plots
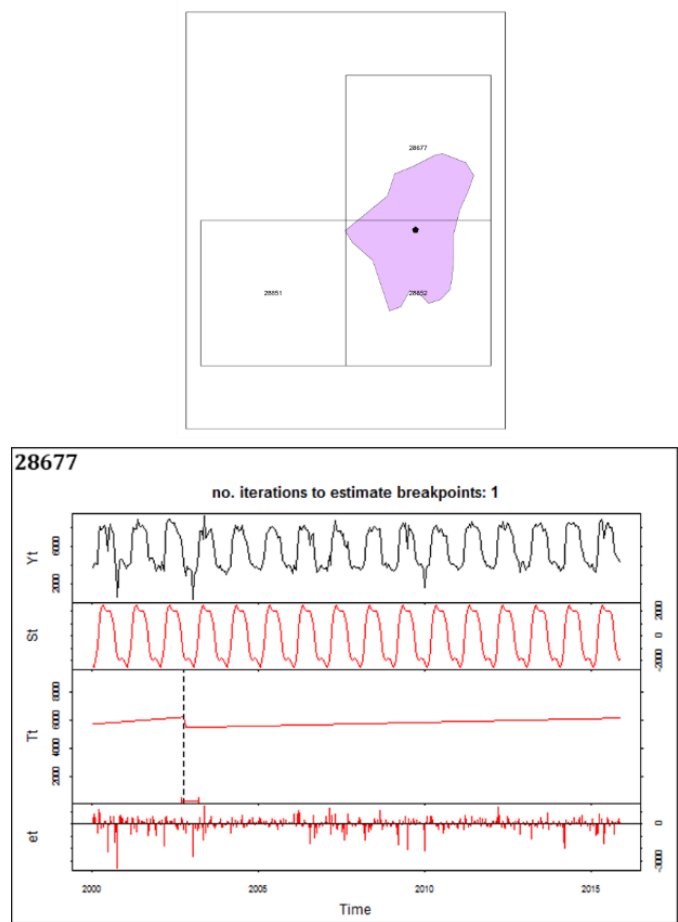

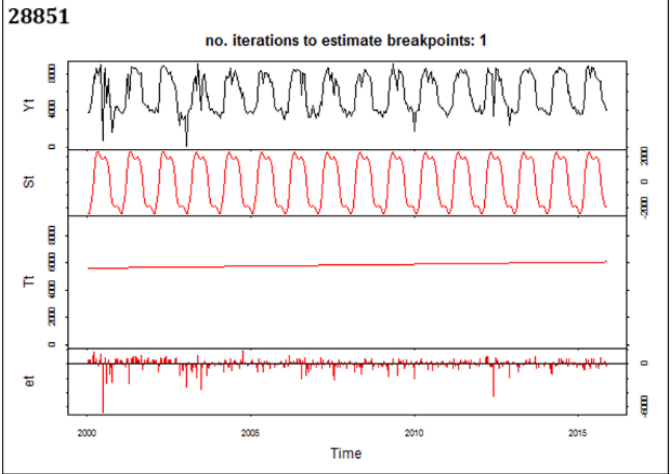

28852

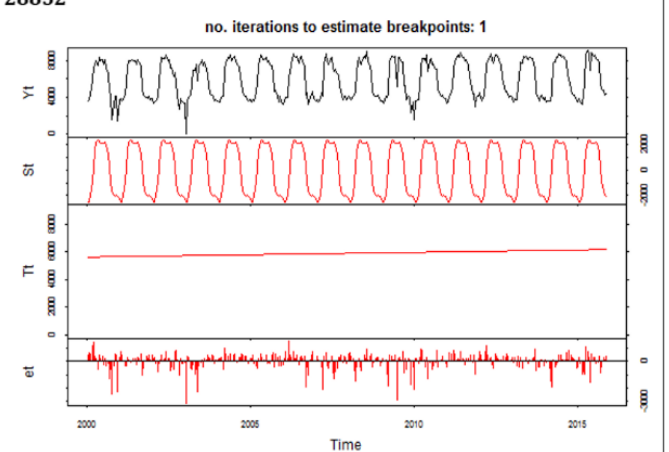
Time

Figure D.2. BFAST plots for all MODIS pixels containing Site \#2. 
Site \#3: BFAST MODIS Plots
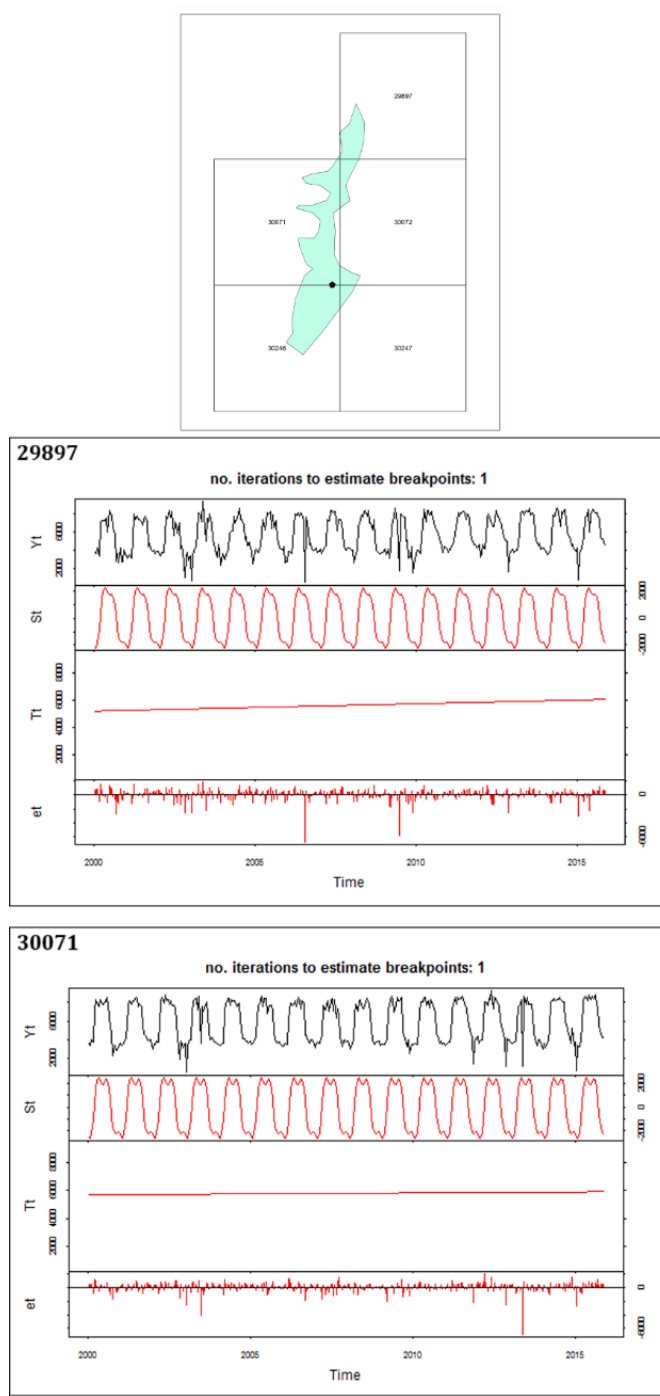
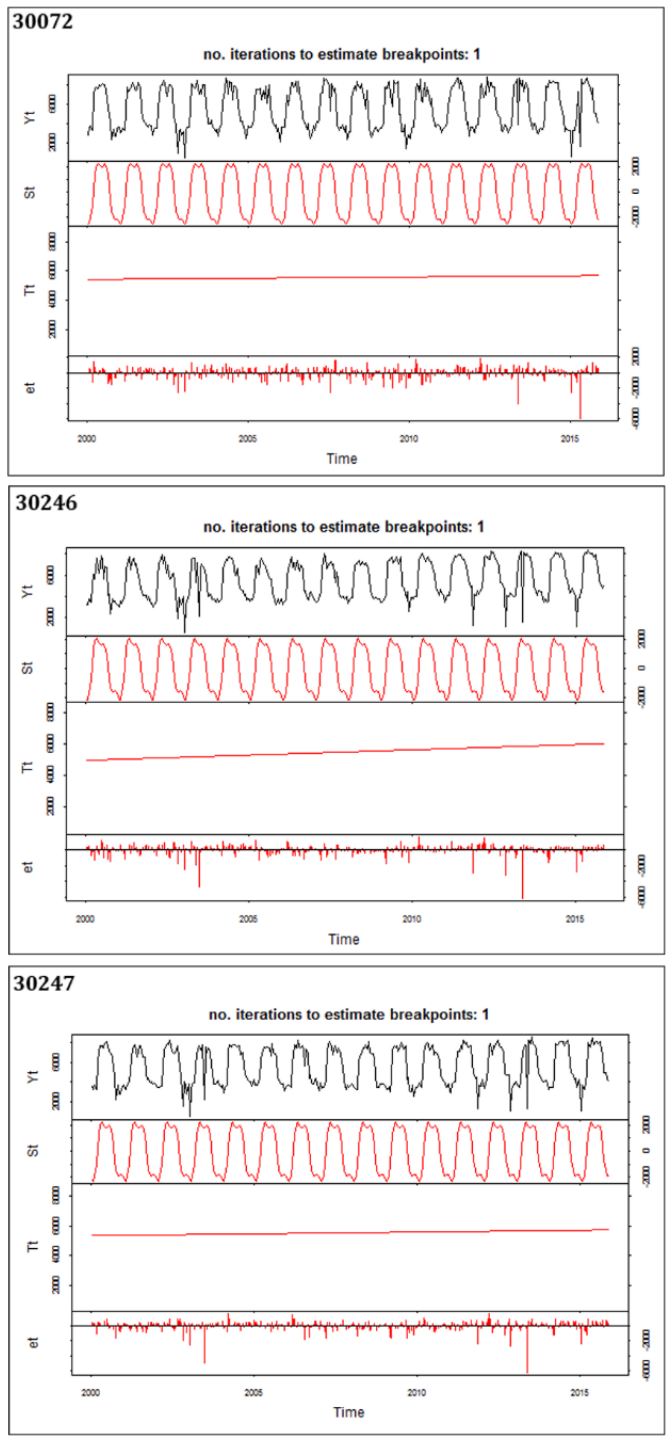

Figure D.3. BFAST plots for all MODIS pixels containing Site \#3. 


\section{APPENDIX E: BFAST PLOTS USING FUSED IMAGERY FOR ALL POINTS}

\section{Site \#1 BFAST Plot}
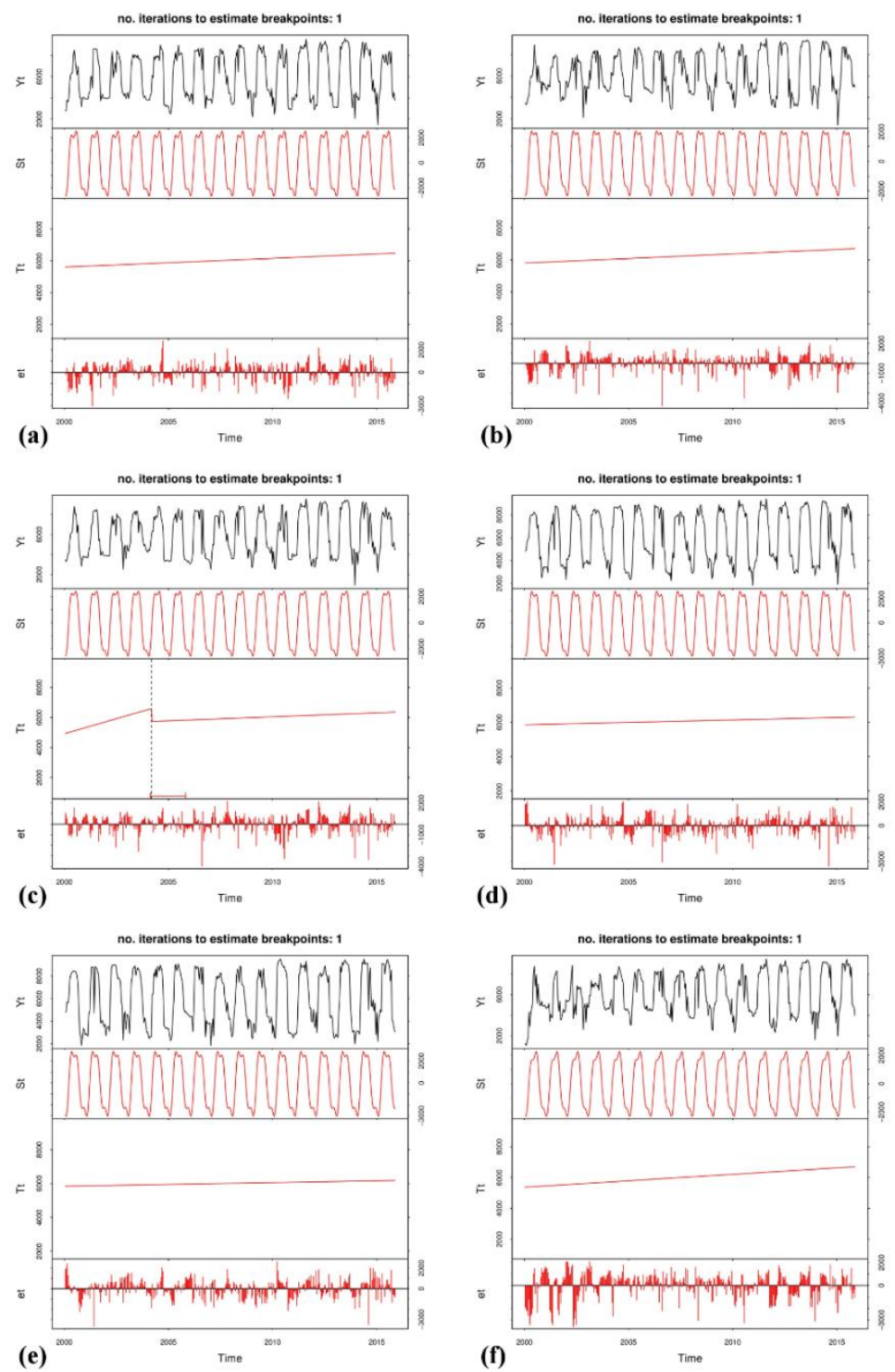

Figure E.1. Site \#1 BFAST plots using fused Landsat-scale data for centroid (a) and random points 0-4 (b-f). 


\section{Site \#2 BFAST Plot}
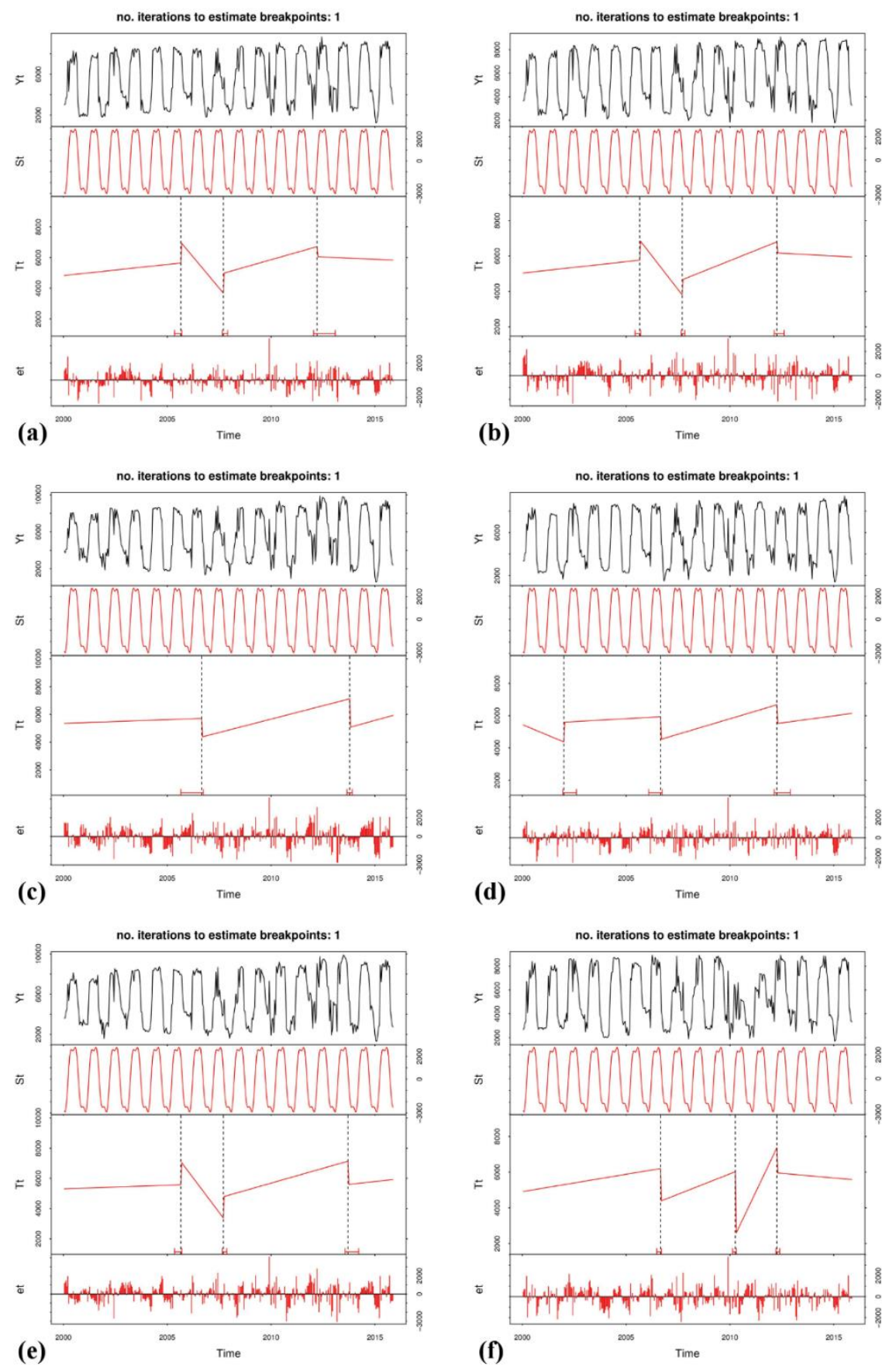

Figure E.2. Site \#2 BFAST plots using fused Landsat-scale data for centroid (a) and random points 0-4 (b-f). 


\section{Site \#3 BFAST Plot}
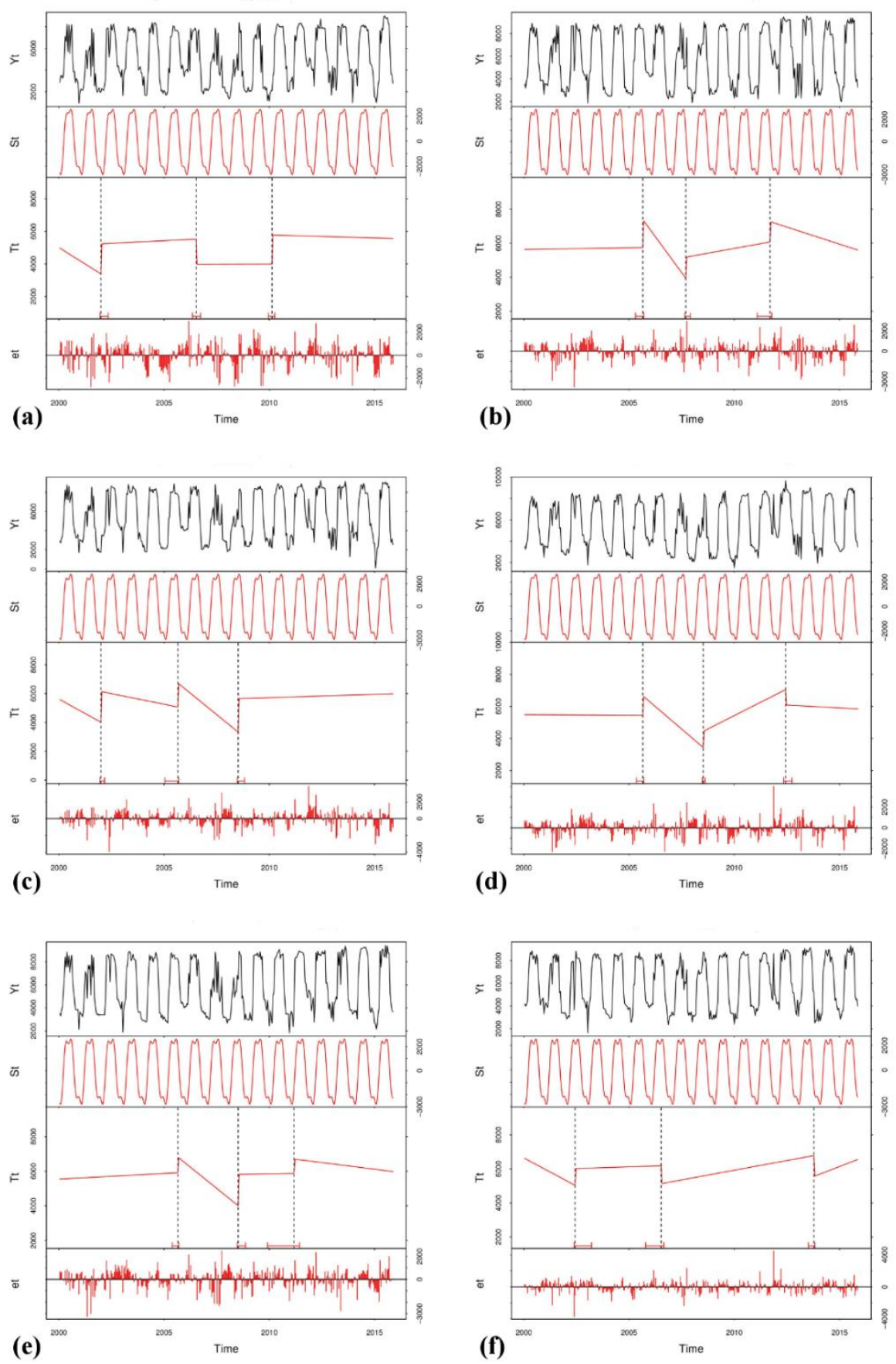

Figure E.3. Site \#3 BFAST plots using fused Landsat-scale data for centroid (a) and random points $0-4(\mathrm{~b}-\mathrm{f})$. 


\section{CURRICULUM VITA}

NAME:

ADDRESS:

DOB:

EDUCATION:

AWARDS:

PROFESSIONAL SOCIETIES:
Faye Elizabeth Peters

Department of Geography and Geosciences

20 Lutz Hall University of Louisville

Louisville, KY 40292

Louisville, Kentucky - October 12, 1983

B. A., Earth and Planetary Sciences

University of New Mexico, 2007

Graduate Teaching Position University of Louisville, Geography and Geosciences 2014

New Mexico Geological Society Fall Conference Scholarship University of New Mexico 2006

Amigo/Amigo Scholarship University of New Mexico 2005

General Thomas Campbell Award University of New Mexico 2005

National Student Exchange

University of Louisville 2003

Association of American Geographers 2015 


\section{TEACHING}

EXPERIENCE: University of Louisville

Geoscience 200: The Global Environment (online course)

2015-2016

Graduate Teaching Assistant

University of Louisville, Geography and Geosciences

2014-2015 